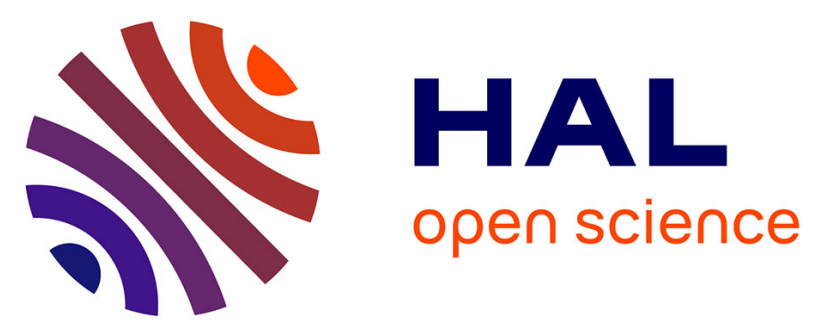

\title{
Development of DANDYs, New 3,5-Diaryl-7-azaindoles Demonstrating Potent DYRK1A Kinase Inhibitory Activity.
}

Stéphanie Gourdain, Julien Dairou, Clément Denhez, Linh Chi Bui, Fernando Rodrigues-Lima, Nathalie Janel, Jean M Delabar, Kevin Cariou, Robert H Dodd

\section{To cite this version:}

Stéphanie Gourdain, Julien Dairou, Clément Denhez, Linh Chi Bui, Fernando Rodrigues-Lima, et al.. Development of DANDYs, New 3,5-Diaryl-7-azaindoles Demonstrating Potent DYRK1A Kinase Inhibitory Activity.. Journal of Medicinal Chemistry, 2013, 56 (23), pp.9569-9585. 10.1021/jm401049v . hal-00933939

\section{HAL Id: hal-00933939 \\ https://hal.science/hal-00933939}

Submitted on 26 Nov 2020

HAL is a multi-disciplinary open access archive for the deposit and dissemination of scientific research documents, whether they are published or not. The documents may come from teaching and research institutions in France or abroad, or from public or private research centers.
L'archive ouverte pluridisciplinaire HAL, est destinée au dépôt et à la diffusion de documents scientifiques de niveau recherche, publiés ou non, émanant des établissements d'enseignement et de recherche français ou étrangers, des laboratoires publics ou privés. 


\section{Development of DANDYs, New 3,5-Diaryl-7-}

azaindoles Demonstrating Potent DYRK1A Kinase

\section{Inhibitory Activity.}

Stéphanie Gourdain, ${ }^{1}$ Julien Dairou, ${ }^{2}$ Clément Denhez, ${ }^{3,4}$ Linh Chi Bui, ${ }^{2}$ Fernando RodriguesLima, ${ }^{2}$ Nathalie Janel, ${ }^{2}$ Jean M. Delabar, ${ }^{2}$ Kevin Cariou, ${ }^{1}$ and Robert H. Dodd ${ }^{* 1}$

${ }^{1}$ Centre de Recherche de Gif, Institut de Chimie des Substances Naturelles, UPR 2301, CNRS, Avenue de la Terrasse, 91198 Gif-sur-Yvette, France

${ }^{2}$ Université Paris Diderot, Sorbonne Paris Cité, Unité de Biologie Fonctionnelle et Adaptative, CNRS EAC 4413, 75013, Paris, France

${ }^{3}$ ICMR UMR7312/ P3M, Université de Reims Champagne-Ardenne, UFR Pharmacie 3, rue du Maréchal Juin 51096 Reims Cedex, France

${ }^{4}$ Multiscale Molecular Modeling Platform, Université de Reims Champagne-Ardenne, rue du Maréchal Juin 51096 Reims Cedex, France

KEYWORDS: DYRK1A, Down Syndrome, Alzheimer's Disease, 7-Azaindoles

ABSTRACT: A series of 3,5-diaryl-1H-pyrrolo[2,3-b]pyridines were synthesized and evaluated for inhibition of DYRKIA kinase in vitro. Derivatives having hydroxy groups on the aryl moieties (2c, $\mathbf{2 j}$-l) demonstrated high inhibitory potencies with $\mathrm{K}_{\mathrm{i}}$ 's in the low nanomolar 
range. Their methoxy analogues were up to 100 times less active. Docking studies at the ATP binding site suggested that these compounds bind tightly to this site via a network of multiple H-bonds with the peptide backbone. None of the active compounds were cytotoxic to KB cells at $10^{-6} \mathrm{M}$. Kinase profiling revealed that compound $\mathbf{2 \mathbf { j }}$ showed significant selectivity for DYRK1A with respect to DYRK2 and DYRK3.

\section{Introduction}

Dual-specificity tyrosine phosphorylation-regulated kinase 1a (DYRK1A) belongs to the DYRK subfamily of protein kinases. The latter are related to the cyclin-dependent kinases (CDKs), mitogen-activated protein kinases (MAPKs), glycogen synthase kinases (GSKs) and CDK-like kinases (CLKs), all of which constitute the CMGC group. ${ }^{1}$ DYRK1A is expressed in human fetal and adult brains and its coding gene is located on chromosome 21 within the Down syndrome (DS) critical region. ${ }^{2}$ The presence of an extra copy of whole or part of human chromosome $21^{3}$ in DS results in an approximately 1.5-fold up-regulation of DYRK1A in DS brains $^{4}$ and this overexpression is strongly suspected to contribute to mental retardation. DS is also associated with other pathologies such as congenital heart defects, immune and endocrine system deregulations ${ }^{5}$ and an increased risk of early Alzheimer's disease (AD). ${ }^{6}$ AD is mainly caused by the intracellular aggregation of hyperphosphorylated forms of the microtubulebinding protein Tau responsible for the formation of neurofibrillary tangles (NFT). ${ }^{7}$ Recent studies have suggested that DYRK1A phosphorylates Tau protein which, in the case of DS, leads to hyperphosphorylation at multiple Ser/Thr sites of the protein. ${ }^{6}$ Moreover, DYRK1A has also been shown to phosphorylate amyloid precursor protein (APP) at the Thr668 residue which in turn increases $\beta$-amyloid production (notably in the forebrain and hippocampus), hence accounting for the early appearance of AD symptoms in DS patients. ${ }^{8}$ 
In view of the numerous deleterious consequences of the overexpression of DYRK1A in $\mathrm{DS}$ and its possible implications in $\mathrm{AD}$, efforts have recently been made to develop inhibitors of this kinase (Figure 1). ${ }^{9}$ Epigallocatechin-3-gallate (EGCG) and harmine have emerged as natural potent DYRK1A inhibitors. While EGCG, the major flavonoid in tea, ${ }^{10,1 \mathrm{c}}$ is a noncompetitive inhibitor, harmine, a $\beta$-carboline alkaloid isolated from Peganum harmala, is a specific and potent ATP-competitive inhibitor of DYRK1A $\left(\mathrm{IC}_{50}=33-350 \mathrm{nM}\right) .{ }^{11}$ Although it represents a standard in terms of activity and selectivity, the numerous side effects of harmine have led to the development and study of various synthetic compounds. Not surprisingly, many of these DYRK1A inhibitors possess a heteroaromatic core. Examples are the purine derivative roscovitine, ${ }^{10 \mathrm{a}}$ the quinazoline NCGC00010037, ${ }^{12}$ the benzothiazoles TG003 ${ }^{13}$ and INDY, ${ }^{14}$ aminopyrimidyl-indoles ${ }^{15}$ or leucettine-derivatives (Figure 1). ${ }^{16}$ A number of potent inhibitors structurally related to harmine incorporate indolic and aza-indolic scaffolds (meridianins, ${ }^{17}$ meriolins, ${ }^{18}$ 2-indoyl-pyridine derivatives ${ }^{19}$ and lamellarin isosters ${ }^{20}$ ). Herein, we report the identification of new Diaryl-Azaindole iNhibitors of DYRK1A (DANDY) and the use of computer-guided molecular design for structural optimization. ${ }^{21}$

\section{Selection of the target compounds}

We began our study by screening our own chemical library for DYRK1A inhibitory activity (using an HPLC-based assay), focusing on 6-azaindole derivatives, a family to which harmine belongs and for which our group has a longstanding experience. ${ }^{22}$ Two compounds, 3 phenyl-5-p-methoxyphenyl-6-azaindole 1a and 3-phenyl-5-p-hydroxyphenyl-6-azaindole 2a, emerged as potential hits with $\mathrm{IC}_{50}$ values of $17.0 \mu \mathrm{M}$ and $27.4 \mu \mathrm{M}$, respectively (Figure 2). Indeed, these values compare favorably with that of harmine $\left(\mathrm{IC}_{50}=0.29 \mu \mathrm{M}\right)$ determined under the same conditions. 
Substrates 1a and 2a share a common 6-azaindole core with harmine. Moreover, when comparing them to other competitive inhibitors of DYRK1A, several common structural characteristics emerge: an aromatic moiety on the indolic 3-position (see meridianin and meriolin) and a crescent-like shape (see leucettine and lamellarin). These analogies prompted us to further explore structural motifs based on 3,5-diphenolic 6- or 7-azaindoles of type 3 . Such compounds can in principle be easily prepared from the corresponding accessible 3,5dihalo-6- or 7-azaindole 4 (Figure 3).

Virtual screening of a representative library of such compounds at the ATP binding site was thus initiated. Four DYRK1A crystal structures are available in the PDB: 3ANR (a DYRK1A-harmine complex), 3ANQ (a DYRK1A-INDY complex), 2VX3 (a DYRK1AK00611A complex) and 2WO6 (a DYRK1A-K00611A complex associated with a peptide substrate).${ }^{14}$ All exhibit complete structural homology except for the presence of a chloride ion in the ATP site in the case of 2VX3 and 2WO6. Because 3ANQ is practically identical to 3ANR, it was excluded. Thus 3ANR, 2WO6 and 2VX3 were virtually prepared and validated using the Schrödinger suite 2012. ${ }^{\mathrm{TM}}$ Docking studies at the ATP binding site were then performed using the model 3,5-diaryl 6- and 7-azaindole substrates shown in Figure 4. These compounds were found to have docking scores within the same range as ATP regardless of the DYRK1A structure used, thus validating our initial structural design.

Several trends emerged from this virtual study. First, the 6-azaindole derivatives were found to bind somewhat more weakly than the 7-azaindoles (compare 1a, 2a with $\mathbf{1 b}, \mathbf{2 b}$ ). Furthermore, in the latter series, the hydroxy compounds appeared potentially more active than the corresponding methoxy compounds (compare $\mathbf{2 b}$ with $\mathbf{1 b}$ and $\mathbf{2 c}$ with $\mathbf{1 c}$ ). Finally, increasing the number of hydroxy groups considerably improved the docking scores (compare tetrahydroxy $\mathbf{2 d}$ with monohydroxy $\mathbf{2 b}$ and dihydroxy $\mathbf{2 c}$ ). 
From this information, a binding model of our proposed DYRK1A inhibitors at the ATP binding site could be defined (Figure 5). Thus, the two nitrogens of the 6- or 7-azaindole cores were found to fix the binding mode by establishing two $\mathrm{H}$-bonds (one $\mathrm{H}$-donating and one $\mathrm{H}$ accepting) with the Glu239 carbonyl and the Leu241 NH, the 7-azaindole nucleus appearing better positioned to do so. ${ }^{23}$ With the binding mode set in this way, the substituents at the C3 and C5 positions of the phenyl rings could be ideally allocated to generate further stabilizing interactions with Ser242, Ileu165 and Lys188. This is the case for the hydroxyphenyl derivatives 2d which, by forming H-bonds with the carbonyl functions of Ser242 and Ileu165 and the ammonium center of Lys 188 obtain the high docking scores noted above.

In order to verify these hypotheses, we then proceeded to synthesize the proposed diaryl 7-azaindole derivatives and assess their DYRK1A inhibitory potency.

\section{Synthesis}

For the preparation of the 3,5-diaryl-substituted 7-azaindole derivatives, a standard synthetic route was established. ${ }^{24}$ Commercially available 5-bromo-7-azaindole 5 was iodinated in the presence of NIS and $N$-protected with a benzenesulfonyl group giving the common precursor 6 in almost quantitative yield (Scheme 1). Two successive Suzuki-Miyaura cross-couplings were then performed using various commercially available arylboronic acids to provide unsymmetrical compounds $\mathbf{7 b}, \mathbf{f}-\mathbf{m}$ in good yields. Alternatively, symmetrical compounds 7c-e,n were synthesized through a one-step double Suzuki-Miyaura cross-coupling reaction using two equivalents of the same arylboronic acid. Deprotection of the indole nitrogen was accomplished with sodium methanolate and led to the desired OMe-DANDYs 1b-d,f-n, as well as the diphenyl derivative 1 e $(n=0)$, with an average yield of $80 \%$. De- $O$-methylation of the former compounds was performed with the adequate amount of $\mathrm{BBr}_{3}$ (3.0 equivalents per 
methyl group) to give the corresponding OH-DANDYs $\mathbf{2 b - d , f - n . ~ A l l ~ t h e ~ d e s i r e d ~ d e r i v a t i v e s ~}$ were thus efficiently obtained in three to four steps from 3-iodo-5-bromo-7-azaindole.

\section{Results and Discussion}

\section{DYRK1A inhibition studies}

The DYRK1A inhibitory potencies of both the hydroxy and methoxy diaryl 7-azaindole derivatives were then evaluated in vitro (HPLC based assay carried out using a fluorescent peptide substrate of DYRK1A). The first set of data was collected for the 7-azaindoles bearing an unsubstituted phenyl group at C3 and a diversely substituted aryl group at C5 (Table 1). While the completely unsubstituted 3,5-diphenyl derivative 1e exhibited an $\mathrm{IC}_{50}$ value in the submicromolar range $(0.41 \mu \mathrm{M})$ i.e. four times more efficient than 6-aza-indole 1a $(1.70 \mu \mathrm{M}$, Figure 2), the incorporation of a $p$-OH function on the $\mathrm{C} 5$ phenyl (2b) afforded a slight improvement in inhibitory potency $\left(\mathrm{IC}_{50}=0.33 \mu \mathrm{M}\right)$. In contrast, activity was considerably decreased in the case of the $m-\mathrm{OH}$ and $o-\mathrm{OH}$ derivatives $2 \mathbf{f}$ and $2 \mathbf{g}\left(\mathrm{IC}_{50}=2.70\right.$ and $3.59 \mu \mathrm{M}$, respectively). Significantly, addition of a $p-\mathrm{OH}$ group to these latter compounds (i.e., $\mathbf{2 i}$ and 2h) doubled the DYRK1A inhibitory potencies with respect to the mono-OH derivative $\mathbf{2 b}$ $\left(\mathrm{IC}_{50}=0.16\right.$ and $0.15 \mu \mathrm{M}$, respectively $\left.v s 0.33 \mu \mathrm{M}\right)$. In accordance with our binding model, the methoxy derivatives, in which H-bonding with the backbone peptide residues of the binding site is precluded, were found to be less potent than the corresponding hydroxy derivatives (compare $1 \mathbf{b} v s \mathbf{2 b}$; $1 \mathbf{f} v s$ 2f; $1 \mathbf{g} v s \mathbf{2 g}$; $1 \mathbf{h} v s \mathbf{2 h}$; $1 \mathbf{i} v s \mathbf{2 i}$ ).

A second set of data was then obtained for compounds in which both aryl rings were substituted with various patterns of mono- and/or di-methoxy groups (Table 2). While the di$p$-methoxy derivative $\mathbf{1 c}$ was less active than the mono- $p$-methoxy analogue $\mathbf{1 b}\left(\mathrm{IC}_{50}=1.74\right.$ 
$\mu \mathrm{M}$ and $0.96 \mu \mathrm{M}$, respectively), the trimethoxy compounds $\mathbf{1 j}\left(\mathrm{IC}_{50}=0.28 \mu \mathrm{M}\right)$ and $\mathbf{1 k}\left(\mathrm{IC}_{50}=\right.$ $0.46 \mu \mathrm{M}$ ) were considerably more active than their corresponding dimethoxy derivatives $\mathbf{1 h}$ and $1 \mathbf{i}\left(\mathrm{IC}_{50}=1.17 \mu \mathrm{M}\right.$ and $3.08 \mu \mathrm{M}$, respectively). This advantage of an additional methoxy group was lost in the case of the tetramethoxy analogues $11\left(\mathrm{IC}_{50}=2.88 \mu \mathrm{M}\right), \mathbf{1} \mathbf{m}\left(\mathrm{IC}_{50}=1.67\right.$ $\mu \mathrm{M})$ and $1 \mathbf{d}\left(\mathrm{IC}_{50}=57.78 \mu \mathrm{M}\right)$. Thus, while good inhibitory activity was maintained with a $p$ methoxy group on the $\mathrm{C} 3$ aryl moiety, derivatives bearing a free hydroxy function on the $\mathrm{C} 5$ aryl still appeared to be superior inhibitors.

This observation also proved true for the derivatives having hydroxy rather than methoxy substituents on the $\mathrm{C} 3$ aryl ring. Indeed, these substrates were found to possess the highest activities toward DYRK1A of any inhibitors reported so far, with several compounds having $\mathrm{IC}_{50}$ s near or under the $10 \mathrm{nM}$ threshold (Table 3 ). Thus, the presence of two $p$-hydroxy groups was found to be essential for high activity (compare $\mathbf{2 c}, \mathrm{IC}_{50}=23.1 \mathrm{nM}$ and $\mathbf{2 n}, \mathrm{IC}_{50}=$ $0.105 \mu \mathrm{M})$. A 2,4-dihydroxyphenyl group at $\mathrm{C} 5$ led to a lowering of the $\mathrm{IC}_{50}\left(2 \mathbf{j}, \mathrm{IC}_{50}=11.7\right.$ $\mathrm{nM}$ ) while the closely related 3,4-dihydroxy analogue (2k) displayed an even higher inhibitory potency $\left(\mathrm{IC}_{50}=3 \mathrm{nM}\right)$. Addition of a $m$-hydroxy group to the $\mathrm{C} 3$ aryl moiety led to some loss of activity $\left(\mathbf{2 l}, \mathrm{IC}_{50}=14.3 \mathrm{nM} ; \mathbf{2 d}, \mathrm{IC}_{50}=12.4 \mathrm{nM}\right)$ though these remained excellent inhibitors. Finally, 2,5-dihydroxy substitution on the C5 phenyl led to some loss of activity (compare $\mathbf{2 m}$, $\mathrm{IC}_{50}=39.1 \mathrm{nM}$ and $\left.\mathbf{2 l}, \mathrm{IC}_{50}=14.3 \mathrm{nM}\right)$.

In order to gain more insight into the mechanism of DYRK1A inhibition by these azaindole derivatives, kinetic experiments were conducted with the more potent compounds. Double-reciprocal plots were carried out with various concentrations of ATP and the peptide substrate. All inhibitors were found to be competitive with ATP but not with the peptide substrate. The exceptional DYRK1A inhibitory potencies of these DANDYs were confirmed, all $\mathrm{K}_{\mathrm{i}}$ values being under $12 \mathrm{nM}$, and the most potent analogue, $\mathbf{2 k}$, demonstrating an $\mathrm{IC}_{50}<2$ nM (Table 3). 


\section{Detailed docking studies of the DANDYs}

The putative binding modes at the ATP binding site of DYRK1A of the most active compounds of the series $(\mathbf{2} \mathbf{c}, \mathbf{2 d}, \mathbf{2} \mathbf{j}$ and $\mathbf{2 k})$ were examined based on the structure of DYRK1A 2WO6.pdb available in the Protein Data Bank (PDB). The docking procedure was first evaluated by the direct docking of K00611A into this native structure of DYRK1A. The proteinligand complex was correctly reproduced in direct docking with a rmsd of $0.45 \AA$, thus validating the procedure used for docking of our active compounds (Figure 6, A).

We then proceeded to dock a virtual ATP molecule with the prepared structure of DYRK1A. The adenine moiety was found to be oriented toward the back of the ATP binding site (Figure 6, B) allowing the $\mathrm{NH}_{2}$ group to form an H-bond with the backbone Glu239 carbonyl while the $\mathrm{N} 1$ atom is $\mathrm{H}$-bonded to the Leu241 NH. Two other H-bonded interactions between the sugar moiety 3'-OH and Asn244 and Glu291 side-chains were also observed. Finally, an H-bond and/or an electrostatic interaction between Lys289 and the pyrophosphate moiety extremity was evident.

Our 3,5-diaryl-7-azaindoles exhibit a similar binding mode with the ATP-binding site of DYRK1A. The 7-azaindole moiety mimics the adenine unit of ATP, forming two H-bonds between the Glu239 carbonyl and N1-H and between N7 and the Leu241 NH. Moreover, the heteroaromatic scaffold is tightly bound to the protein by hydrophobic interactions with Ileu165, Val173, Val222, Phe238, Leu241, Leu294 and Val306 side-chains (not shown in Figure 7). Finally, the aromatic unit at the 3-position of the 7-azaindole pharmacophore interacts deep within the ATP binding site via the Lys 188 side-chain while the aromatic moiety on $\mathrm{C} 5$ interacts with the left edge of the active site. 
The molecular modeling study also provides a rationale for the unfavorable impact of the methoxy groups on the biological activity. For instance, compound 1c featuring a $p$ methoxy group on each of the two phenyl moieties of the 7-azaindole pharmacophore, demonstrates an $\mathrm{IC}_{50}$ of $1.74 \mu \mathrm{M}$, whereas its dihydroxy counterpart $\mathbf{2 c}$ (Figure $7, \mathrm{~A}$ ) is more active by almost two orders of magnitude $\left(\mathrm{IC}_{50}=23.1 \mathrm{nM}\right)$. While the docking experiment shows that the two compounds share the same general binding mode, the main difference lies in the possibility of formation, in the case of 2c, of an extra H-bond with Ileu165 (1.71 $\AA$ ) situated at the edge of the ATP binding site. Therefore, the H-bond donor character of the group borne by the C5 aromatic moiety appears to be essential for effective inhibition of DYRK1A. Further binding features of $\mathbf{2 c}$ include a strong H-bond between the indole NH and both Glu239 and Leu241 (1.91 $\AA$ and $2.03 \AA$, respectively) and a weaker H-bond between the $\mathrm{C} 3$ phenyl OH group and Lys $188(2.98 \AA ̊)$.

Addition of an ortho-hydroxy function to the C5 phenyl group of $\mathbf{2 c}$ (i.e., $\mathbf{2 j}$, Figure 7, B) allows formation of an additional H-bond with Leu241 (1.87 $\AA$ ) with little perturbation of the overall binding mode. This supplementary H-bond translates into a doubling of the inhibitory potency of $\mathbf{2} \mathbf{j}$ with respect to $\mathbf{2} \mathbf{c}$.

Compound 2d (Figure 7, C) presents an interesting structural variation of $\mathbf{2 c}$ in which a meta-OH has been added to each phenyl ring. Again, this substrate maintains the H-bonding pattern of the 7-azaindole pharmacophore with the Glu239 carbonyl and the Leu241 NH (1.86 $\AA$ and $2.06 \AA$, respectively). The diphenol residue at the C3 position now interacts with Lys188 by a 3-centered H-bond network (2.03 $\AA$ and $2.92 \AA$ ). However, the presence of the meta/para dihydroxy substitution on the $\mathrm{C} 5$ aromatic moiety leads to twisting of this phenyl ring such that now only the meta-hydroxy group is H-bonded to Ileu165. It can be speculated that the greater inhibitory potency of $\mathbf{2 d}\left(\mathrm{IC}_{50}=12.4 \mathrm{nM}\right)$ compared to $\mathbf{2} \mathbf{c}\left(\mathrm{IC}_{50}=23.1 \mathrm{nM}\right)$ is at least partly the consequence of this quite strong H-bond (1.85 $\AA$ ). 
Finally, removal of the meta-OH of the $\mathrm{C} 3$ aryl group of $\mathbf{2 d}$ leads to compound $\mathbf{2} \mathbf{k}$ (Figure 7, D) which demonstrates the highest inhibitory potency of all the DANDYs synthesized $\left(\mathrm{IC}_{50}=3 \mathrm{nM}\right.$ ) and of any compound reported so far. Surprisingly, no significant changes in the binding mode of this compound can be highlighted to rationalize the inhibition strength of this compound. Complementary studies implicating the water network surrounding the Lys 188 side-chain residue ${ }^{24}$ are under investigation.

The ATP binding site model of DYRK1A which we describe thus reasonably accounts for the observed DYRK1A inhibitory activities of the various DANDYs synthesized and should serve as a useful model for the preparation of more active and/or selective inhibitors.

\section{Kinase profiling of selected DANDYs}

The selectivities of four of the more active 7-azaindole derivatives ( $\mathbf{2} \mathbf{c}, \mathbf{2 d}, \mathbf{2} \mathbf{j}$ and $\mathbf{2} \mathbf{k})$ were evaluated at $5 \times 10^{-8} \mathrm{M}$ (ie between 5 and 15 times higher than their $\mathrm{IC}_{50}$ ) for inhibitory activities on a panel of 13 different kinases belonging to several families: DYRK (DYRK2, DYRK3 as well as DYRK1A), the closely related CMGCs (CDK2, CDK5, CLK1, ERK2, GSK3 $\beta$ ), other families of serine/threonine (AKT1, Pim1, CK1 $\alpha$ ) and tyrosine kinases (JAK3, TRKA) (Figure 8). ${ }^{25}$ While 2d was generally non-selective for the tested kinases (except AKT1), $\mathbf{2 c}, \mathbf{2} \mathbf{j}$ and $\mathbf{2 k}$ showed a more favorable selectivity profile. The latter three compounds were thus poor inhibitors of ERK2, GSK3 $\beta$, Pim1 and TRKA. Moreover, $\mathbf{2} \mathbf{j}$ only moderately inhibited $(<50 \%)$ CDK2, CK1 $\alpha$, DYRK2 and DYRK3. This selectivity of $\mathbf{2} \mathbf{j}$ for DYRK1A compared to DYRK2 and DYRK3 is surprising in view of the close homology of these three kinases and suggests that these enzymes can indeed be differentiated by suitably engineered ligands. 


\section{Cytotoxicity Assessment of Active DANDYs}

Since kinase inhibitory activity is often associated with cytotoxicity (a property that would be a deterrent in view of a potential DS or AD treatment), several DANDYs were evaluated for growth inhibition of KB cells in vitro (Table 4). While compounds $\mathbf{2 c}, \mathbf{2} \mathbf{j}$ and $\mathbf{2 k}$ inhibit between $83 \%$ to $95 \%$ of $\mathrm{KB}$ cell proliferation at $10^{-5} \mathrm{M}$ concentrations, growth inhibition decreases to approximately $50 \%(\mathbf{2 c}, \mathbf{2 k})$ and $21 \%(\mathbf{2} \mathbf{j})$ when tested at $10^{-6} \mathrm{M}$ concentrations. On the other hand, compounds $\mathbf{2} \mathbf{d}$ and $\mathbf{2} \mathbf{l}$ can be considered almost completely non-cytotoxic ( $11 \%$ and $9 \%$ growth inhibition, respectively, at $\left.10^{-5} \mathrm{M}\right)$. There thus appears to be no correlation between inhibition of KB cell growth and of DYRK1A by the DANDY derivatives and these can generally be considered to be only weakly cytotoxic.

\section{Conclusion}

Starting from a screening of 6-azaindole-based harmine lookalikes a new family of DYRK1A inhibitors was developed. In silico studies combined with a highly convergent synthetic strategy allowed the rapid synthesis of a relevant library of Diaryl-Azaindole iNhibitors of DYRK1A (DANDY) the activity of which was then evaluated in vitro. Among these, six compounds were found to exhibit Ki under the $15 \mathrm{nM}$ threshold, making them the most potent inhibitors of DYRK1A reported to date. ${ }^{26}$ Complementary studies showed that these compounds are non-cytotoxic, thus paving the way for studying their potential for treatment of neurodegenerative pathologies in appropriate animal models. 


\section{Experimental Section}

Chemistry: General Methods. Commercial grade reagents and solvents were used without further purification except as indicated below. Analytical thin-layer chromatography was performed on silica gel $60 \mathrm{~F}_{254}$ on aluminum plates (Merck) and visualized under a UVP Mineralight UVLS-28 lamp (254 nm) and with 4-anisaldehyde and phosphomolybdic acid stains in ethanol. Infrared spectra were recorded on a Perkin Elmer Spectrum BX FT-IR spectrometer (ATR). ${ }^{1} \mathrm{H}$ NMR was recorded at 300 or $500 \mathrm{MHz}$ (Bruker Avance 300 / 500 $\mathrm{MHz}$ ) for ${ }^{1} \mathrm{H}$ NMR and at 75 or $125 \mathrm{MHz}$ for ${ }^{13} \mathrm{C}$ NMR. Chemical shifts are quoted in parts per million (ppm) referenced to the appropriate solvent peak. ${ }^{13} \mathrm{C}$ chemical shifts are reported in ppm referenced to the center line of a triplet at $77.0 \mathrm{ppm}$ of chloroform- $d$ and at $49.0 \mathrm{ppm}$ of methanol- $d_{4}$. The following abbreviations are used to describe peak splitting patterns when appropriate: $\mathrm{br}=$ broad, $\mathrm{s}=$ singlet, $\mathrm{d}=$ doublet, $\mathrm{t}=$ triplet, $\mathrm{q}=$ quartet, $\mathrm{m}=$ multiplet, $\mathrm{dd}=\mathrm{doublet}$ of doublet. Coupling constants $J$ are reported in hertz units (Hz). Mass spectra were obtained either with an LCT (Micromass) instrument using electrospray ionization (ES), or from a Time of Flight analyzer (ESI-MS) for the high resolution mass spectra (HRMS). Flash chromatography was conducted on Merck silica gel $60(40-63 \mu \mathrm{m})$ at medium pressure (300 mbar). Preparative thin layer chromatography (TLC) was performed on precoated silica gel $60 \mathrm{~F}_{254}$ glass plates (Merck) and visualization on TLC was achieved by UV light (254 and $354 \mathrm{~nm}$ ). Flash column chromatography was undertaken on silica gel SI60 40-63 $\mu \mathrm{m}$ (Merck). Melting points were obtained on a Buchi Melting Point B-540 apparatus. Ultra Performance Liquid Chromatography analyses for checking purity ( $>95 \%$ area) of synthesized compounds were performed on a Waters UPLC instrument coupled with a Triple Quadrupole mass spectrometer detector (Acquity UPLC-TQD Waters) and equipped with a UPLC HSS C 18 column $(2.1 \times 50$ 
$\mathrm{mm}, 1.8 \mu \mathrm{m})$. Before UPLC/MS investigations, the samples were filtered through a $0.2 \mu \mathrm{m}$ nylon membrane filter. The mobile Phase A was water and B was acetonitrile, both containing $0.1 \%$ formic acid. The gradient started at $20 \% \mathrm{~B}$, was kept at $20 \%$ for ten minutes and was then increased linearly to $100 \%$ B over 0.2 minute. An equilibration time of 3 minutes was allowed before the next analysis. The flow rate was fixed at $0.6 \mathrm{~mL} / \mathrm{min}$ and the column temperature was maintained at $40{ }^{\circ} \mathrm{C}$.

3-Iodo-5-bromo-1H-pyrrolo[2,3-b]-pyridine. To a solution of the commercially available 5bromo-1H-pyrrolo[2,3-b]-pyridine $(1 \mathrm{~g}, 5.10 \mathrm{mmol})$ in $\mathrm{CH}_{2} \mathrm{Cl}_{2}(200 \mathrm{~mL})$ was added $\mathrm{KOH}(145$ $\mathrm{mg}, 2.55 \mathrm{mmol})$ at room temperature. After $30 \mathrm{~min}, \mathrm{~N}$-iodosuccinimide (1.2 g, $5.10 \mathrm{mmol})$ was added, the mixture was stirred during $15 \mathrm{~h}$, quenched with a saturated solution of $\mathrm{Na}_{2} \mathrm{~S}_{2} \mathrm{O}_{3}$ and extracted with $\mathrm{CH}_{2} \mathrm{Cl}_{2}$. The combined organic layers were dried $\left(\mathrm{MgSO}_{4}\right)$ and concentrated in vacuo. The desired product was obtained in quantitative yield and used in the next step without further purification. ${ }^{1} \mathrm{H}$ NMR (DMSO- $\left.d_{6}, 300 \mathrm{MHz}\right) \delta 12.34(\mathrm{~s}, 1 \mathrm{H}), 8.31(\mathrm{~d}, J=2.1 \mathrm{~Hz}, 1 \mathrm{H})$, $7.86(\mathrm{~d}, J=2.1 \mathrm{~Hz}, 1 \mathrm{H}), 7.30(\mathrm{~s}, 1 \mathrm{H}) ;{ }^{13} \mathrm{C} \mathrm{NMR}\left(\mathrm{DMSO}-d_{6}, 75 \mathrm{MHz}\right) \delta 146.5(\mathrm{Cq}), 143.8(\mathrm{CH})$, $132.5(\mathrm{Cq}), 129.9(\mathrm{CH}), 123.8(\mathrm{Cq}), 111.5(\mathrm{CH}), 53.6(\mathrm{Cq})$. HRMS (ESI+) calcd for $\mathrm{C}_{7} \mathrm{H}_{4}{ }^{79} \mathrm{BrIN}_{2}[\mathrm{M}+\mathrm{H}]^{+} 322.8681$, found 322.8682 , HRMS (ESI+) calcd for $\mathrm{C}_{7} \mathrm{H}_{4}{ }^{81} \mathrm{BrIN}_{2}[\mathrm{M}+\mathrm{H}]^{+}$ 324.8660, found 324.8670. IR (neat, $\mathrm{cm}^{-1}$ ): $v 3118,2821,1638$.

3-Iodo-5-bromo-1-(phenylsulfonyl)-1H-pyrrolo[2,3-b]pyridine (6). To a solution of 3-iodo5-bromo-1H-pyrrolo[2,3-b]-pyridine (500 mg, $1.55 \mathrm{mmol}$ ) in $\mathrm{CH}_{2} \mathrm{Cl}_{2}(4.1 \mathrm{~mL})$ were added sodium hydride $60 \%$ (186 mg, $4.66 \mathrm{mmol})$ and benzyltriethylammonium chloride $(8 \mathrm{mg}, 0.03$ mmol) under argon, at $0^{\circ} \mathrm{C}$. After $30 \mathrm{~min}$, benzenesulfonyl chloride $(240 \mu \mathrm{L}, 1.86 \mathrm{mmol})$ was added at $0^{\circ} \mathrm{C}$ and the mixture was stirred at room temperature during $2 \mathrm{~h}$. The mixture was quenched with water and extracted with $\mathrm{CH}_{2} \mathrm{Cl}_{2}$. The combined organic layers were dried 
$\left(\mathrm{MgSO}_{4}\right)$ and concentrated in vacuo. The residue was precipitated in $\mathrm{MeOH}$ and filtered off to give 6 as a pale pink solid (97\% yield). ${ }^{1} \mathrm{H} \mathrm{NMR}\left(\mathrm{CDCl}_{3}, 500 \mathrm{MHz}\right) \delta 8.46(\mathrm{~d}, J=2.0 \mathrm{~Hz}, 1 \mathrm{H})$, $8.19(\mathrm{~d}, J=8.0 \mathrm{~Hz}, 2 \mathrm{H}), 7.88(\mathrm{~s}, 1 \mathrm{H}), 7.82(\mathrm{~d}, J=2.5 \mathrm{~Hz}, 1 \mathrm{H}), 7.64-7.61(\mathrm{~m}, 1 \mathrm{H}), 7.54-7.51$ $(\mathrm{m}, 2 \mathrm{H}) ;{ }^{13} \mathrm{C} \mathrm{NMR}\left(\mathrm{CDCl}_{3}, 75 \mathrm{MHz}\right) \delta 146.7(\mathrm{CH}), 144.7(\mathrm{Cq}), 137.6(\mathrm{Cq}), 134.6(\mathrm{CH}), 132.5$ (CH), $131.2(\mathrm{CH}), 129.2(2 \mathrm{CH}), 128.2(2 \mathrm{CH}), 126.7(\mathrm{Cq}), 116.0(\mathrm{Cq}), 60.6(\mathrm{Cq})$. HRMS (ESI+) calcd for $\mathrm{C}_{13} \mathrm{H}_{9} \mathrm{~N}_{2} \mathrm{O}_{2} \mathrm{~S}^{79} \mathrm{Br}[\mathrm{M}+\mathrm{H}]^{+}$462.8613, found 462.8605, HRMS (ESI+) calcd for $\mathrm{C}_{13} \mathrm{H}_{9} \mathrm{~N}_{2} \mathrm{O}_{2} \mathrm{~S}^{81} \mathrm{Br}[\mathrm{M}+\mathrm{H}]^{+}$464.8592, found 464.8596. IR (neat, $\mathrm{cm}^{-1}$ ): $v 2851,1613,1370$.

Representative Procedure for Mono-Suzuki Coupling (RP1):

3-Phenyl-5-bromo-1-(phenylsulfonyl)- $1 \boldsymbol{H}$-pyrrolo[2,3-b]pyridine. To solution of 6 (250 $\mathrm{mg}, 0.54 \mathrm{mmol})$ in toluene/ethanol 3:1 (17 mL) were added benzeneboronic acid (65 $\mathrm{mg}, 0.54$ $\mathrm{mmol}), \mathrm{K}_{2} \mathrm{CO}_{3}(1.6 \mathrm{~mL}$ of a $2 \mathrm{M}$ solution in water, $3.20 \mathrm{mmol})$ and $\mathrm{Pd}\left(\mathrm{PPh}_{3}\right)_{4}(1.5 \mathrm{~mol} \%)$ and the reaction was heated to $110^{\circ} \mathrm{C}$ for $3.5 \mathrm{~h}$ under argon. The reaction mixture was cooled to room temperature, concentrated in vacuo and then partitioned between water and $\mathrm{CH}_{2} \mathrm{Cl}_{2}$. The aqueous layer was extracted with $\mathrm{CH}_{2} \mathrm{Cl}_{2}$ and the combined organic layers were dried $\left(\mathrm{MgSO}_{4}\right)$ and concentrated in vacuo. The residue was purified by flash chromatography on silica gel $\left(\mathrm{CH}_{2} \mathrm{Cl}_{2} 100 \%\right)$ to give the product as a white solid (89\% yield). ${ }^{1} \mathrm{H} \mathrm{NMR}\left(\mathrm{CDCl}_{3}, 300 \mathrm{MHz}\right) \delta$ $8.50(\mathrm{~d}, J=2.1 \mathrm{~Hz}, 1 \mathrm{H}), 8.25-8.20(\mathrm{~m}, 3 \mathrm{H}), 7.90(\mathrm{~s}, 1 \mathrm{H}), 7.64-7.36(\mathrm{~m}, 8 \mathrm{H}) ;{ }^{13} \mathrm{C} \mathrm{NMR}\left(\mathrm{CDCl}_{3}\right.$, $75 \mathrm{MHz}) \delta 145.7(\mathrm{Cq}), 145.6(\mathrm{CH}), 137.9(\mathrm{Cq}), 134.3(\mathrm{CH}), 131.8(\mathrm{Cq}), 131.1(\mathrm{CH}), 129.1$ $(\mathrm{CH}), 129.0(\mathrm{CH}), 128.0(\mathrm{CH}), 127.9(\mathrm{CH}), 127.3(\mathrm{CH}), 123.9(\mathrm{CH}), 123.1(\mathrm{Cq}), 119.8(\mathrm{Cq})$, 115.5 (Cq). HRMS (ESI+) calcd for $\mathrm{C}_{19} \mathrm{H}_{14} \mathrm{~N}_{2} \mathrm{O}_{2} \mathrm{~S}^{79} \mathrm{Br}[\mathrm{M}+\mathrm{H}]^{+}$412.9959, found 412.9969, HRMS (ESI+) calcd for $\mathrm{C}_{19} \mathrm{H}_{14} \mathrm{~N}_{2} \mathrm{O}_{2} \mathrm{~S}^{81} \mathrm{Br}[\mathrm{M}+\mathrm{H}]^{+}$414.9939, found 412.9958. IR (neat, $\mathrm{cm}^{-1}$ ): $v 2919,1605,1383$.

Representative Procedure for Double Suzuki Coupling (RP2): 
3,5-Diphenyl-1-(phenylsulfonyl)-1H-pyrrolo[2,3-b]pyridine (7e). To a solution of 6 (200 $\mathrm{mg}, 0.43 \mathrm{mmol})$ in acetone $(2 \mathrm{~mL})$ were added benzeneboronic acid $(98 \mathrm{mg}, 0.86 \mathrm{mmol})$, $\mathrm{Na}_{2} \mathrm{CO}_{3}(1.3 \mathrm{~mL}$ of a $2 \mathrm{M}$ solution in water, $5.00 \mathrm{mmol}), \mathrm{Pd}(\mathrm{OAc})_{2}(5 \mathrm{~mol} \%)$, and triphenylphosphine $(10 \mathrm{~mol} \%)$. The reaction mixture was heated at $85{ }^{\circ} \mathrm{C}$ during $2 \mathrm{~h}$ under argon then cooled to room temperature, concentrated in vacuo and partitioned between water and $\mathrm{CH}_{2} \mathrm{Cl}_{2}$. The aqueous layer was extracted with $\mathrm{CH}_{2} \mathrm{Cl}_{2}$ and the combined organic layers were dried $\left(\mathrm{MgSO}_{4}\right)$ and concentrated in vacuo. The residue was purified by flash chromatography on silica gel (heptane/ethyl acetate, gradient 97:3 to 95:5) to give 7e as a white solid (72\% yield). ${ }^{1} \mathrm{H}$ NMR $\left(\mathrm{CDCl}_{3}, 300 \mathrm{MHz}\right) \delta 9.72(\mathrm{~d}, J=2.0 \mathrm{~Hz}, 1 \mathrm{H}), 8.31-8.25(\mathrm{~m}, 3 \mathrm{H})$, $7.93(\mathrm{~s}, 1 \mathrm{H}), 7.66-7.38(\mathrm{~m}, 13 \mathrm{H}) ;{ }^{13} \mathrm{C} \mathrm{NMR}\left(\mathrm{CDCl}_{3}, 75 \mathrm{MHz}\right) \delta 146.9(\mathrm{Cq}), 144.4(\mathrm{CH}), 138.3$ $(\mathrm{Cq}), 138.2(\mathrm{Cq}), 134.1(\mathrm{CH}), 133.0(\mathrm{Cq}), 132.5(\mathrm{Cq}), 129.2(\mathrm{CH}), 129.1(\mathrm{CH}), 129.0(\mathrm{CH})$, $128.1(\mathrm{CH}), 127.8(\mathrm{CH}), 127.7(\mathrm{CH}), 127.5(\mathrm{CH}), 127.4(\mathrm{CH}), 127.2(\mathrm{CH}), 123.2(\mathrm{CH}), 121.6$ (Cq), 120.6 (Cq). HRMS (ESI+) calcd for $\mathrm{C}_{25} \mathrm{H}_{19} \mathrm{~N}_{2} \mathrm{O}_{2} \mathrm{~S}[\mathrm{M}+\mathrm{H}]^{+}$411.1167, found 411.1167. IR (neat, $\left.\mathrm{cm}^{-1}\right): v 2848,1601,1383$.

3-Phenyl-5-(4-methoxyphenyl)-1-(phenylsulfonyl)-1 $H$-pyrrolo[2,3-b]pyridine (7b). This compound was prepared according to RP1 using 3-phenyl-5-bromo-1-(phenylsulfonyl)-1Hpyrrolo[2,3-b]pyridine (333 mg, $0.81 \mathrm{mmol})$, 4-methoxybenzeneboronic acid (189 mg, 0.97 $\mathrm{mmol}), \mathrm{K}_{2} \mathrm{CO}_{3}(2.6 \mathrm{~mL}$ of a $2 \mathrm{M}$ solution in water, $4.84 \mathrm{mmol})$ and $\mathrm{Pd}\left(\mathrm{PPh}_{3}\right)_{4}(1.5 \mathrm{~mol} \%)$ in toluene/ethanol 3:1 (26 mL). The residue was purified by flash chromatography on silica gel $\left(\mathrm{CH}_{2} \mathrm{Cl}_{2} 100 \%\right)$ to give $7 \mathbf{b}$ as a white solid (98\% yield). ${ }^{1} \mathrm{H} \mathrm{NMR}\left(\mathrm{CDCl}_{3}, 300 \mathrm{MHz}\right) \delta 8.68(\mathrm{~d}$, $J=2.1 \mathrm{~Hz}, 1 \mathrm{H}), 8.27-8.30(\mathrm{~m}, 2 \mathrm{H}), 8.20(\mathrm{~d}, J=2.1 \mathrm{~Hz}, 1 \mathrm{H}), 7.92(\mathrm{~s}, 1 \mathrm{H}), 7.65-7.58(\mathrm{~m}, 3 \mathrm{H})$, 7.55-7.47 (m, 6H), 7.42-7.37 (m, 1H), 7.01 (br d, $J=8.7 \mathrm{~Hz}, 1 \mathrm{H}), 3.86(\mathrm{~s}, 3 \mathrm{H}) ;{ }^{13} \mathrm{C}$ NMR $\left(\mathrm{CDCl}_{3}, 75 \mathrm{MHz}\right) \delta 159.5(\mathrm{Cq}), 146.6(\mathrm{Cq}), 144.1(\mathrm{CH}), 138.3(\mathrm{Cq}), 134.0(\mathrm{CH}), 132.7(\mathrm{CH})$ $132.5(\mathrm{Cq}), 130.7(\mathrm{Cq}), 129.1(2 \mathrm{CH}), 129.0(2 \mathrm{CH}), 128.5(2 \mathrm{CH}), 128.0(2 \mathrm{CH}), 127.7(\mathrm{CH})$, 
$127.5(2 \mathrm{CH}), 126.7(\mathrm{CH}), 123.1(\mathrm{CH}), 121.6(\mathrm{Cq}), 120.6(\mathrm{Cq}), 114.5(2 \mathrm{CH}), 55.3\left(\mathrm{CH}_{3}\right) . \mathrm{HRMS}$ (ESI+) calcd for $\mathrm{C}_{26} \mathrm{H}_{21} \mathrm{~N}_{2} \mathrm{O}_{3} \mathrm{~S}[\mathrm{M}+\mathrm{H}]^{+}$441.1273, found 441.1263. IR (neat, $\mathrm{cm}^{-1}$ ): $v$ 2931, $1607,1382$.

\section{3,5-Di-(4-methoxyphenyl)-1-(phenylsulfonyl)-1H-pyrrolo[2,3-b]pyridine $\quad$ (7c). This} compound was prepared according to RP2 using 6 (300 $\mathrm{mg}, 0.65 \mathrm{mmol})$, 4methoxybenzeneboronic acid $(296 \mathrm{mg}, 1.95 \mathrm{mmol}), \mathrm{K}_{2} \mathrm{CO}_{3}(1.9 \mathrm{~mL}$ of a $2 \mathrm{M}$ solution in water, $3.80 \mathrm{mmol})$ and $\mathrm{Pd}\left(\mathrm{PPh}_{3}\right)_{4}(1.5 \mathrm{~mol} \%)$ in toluene/ethanol 3:1 $(20 \mathrm{~mL})$. The residue was purified by flash chromatography on silica gel $\left(\mathrm{CH}_{2} \mathrm{Cl}_{2} / \mathrm{MeOH}\right.$, gradient 100:0 to 99:1) to give 7c as a white solid (85\% yield). ${ }^{1} \mathrm{H} \mathrm{NMR}\left(\mathrm{CDCl}_{3}, 300 \mathrm{MHz}\right) \delta 8.66(\mathrm{~d}, J=2.1 \mathrm{~Hz}, 1 \mathrm{H}), 8.26(\mathrm{dd}, J=$ $7.2 \mathrm{~Hz}, 2.1 \mathrm{~Hz}, 2 \mathrm{H}), 8.16(\mathrm{~d}, J=2.1 \mathrm{~Hz}, 1 \mathrm{H}), 7.83(\mathrm{~s}, 1 \mathrm{H}), 7.60-7.48(\mathrm{~m}, 7 \mathrm{H}), 7.05-6.99$ (m, 4H), $3.87(\mathrm{~s}, 3 \mathrm{H}), 3.86(\mathrm{~s}, 3 \mathrm{H}) ;{ }^{13} \mathrm{C} \mathrm{NMR}\left(\mathrm{CDCl}_{3}, 75 \mathrm{MHz}\right) \delta 159.5(\mathrm{Cq}), 159.3(\mathrm{Cq}), 146.6$ $(\mathrm{Cq}), 144.0(\mathrm{CH}), 138.3(\mathrm{Cq}), 134.0(\mathrm{CH}), 132.6(\mathrm{Cq}), 130.8(\mathrm{Cq}), 129.0(2 \mathrm{CH}), 128.7(2 \mathrm{CH})$, $128.5(2 \mathrm{CH}), 128.0(2 \mathrm{CH}), 126.7(\mathrm{CH}), 124.9(\mathrm{Cq}), 122.4(\mathrm{Cq}), 121.8(\mathrm{Cq}), 120.4(\mathrm{Cq}), 114.6$ $(\mathrm{CH}), 114.5(\mathrm{CH}), 55.3\left(2 \mathrm{CH}_{3}\right)$. HRMS (ESI+) calcd for $\mathrm{C}_{27} \mathrm{H}_{23} \mathrm{~N}_{2} \mathrm{O}_{4} \mathrm{~S}[\mathrm{M}+\mathrm{H}]^{+}$471.1379, found 471.1389. IR (neat, $\mathrm{cm}^{-1}$ ): $v 2830,1610,1373$.

3,5-Di-(3,4-Dimethoxyphenyl)-1-(phenylsulfonyl)-1 $H$-pyrrolo[2,3-b]pyridine (7d). This compound was prepared according to RP2 using 6 (407 mg, 0.88 mmol), 3,4dimethoxybenzeneboronic acid $(480 \mathrm{mg}, 2.64 \mathrm{mmol}), \mathrm{K}_{2} \mathrm{CO}_{3}(2.7 \mathrm{~mL}$ of a $2 \mathrm{M}$ solution in water, $5.4 \mathrm{mmol})$ and $\mathrm{Pd}\left(\mathrm{PPh}_{3}\right)_{4}(1.5 \mathrm{~mol} \%)$ in toluene/ethanol 3:1 $(20 \mathrm{~mL})$. The residue was purified by flash chromatography on silica gel $\left(\mathrm{CH}_{2} \mathrm{Cl}_{2} / \mathrm{MeOH}\right.$, gradient 100:0 to 98:2) to give 7d as a white solid (91\% yield). ${ }^{1} \mathrm{H}$ NMR $\left(\mathrm{CDCl}_{3}, 300 \mathrm{MHz}\right) \delta 8.66(\mathrm{~d}, J=2.1 \mathrm{~Hz}, 1 \mathrm{H}), 8.27$ $(\mathrm{d}, J=7.2 \mathrm{~Hz}, 2 \mathrm{H}), 8.17(\mathrm{~d}, J=2.4 \mathrm{~Hz}, 1 \mathrm{H}), 7.86(\mathrm{~s}, 1 \mathrm{H}), 7.61-7.49(\mathrm{~m}, 3 \mathrm{H}), 7.18(\mathrm{dd}, J=8.2$ $\mathrm{Hz}, 2.0 \mathrm{~Hz}, 1 \mathrm{H}), 7.13-6.95(\mathrm{~m}, 5 \mathrm{H}), 3.69(\mathrm{~s}, 3 \mathrm{H}), 3.67(\mathrm{~s}, 3 \mathrm{H}), 3.66(\mathrm{~s}, 3 \mathrm{H}), 3.65(\mathrm{~s}, 3 \mathrm{H}) ;{ }^{13} \mathrm{C}$ 
$\operatorname{NMR}\left(\mathrm{CDCl}_{3}, 75 \mathrm{MHz}\right) \delta 149.4(\mathrm{Cq}), 149.3(\mathrm{Cq}), 149.0(\mathrm{Cq}), 148.9(\mathrm{Cq}), 146.6(\mathrm{Cq}), 144.2$ $(\mathrm{CH}), 138.3(\mathrm{Cq}), 134.0(\mathrm{CH}), 132.9(\mathrm{Cq}), 131.2(\mathrm{Cq}), 129.1(2 \mathrm{CH}), 128.0(2 \mathrm{CH}), 126.8(\mathrm{CH})$, $125.2(\mathrm{Cq}), 122.6(\mathrm{CH}), 121.8(\mathrm{Cq}), 120.5(\mathrm{Cq}), 120.0(\mathrm{CH}), 119.8(\mathrm{CH}), 111.7(2 \mathrm{CH}), 110.7$ $(\mathrm{CH}), 110.6(\mathrm{CH}), 56.0\left(2 \mathrm{CH}_{3}\right), 55.9\left(2 \mathrm{CH}_{3}\right)$. HRMS (ESI+) calcd for $\mathrm{C}_{29} \mathrm{H}_{27} \mathrm{~N}_{2} \mathrm{O}_{6} \mathrm{~S}[\mathrm{M}+\mathrm{H}]^{+}$ 531.1590, found 531.1594. IR (neat, $\mathrm{cm}^{-1}$ ): $v 2928,1602,1383$.

3-Phenyl-5-(3-methoxyphenyl)-1-(phenylsulfonyl)-1 $H$-pyrrolo[2,3-b]pyridine (7f). This compound was prepared according to RP1 using 3-phenyl-5-bromo-1-(phenylsulfonyl)-1Hpyrrolo[2,3-b]pyridine (155 mg, $0.38 \mathrm{mmol}), 3$-methoxybenzeneboronic acid (80 $\mathrm{mg}, 0.53$ mmol), $\mathrm{K}_{2} \mathrm{CO}_{3}(1.2 \mathrm{~mL}$ of a $2 \mathrm{M}$ solution in water, $2.40 \mathrm{mmol})$ and $\mathrm{Pd}\left(\mathrm{PPh}_{3}\right)_{4}(1.5 \mathrm{~mol} \%)$ in toluene/ethanol 3:1 (13 $\mathrm{mL})$. The residue was purified by flash chromatography on silica gel $\left(\mathrm{CH}_{2} \mathrm{Cl}_{2} 100 \%\right)$ to give $7 \mathbf{f}$ as a white solid (98\% yield). ${ }^{1} \mathrm{H} \mathrm{NMR}\left(\mathrm{CDCl}_{3}, 300 \mathrm{MHz}\right) \delta 8.70(\mathrm{~d}$, $J=2.1 \mathrm{~Hz}, 1 \mathrm{H}), 8.30-8.24(\mathrm{~m}, 3 \mathrm{H}), 7.92(\mathrm{~s}, 1 \mathrm{H}), 7.65-7.58(\mathrm{~m}, 3 \mathrm{H})$, 7.56-7.47 (m, 4H), 7.43$7.36(\mathrm{~m}, 2 \mathrm{H}), 7.15(\mathrm{~d}, J=7.8 \mathrm{~Hz}, 1 \mathrm{H}), 7.1(\mathrm{t}, J=2.1 \mathrm{~Hz}, 1 \mathrm{H}), 6.94(\mathrm{dd}, J=8.1 \mathrm{~Hz}, 2.4 \mathrm{~Hz}$, 1H), 3.87 (s, 3H); ${ }^{13} \mathrm{C} \mathrm{NMR}\left(\mathrm{CDCl}_{3}, 75 \mathrm{MHz}\right) \delta 160.1(\mathrm{Cq}), 147.0(\mathrm{Cq}), 144.4(\mathrm{CH}), 139.8$ $(\mathrm{Cq}), 138.3(\mathrm{Cq}), 134.1(\mathrm{CH}), 132.9(\mathrm{Cq}), 132.5(\mathrm{Cq}), 130.1(\mathrm{CH}), 129.2(2 \mathrm{CH}), 129.1(2 \mathrm{CH})$, $128.1(2 \mathrm{CH}), 127.8(\mathrm{CH}), 127.5(2 \mathrm{CH}), 127.3(\mathrm{CH}), 123.2(\mathrm{CH}), 121.6(\mathrm{Cq}), 120.7(\mathrm{Cq}), 119.9$ (CH), $113.5(\mathrm{CH}), 112.9(\mathrm{CH}), 53.4\left(\mathrm{CH}_{3}\right)$. HRMS (ESI+) calcd for $\mathrm{C}_{26} \mathrm{H}_{21} \mathrm{~N}_{2} \mathrm{O}_{3} \mathrm{~S}[\mathrm{M}+\mathrm{H}]^{+}$ 441.1273, found 441.1260. IR (neat, $\mathrm{cm}^{-1}$ ): $v$ 2913, 2851, 1607, 1355.

3-Phenyl-5-(2-methoxyphenyl)-1-(phenylsulfonyl)-1 $H$-pyrrolo[2,3-b]pyridine (7g). This compound was prepared according to RP1 using 3-phenyl-5-bromo-1-(phenylsulfonyl)-1Hpyrrolo[2,3-b]pyridine (309 mg, $0.75 \mathrm{mmol})$, 2-methoxybenzeneboronic acid (125 mg, 0.83 $\mathrm{mmol}), \mathrm{K}_{2} \mathrm{CO}_{3}(2.4 \mathrm{~mL}$ of a $2 \mathrm{M}$ solution in water, $4.50 \mathrm{mmol})$ and $\mathrm{Pd}\left(\mathrm{PPh}_{3}\right)_{4}(1.5 \mathrm{~mol} \%)$ in toluene/ethanol 3:1 (24 mL). The residue was purified by flash chromatography on silica gel 
$\left(\mathrm{CH}_{2} \mathrm{Cl}_{2} 100 \%\right)$ to give $7 \mathrm{~g}$ as a clear oil (98\% yield). ${ }^{1} \mathrm{H} \mathrm{NMR}\left(\mathrm{CDCl}_{3}, 300 \mathrm{MHz}\right) \delta 8.66(\mathrm{~d}, J$ $=2.1 \mathrm{~Hz}, 1 \mathrm{H}), 8.31-8.25(\mathrm{~m}, 3 \mathrm{H}), 7.92(\mathrm{~s}, 1 \mathrm{H}), 7.65-7.58(\mathrm{~m}, 3 \mathrm{H}), 7.55-7.45(\mathrm{~m}, 4 \mathrm{H}), 7.41-$ $7.30(\mathrm{~m}, 3 \mathrm{H}), 7.1-7.0(\mathrm{~m}, 2 \mathrm{H}), 3.81(\mathrm{~s}, 3 \mathrm{H}) ;{ }^{13} \mathrm{C} \mathrm{NMR}\left(\mathrm{CDCl}_{3}, 75 \mathrm{MHz}\right) \delta 156.5(\mathrm{Cq}), 146.5$ $(\mathrm{Cq}), 146.3(\mathrm{CH}), 138.4(\mathrm{Cq}), 134.0(\mathrm{CH}), 132.7(\mathrm{Cq}), 131.0(\mathrm{CH}), 130.1(\mathrm{Cq}), 129.6(\mathrm{CH})$, $129.3(\mathrm{CH}), 129.0(2 \mathrm{CH}), 129.0(2 \mathrm{CH}), 128.0(2 \mathrm{CH}), 127.6(\mathrm{CH}), 127.4(2 \mathrm{CH}), 127.3(\mathrm{Cq})$, 122.7 (CH), $121.1(\mathrm{Cq}), 121.0(\mathrm{CH}), 120.6(\mathrm{Cq}), 111.2(\mathrm{CH}), 55.5\left(\mathrm{CH}_{3}\right)$. HRMS (ESI+) calcd for $\mathrm{C}_{26} \mathrm{H}_{21} \mathrm{~N}_{2} \mathrm{O}_{3} \mathrm{~S}[\mathrm{M}+\mathrm{H}]^{+}$441.1273, found 441.1273. IR (neat, $\mathrm{cm}^{-1}$ ): $v$ 2925, 1601, 1385.

\section{3-Phenyl-5-(2,4-dimethoxyphenyl)-1-(phenylsulfonyl)-1 $H$-pyrrolo[2,3-b]pyridine}

(7h).

This compound was according to RP1 using 3-phenyl-5-bromo-1-(phenylsulfonyl)-1Hpyrrolo[2,3-b]pyridine (327 mg, $0.79 \mathrm{mmol}$ ), 2,4-dimethoxybenzeneboronic acid (159 mg, 0.87 $\mathrm{mmol}), \mathrm{K}_{2} \mathrm{CO}_{3}(2.5 \mathrm{~mL}$ of a $2 \mathrm{M}$ solution in water, $4.76 \mathrm{mmol})$ and $\mathrm{Pd}\left(\mathrm{PPh}_{3}\right)_{4}(1.5 \mathrm{~mol} \%)$ in toluene/ethanol 3:1 (25 mL). The residue was purified by flash chromatography on silica gel $\left(\mathrm{CH}_{2} \mathrm{Cl}_{2} 100 \%\right)$ to give $7 \mathbf{h}$ as a white solid (70\% yield). ${ }^{1} \mathrm{H} \mathrm{NMR}\left(\mathrm{CDCl}_{3}, 300 \mathrm{MHz}\right) \delta 8.61(\mathrm{~d}$, $J=2.0 \mathrm{~Hz}, 1 \mathrm{H}), 8.30-8.26(\mathrm{~m}, 2 \mathrm{H}), 8.21(\mathrm{~d}, J=2.0 \mathrm{~Hz}, 1 \mathrm{H}), 7.90(\mathrm{~s}, 1 \mathrm{H}), 7.65-7.58(\mathrm{~m}, 3 \mathrm{H})$, 7.54-7.45 (m, 4H), 7.40-7.37 (m, 1H), 7.25-7.22 (m, 1H), 6.62-6.59 (m, 2H), $3.89(\mathrm{~s}, 3 \mathrm{H}), 3.79$ $(\mathrm{s}, 3 \mathrm{H}) ;{ }^{13} \mathrm{C} \mathrm{NMR}\left(\mathrm{CDCl}_{3}, 75 \mathrm{MHz}\right) \delta 160.8(\mathrm{Cq}), 157.5(\mathrm{Cq}), 146.4(\mathrm{CH}), 146.3(\mathrm{CH}), 138.4$ $(\mathrm{Cq}), 134.0(\mathrm{CH}), 132.8(\mathrm{Cq}), 131.4(\mathrm{CH}), 130.0(\mathrm{Cq}), 129.4(\mathrm{Cq}), 129.0(2 \mathrm{CH}), 129.0(2 \mathrm{CH})$, $128.0(2 \mathrm{CH}), 127.6(\mathrm{CH}), 127.5(2 \mathrm{CH}), 122.7(\mathrm{CH}), 121.1(\mathrm{Cq}), 120.6(\mathrm{Cq}), 120.1(\mathrm{Cq}), 104.9$ $(\mathrm{CH}), 99.0(\mathrm{CH}), 55.5\left(\mathrm{CH}_{3}\right), 55.4\left(\mathrm{CH}_{3}\right)$. HRMS (ESI+) calcd for $\mathrm{C}_{27} \mathrm{H}_{23} \mathrm{~N}_{2} \mathrm{O}_{4} \mathrm{~S}[\mathrm{M}+\mathrm{H}]^{+}$ 471.1379, found 471.1392. IR (neat, $\mathrm{cm}^{-1}$ ): $v 2931,1611,1383$.

\section{3-Phenyl-5-(3,4-dimethoxyphenyl)-1-(phenylsulfonyl)-1H-pyrrolo[2,3-b]pyridine}

(7i).

This compound was prepared according to RP1 using 3-phenyl-5-bromo-1-(phenylsulfonyl)1H-pyrrolo[2,3-b]pyridine (260 mg, $0.63 \mathrm{mmol})$, 3,4-dimethoxybenzeneboronic acid (126 mg, 
$0.69 \mathrm{mmol}), \mathrm{K}_{2} \mathrm{CO}_{3}(2.0 \mathrm{~mL}$ of a $2 \mathrm{M}$ solution in water, $4.00 \mathrm{mmol})$ and $\mathrm{Pd}\left(\mathrm{PPh}_{3}\right)_{4}(1.5 \mathrm{~mol} \%)$ in toluene/ethanol 3:1 (20 $\mathrm{mL})$. The residue was purified by flash chromatography on silica gel $\left(\mathrm{CH}_{2} \mathrm{Cl}_{2} / \mathrm{MeOH}\right.$, gradient 100:0 to $\left.99: 1\right)$ to give $7 \mathbf{i}$ as a white solid (67\% yield). ${ }^{1} \mathrm{H}$ NMR $\left(\mathrm{CDCl}_{3}, 300 \mathrm{MHz}\right) \delta 8.67(\mathrm{~d}, J=2.0 \mathrm{~Hz}, 1 \mathrm{H}), 8.30-8.26(\mathrm{~m}, 2 \mathrm{H}), 8.19(\mathrm{~d}, J=2.0 \mathrm{~Hz}, 1 \mathrm{H}), 7.92$ (s, 1H), 7.65-7.59 (m, 3H), 7.55-7.48 (m, 4H), 7.43-7.41 (m, 1H), $7.11(\mathrm{dd}, J=8.4 \mathrm{~Hz}, 2.1 \mathrm{~Hz}$ 1H), $7.05(\mathrm{~d}, J=2.1 \mathrm{~Hz}, 1 \mathrm{H}), 6.67(\mathrm{br} \mathrm{d}, J=8.4 \mathrm{~Hz}, 1 \mathrm{H}), 3.94(\mathrm{~s}, 3 \mathrm{H}), 3.93(\mathrm{~s}, 3 \mathrm{H}) ;{ }^{13} \mathrm{C} \mathrm{NMR}$ $\left(\mathrm{CDCl}_{3}, 75 \mathrm{MHz}\right) \delta 149.4(\mathrm{Cq}), 149.0(\mathrm{Cq}), 146.7(\mathrm{Cq}), 144.3(\mathrm{CH}), 138.3(\mathrm{Cq}), 134.1(\mathrm{CH})$, $133.0(\mathrm{Cq}), 132.6(\mathrm{Cq}), 131.3(\mathrm{Cq}), 129.2(2 \mathrm{CH}), 129.1(2 \mathrm{CH}), 128.1(2 \mathrm{CH}), 127.8(\mathrm{CH}), 127.5$ $(2 \mathrm{CH}), 126.9(\mathrm{CH}), 123.2(\mathrm{CH}), 121.6(\mathrm{Cq}), 120.6(\mathrm{Cq}), 119.9(\mathrm{CH}), 111.7(\mathrm{CH}), 110.8(\mathrm{CH})$, $56.1\left(\mathrm{CH}_{3}\right), 56.0\left(\mathrm{CH}_{3}\right)$. HRMS (ESI+) calcd for $\mathrm{C}_{27} \mathrm{H}_{23} \mathrm{~N}_{2} \mathrm{O}_{4} \mathrm{~S}[\mathrm{M}+\mathrm{H}]^{+}$471.1379, found 471.1384. IR (neat, $\mathrm{cm}^{-1}$ ): $v 2824,1604,1382$.

3-(4-Methoxyphenyl)-5-bromo-1-(phenylsulfonyl)-1 $\boldsymbol{H}$-pyrrolo[2,3-b]pyridine. This compound was prepared according to RP1 using 6 (725 mg, $1.57 \mathrm{mmol})$, 4methoxybenzeneboronic acid $(262 \mathrm{mg}, 1.72 \mathrm{mmol}), \mathrm{K}_{2} \mathrm{CO}_{3}(5.0 \mathrm{~mL}$ of a $2 \mathrm{M}$ solution in water, $10.00 \mathrm{mmol})$ and $\mathrm{Pd}\left(\mathrm{PPh}_{3}\right)_{4}(1.5 \mathrm{~mol} \%)$ in toluene/ethanol 3:1 $(51 \mathrm{~mL})$. The residue was purified by flash chromatography on silica gel $\left(\mathrm{CH}_{2} \mathrm{Cl}_{2}: 100 \%\right)$ to give the product as a white solid $\left(71 \%\right.$ yield). ${ }^{1} \mathrm{H}$ NMR $\left(\mathrm{CDCl}_{3}, 300 \mathrm{MHz}\right) \delta 8.49(\mathrm{~d}, J=2.1 \mathrm{~Hz}, 1 \mathrm{H}), 8.23-8.18(\mathrm{~m}, 3 \mathrm{H})$, $7.82(\mathrm{~s}, 1 \mathrm{H}), 7.62-7.54(\mathrm{~m}, 1 \mathrm{H}), 7.54-7.46(\mathrm{~m}, 4 \mathrm{H}), 7.02(\mathrm{~d}, J=8.7 \mathrm{~Hz}, 2 \mathrm{H}), 3.88(\mathrm{~s}, 3 \mathrm{H}) ;{ }^{13} \mathrm{C}$ NMR $\left(\mathrm{CDCl}_{3}, 75 \mathrm{MHz}\right) \delta 159.3(\mathrm{Cq}), 145.8(\mathrm{Cq}), 145.7(\mathrm{CH}), 138.0(\mathrm{Cq}), 134.3(\mathrm{CH}), 131.1$ $(\mathrm{CH}), 129.1(2 \mathrm{CH}), 128.6(2 \mathrm{CH}), 128.1(2 \mathrm{CH}), 124.3(\mathrm{Cq}), 123.4(\mathrm{Cq}), 123.2(\mathrm{CH}), 119.7(\mathrm{Cq})$, $115.5(\mathrm{Cq}), 114.7(2 \mathrm{CH}), 55.4\left(\mathrm{CH}_{3}\right)$. HRMS (ESI+) calcd for $\mathrm{C}_{20} \mathrm{H}_{16} \mathrm{~N}_{2} \mathrm{O}_{3} \mathrm{~S}^{79} \mathrm{Br}[\mathrm{M}+\mathrm{H}]^{+}$ 443.0065, found 443.0077, HRMS (ESI+) calcd for $\mathrm{C}_{20} \mathrm{H}_{16} \mathrm{~N}_{2} \mathrm{O}_{3} \mathrm{~S}^{81} \mathrm{Br}[\mathrm{M}+\mathrm{H}]^{+} 445.0045$, found 445.0056. IR (neat, $\mathrm{cm}^{-1}$ ): $v 2848,1611,1373$. 


\section{3-(4-Methoxyphenyl)-5-(2,4-dimethoxyphenyl)-1-(phenylsulfonyl)-1 H-pyrrolo[2,3-}

b]pyridine (7j). This compound was prepared according to RP1 using 3-(4-methoxyphenyl)5-bromo-1-(phenylsulfonyl)-1H-pyrrolo[2,3-b]pyridine $\quad(180 \quad \mathrm{mg}, \quad 0.41 \quad \mathrm{mmol}), \quad 2,4-$ dimethoxybenzeneboronic acid $(104 \mathrm{mg}, 0.61 \mathrm{mmol}), \mathrm{K}_{2} \mathrm{CO}_{3}(1.2 \mathrm{~mL}$ of a $2 \mathrm{M}$ solution in water, $2.40 \mathrm{mmol})$ and $\mathrm{Pd}\left(\mathrm{PPh}_{3}\right)_{4}(1.5 \mathrm{~mol} \%)$ in toluene/ethanol 3:1 $(14 \mathrm{~mL})$. The residue was purified by flash chromatography on silica gel $\left(\mathrm{CH}_{2} \mathrm{Cl}_{2}: 100 \%\right)$ to give $7 \mathbf{j}$ as a white solid (98\% yield). ${ }^{1} \mathrm{H} \mathrm{NMR}\left(\mathrm{CDCl}_{3}, 300 \mathrm{MHz}\right) \delta 8.60(\mathrm{~d}, J=2.1 \mathrm{~Hz}, 1 \mathrm{H}), 8.26(\mathrm{dd}, J=8.5 \mathrm{~Hz}, 1.2 \mathrm{~Hz}$, $2 \mathrm{H}), 8.16(\mathrm{~d}, J=2.1 \mathrm{~Hz}, 1 \mathrm{H}), 7.82(\mathrm{~s}, 1 \mathrm{H}), 7.60-7.51(\mathrm{~m}, 5 \mathrm{H}), 7.22(\mathrm{~d}, J=9.0 \mathrm{~Hz}, 1 \mathrm{H}),$, $(\mathrm{d}, J=9.0 \mathrm{~Hz}, 2 \mathrm{H}), 6.60-6.58(\mathrm{~m}, 2 \mathrm{H}), 3.86(\mathrm{~s}, 6 \mathrm{H}), 3.79(\mathrm{~s}, 3 \mathrm{H}) ;{ }^{13} \mathrm{C} \mathrm{NMR}\left(\mathrm{CDCl}_{3}, 75 \mathrm{MHz}\right)$ $\delta 160.8(\mathrm{Cq}), 159.2(\mathrm{Cq}), 157.5(\mathrm{Cq}), 146.3(\mathrm{Cq}), 146.2(\mathrm{CH}), 138.5(\mathrm{Cq}), 133.9(\mathrm{CH}), 131.4$ $(\mathrm{CH}), 129.9(\mathrm{Cq}), 129.4(\mathrm{CH}), 129.0(2 \mathrm{CH}), 128.6(2 \mathrm{CH}), 128.0(2 \mathrm{CH}), 125.2(\mathrm{Cq}), 121.9$ $(\mathrm{CH}), 121.3(\mathrm{Cq}), 120.3(\mathrm{Cq}), 120.2(\mathrm{Cq}), 114.5(2 \mathrm{CH}), 104.9(\mathrm{CH}), 99.0(\mathrm{CH}), 55.5\left(\mathrm{CH}_{3}\right)$, $55.4\left(\mathrm{CH}_{3}\right), 55.3\left(\mathrm{CH}_{3}\right)$. HRMS (ESI+) calcd for $\mathrm{C}_{28} \mathrm{H}_{25} \mathrm{~N}_{2} \mathrm{O}_{5} \mathrm{~S}[\mathrm{M}+\mathrm{H}]^{+}$501.1484, found 501.1479. IR (neat, $\mathrm{cm}^{-1}$ ): $v 2848,1607,1373$.

\section{3-(4-Methoxyphenyl)-5-(3,4-dimethoxyphenyl)-1-(phenylsulfonyl)-1 $H$-pyrrolo[2,3-}

b]pyridine (7k). This compound was prepared according to RP1 using 3-(4-methoxyphenyl)5-bromo-1-(phenylsulfonyl)-1H-pyrrolo[2,3-b]pyridine $\quad(326 \quad \mathrm{mg}, \quad 0.74 \quad \mathrm{mmol}), \quad 3,4-$ dimethoxybenzeneboronic acid $(148 \mathrm{mg}, 0.81 \mathrm{mmol}), \mathrm{K}_{2} \mathrm{CO}_{3}(2.4 \mathrm{~mL}$ of a $2 \mathrm{M}$ solution in water, $4.80 \mathrm{mmol})$ and $\mathrm{Pd}\left(\mathrm{PPh}_{3}\right)_{4}(1.5 \mathrm{~mol} \%)$ in toluene/ethanol 3:1 (14 mL). The residue was purified by flash chromatography on silica gel $\left(\mathrm{CH}_{2} \mathrm{Cl}_{2} / \mathrm{MeOH}\right.$ : 100:0 to $\left.98: 2\right)$ to give the product as a white solid (78\% yield). ${ }^{1} \mathrm{H}$ NMR $\left(\mathrm{CDCl}_{3}, 300 \mathrm{MHz}\right) \delta 8.66(\mathrm{~d}, J=2.1 \mathrm{~Hz}, 1 \mathrm{H})$, $8.27($ br d, $J=8.1 \mathrm{~Hz}, 2 \mathrm{H}), 8.15(\mathrm{~d}, J=2.1 \mathrm{~Hz}, 1 \mathrm{H}), 7.84(\mathrm{~s}, 1 \mathrm{H}), 7.63-7.50(\mathrm{~m}, 5 \mathrm{H}), 7.13-6.96$

(m, 5H), $3.94(\mathrm{~s}, 3 \mathrm{H}), 3.93(\mathrm{~s}, 3 \mathrm{H}), 3.87(\mathrm{~s}, 3 \mathrm{H}) ;{ }^{13} \mathrm{C} \mathrm{NMR}\left(\mathrm{CDCl}_{3}, 75 \mathrm{MHz}\right) \delta 159.3(\mathrm{Cq})$, $149.4(\mathrm{Cq}), 149.0(\mathrm{Cq}), 146.7(\mathrm{Cq}), 144.2(\mathrm{CH}), 138.4(\mathrm{Cq}), 134.0(\mathrm{CH}), 132.9(\mathrm{Cq}), 131.3$ (Cq), $129.1(2 \mathrm{CH}), 128.7(2 \mathrm{CH}), 128.0(2 \mathrm{CH}), 126.8(\mathrm{CH}), 124.9(\mathrm{Cq}), 122.5(\mathrm{CH}), 121.8(\mathrm{Cq})$, 
$120.3(\mathrm{Cq}), 119.9(\mathrm{CH}), 114.6(2 \mathrm{CH}), 111.7(\mathrm{CH}), 110.8(\mathrm{CH}), 56.0\left(\mathrm{CH}_{3}\right), 55.9\left(\mathrm{CH}_{3}\right), 55.4$ $\left(\mathrm{CH}_{3}\right)$. HRMS (ESI+) calcd for $\mathrm{C}_{28} \mathrm{H}_{25} \mathrm{~N}_{2} \mathrm{O}_{5} \mathrm{~S}[\mathrm{M}+\mathrm{H}]^{+}$501.1484, found 501.1473. IR (neat, $\mathrm{cm}^{-}$ 1): $v 2830,1608,1382$.

3-(3,4-Dimethoxyphenyl)-5-bromo-1-(phenylsulfonyl)-1H-pyrrolo[2,3-b]pyridine. This compound was prepared according to RP1 using 6 (1 g, $2.16 \mathrm{mmol}), 3,4-$ dimethoxybenzeneboronic acid $(432 \mathrm{mg}, 2.38 \mathrm{mmol}), \mathrm{K}_{2} \mathrm{CO}_{3}(7.0 \mathrm{~mL}$ of a $2 \mathrm{M}$ solution in water, $14.00 \mathrm{mmol})$ and $\mathrm{Pd}\left(\mathrm{PPh}_{3}\right)_{4}(1.5 \mathrm{~mol} \%)$ in toluene/ethanol 3:1 (69 mL). The residue was purified by flash chromatography on silica gel $\left(\mathrm{CH}_{2} \mathrm{Cl}_{2}: 100 \%\right)$ to give the product as a white solid (88\% yield). ${ }^{1} \mathrm{H}$ NMR $\left(\mathrm{CDCl}_{3}, 500 \mathrm{MHz}\right) \delta 8.49(\mathrm{~d}, J=2.5 \mathrm{~Hz}, 1 \mathrm{H}), 8.22(\mathrm{~d}, J=7.5 \mathrm{~Hz}$, 2H), $8.19(\mathrm{~d}, J=2.0 \mathrm{~Hz}, 1 \mathrm{H}), 7.84(\mathrm{~s}, 1 \mathrm{H}), 7.64-7.60(\mathrm{~m}, 1 \mathrm{H}), 7.54-7.51(\mathrm{~m}, 2 \mathrm{H}), 7.10(\mathrm{dd}, J=$ $8.0 \mathrm{~Hz}, 2.0 \mathrm{~Hz}, 1 \mathrm{H}), 7.02(\mathrm{~d}, J=2.0 \mathrm{~Hz}, 1 \mathrm{H}), 6.98(\mathrm{~d}, J=8.5 \mathrm{~Hz}, 1 \mathrm{H}), 3.97(\mathrm{~s}, 3 \mathrm{H}), 3.95(\mathrm{~s}$, $3 \mathrm{H}) ;{ }^{13} \mathrm{C} \mathrm{NMR}\left(\mathrm{CDCl}_{3}, 75 \mathrm{MHz}\right) \delta 149.5(\mathrm{Cq}), 149.1(\mathrm{Cq}), 145.7(\mathrm{CH}+\mathrm{Cq}), 138.0(\mathrm{Cq}), 134.3$ (CH), $131.1(\mathrm{CH}), 129.1(2 \mathrm{CH}), 128.1(2 \mathrm{CH}), 124.5(\mathrm{Cq}), 123.3(\mathrm{CH}), 123.3(\mathrm{Cq}), 120.0(\mathrm{CH})$, $119.8(\mathrm{Cq}), 115.5(\mathrm{Cq}), 111.7(\mathrm{CH}), 110.6(\mathrm{CH}), 56.1\left(\mathrm{CH}_{3}\right), 56.0\left(\mathrm{CH}_{3}\right)$. HRMS (ESI+) calcd for $\mathrm{C}_{21} \mathrm{H}_{18} \mathrm{~N}_{2} \mathrm{O}_{4} \mathrm{~S}^{79} \mathrm{Br} \quad[\mathrm{M}+\mathrm{H}]^{+}$473.0171, found 473.0172, HRMS (ESI+) calcd for $\mathrm{C}_{21} \mathrm{H}_{18} \mathrm{~N}_{2} \mathrm{O}_{4} \mathrm{~S}^{81} \mathrm{Br}[\mathrm{M}+\mathrm{H}]^{+}$475.0150, found 475.0162. IR (neat, $\mathrm{cm}^{-1}$ ): $v 2928,1592,1358$.

\section{3-(3,4-Dimethoxyphenyl)-5-(2,4-dimethoxyphenyl)-1-(phenylsulfonyl)-1H-pyrrolo[2,3-}

b]pyridine (7l). This compound was prepared according to RP1 using 3-(3,4dimethoxyphenyl)-5-bromo-1-(phenylsulfonyl)-1H-pyrrolo[2,3-b]pyridine (315 mg, 0.68 mmol), 2,4-dimethoxybenzeneboronic acid (134 mg, $0.73 \mathrm{mmol}), \mathrm{K}_{2} \mathrm{CO}_{3}(2.1 \mathrm{~mL}$ of a $2 \mathrm{M}$ solution in water, $4.20 \mathrm{mmol})$ and $\mathrm{Pd}\left(\mathrm{PPh}_{3}\right)_{4}(1.5 \mathrm{~mol} \%)$ in toluene/ethanol 3:1 (14 mL). The residue was purified by flash chromatography on silica gel $\left(\mathrm{CH}_{2} \mathrm{Cl}_{2} 100 \%\right)$ to give $7 \mathbf{l}$ as a clear oil (41\% yield). ${ }^{1} \mathrm{H}$ NMR $\left(\mathrm{CDCl}_{3}, 300 \mathrm{MHz}\right) \delta 8.60$ (br s, $\left.1 \mathrm{H}\right), 8.27$ (br d, $\left.J=7.8 \mathrm{~Hz}, 2 \mathrm{H}\right), 8.19$ 
(s, 1H), $7.83(\mathrm{~s}, 1 \mathrm{H}), 7.60-7.48(\mathrm{~m}, 3 \mathrm{H}), 7.24-7.15(\mathrm{~m}, 2 \mathrm{H}), 7.11$ (br s, $1 \mathrm{H}), 6.96$ (br d, $J=8.1$ $\mathrm{Hz}, 1 \mathrm{H}), 6.61-6.58(\mathrm{~m}, 2 \mathrm{H}), 3.95(\mathrm{~s}, 3 \mathrm{H}), 3.94(\mathrm{~s}, 3 \mathrm{H}), 3.86(\mathrm{~s}, 3 \mathrm{H}), 3.79(\mathrm{~s}, 3 \mathrm{H}) ;{ }^{13} \mathrm{C} \mathrm{NMR}$ $\left(\mathrm{CDCl}_{3}, 75 \mathrm{MHz}\right) \delta 160.8(\mathrm{Cq}), 157.5(\mathrm{Cq}), 149.4(\mathrm{Cq}), 148.8(\mathrm{Cq}), 146.3(\mathrm{CH}+\mathrm{Cq}), 138.4$ $(\mathrm{Cq}), 134.0(\mathrm{CH}), 131.4(\mathrm{CH}), 129.9(\mathrm{Cq}), 129.4(\mathrm{CH}), 129.0(2 \mathrm{CH}), 128.0(2 \mathrm{CH}), 125.5(\mathrm{Cq})$, $122.1(\mathrm{CH}), 121.2(\mathrm{Cq}), 120.5(\mathrm{Cq}), 120.2(\mathrm{Cq}), 119.9(\mathrm{CH}), 111.6(\mathrm{CH}), 110.7(\mathrm{CH}), 104.9$ (CH), $99.0(\mathrm{CH}), 56.0\left(\mathrm{CH}_{3}\right), 55.9\left(\mathrm{CH}_{3}\right), 55.5\left(\mathrm{CH}_{3}\right), 55.4\left(\mathrm{CH}_{3}\right)$. HRMS (ESI+) calcd for $\mathrm{C}_{29} \mathrm{H}_{27} \mathrm{~N}_{2} \mathrm{O}_{6} \mathrm{~S}[\mathrm{M}+\mathrm{H}]^{+}$531.1590, found 531.1570. IR (neat, $\mathrm{cm}^{-1}$ ): $v$ 2833, 1608, 1377.

\section{3-(3,4-Dimethoxyphenyl)-5-(2,5-dimethoxyphenyl)-1-(phenylsulfonyl)-1H-pyrrolo[2,3-}

b]pyridine (7m). This compound was prepared according to RP1 using 3-(3,4dimethoxyphenyl)-5-bromo-1-(phenylsulfonyl)-1H-pyrrolo[2,3-b]pyridine $\quad(500 \mathrm{mg}, \quad 1.06$ mmol), 2,5-dimethoxybenzeneboronic acid (386 mg, $2.12 \mathrm{mmol}), \mathrm{K}_{2} \mathrm{CO}_{3}(3.3 \mathrm{~mL}$ of a $2 \mathrm{M}$ solution in water, $6.60 \mathrm{mmol})$ and $\mathrm{Pd}\left(\mathrm{PPh}_{3}\right)_{4}(1.5 \mathrm{~mol} \%)$ in toluene/ethanol 3:1 (14 mL). The residue was purified by flash chromatography on silica gel $\left(\mathrm{CH}_{2} \mathrm{Cl}_{2} 100 \%\right)$ to give an inseparable mixture of $\mathbf{7} \mathbf{m}$ and 1,4-dimethoxybenzene (resulting from the protodeboration of the starting boronic acid) (41\% yield of the desired compound). ${ }^{1} \mathrm{H} \mathrm{NMR}\left(\mathrm{CDCl}_{3}, 300 \mathrm{MHz}\right) \delta$ $8.63(\mathrm{~d}, J=2.1 \mathrm{~Hz}, 1 \mathrm{H}), 8.28$ (br d, $J=7.2 \mathrm{~Hz}, 2 \mathrm{H}), 8.19$ (d, $J=2.1 \mathrm{~Hz}, 1 \mathrm{H}), 7.85(\mathrm{~s}, 1 \mathrm{H})$, 7.60-7.49 (m, 3H), 7.17 (dd, $J=8.4 \mathrm{~Hz}, 2.1 \mathrm{~Hz}, 1 \mathrm{H}), 7.11$ (d, $J=1.8 \mathrm{~Hz}, 1 \mathrm{H}), 6.99-6.84$ (m, 4H), $3.96(\mathrm{~s}, 3 \mathrm{H}), 3.95(\mathrm{~s}, 3 \mathrm{H}), 3.80(\mathrm{~s}, 3 \mathrm{H}), 3.75(\mathrm{~s}, 3 \mathrm{H}) ;{ }^{13} \mathrm{C} \mathrm{NMR}\left(\mathrm{CDCl}_{3}, 75 \mathrm{MHz}\right) \delta 153.8$ $(\mathrm{Cq}), 150.7(\mathrm{Cq}), 149.4(\mathrm{Cq}), 148.8(\mathrm{Cq}), 146.5(\mathrm{Cq}), 146.1(\mathrm{CH}), 138.4(\mathrm{Cq}), 134.0(\mathrm{CH})$, $129.8(\mathrm{CH}), 129.6(\mathrm{CH}), 129.0(2 \mathrm{CH}), 128.3(\mathrm{Cq}), 128.0(2 \mathrm{CH}), 125.3(\mathrm{Cq}), 122.2(\mathrm{CH}), 121.2$ $(\mathrm{Cq}), 120.5(\mathrm{Cq}), 119.9(\mathrm{CH}), 116.9(\mathrm{CH}), 113.6(\mathrm{CH}), 112.5(\mathrm{Cq}), 111.7(\mathrm{CH}), 110.7(\mathrm{CH})$, $56.2\left(\mathrm{CH}_{3}\right), 56.0\left(\mathrm{CH}_{3}\right), 55.9\left(\mathrm{CH}_{3}\right), 55.8\left(\mathrm{CH}_{3}\right)$. HRMS (ESI+) calcd for $\mathrm{C}_{29} \mathrm{H}_{27} \mathrm{~N}_{2} \mathrm{O}_{6} \mathrm{~S}[\mathrm{M}+\mathrm{H}]^{+}$ 531.1590, found 531.1588. IR (neat, $\mathrm{cm}^{-1}$ ): $v 2833,1608,1377$. 
3,5-Di-(3-methoxyphenyl)-1-(phenylsulfonyl)-1 $H$-pyrrolo[2,3-b]pyridine $\quad(7 \mathrm{n}) . \quad$ This compound was prepared according to RP2 using 6 (635 mg, $1.37 \mathrm{mmol})$, 3methoxybenzeneboronic acid (521 mg, $3.43 \mathrm{mmol}), \mathrm{K}_{2} \mathrm{CO}_{3}(4.4 \mathrm{~mL}$ of a $2 \mathrm{M}$ solution in water, $8.80 \mathrm{mmol})$ and $\mathrm{Pd}\left(\mathrm{PPh}_{3}\right)_{4}(1.5 \mathrm{~mol} \%)$ in toluene/ethanol 3:1 $(20 \mathrm{~mL})$. The residue was purified by flash chromatography on silica gel $\left(\mathrm{CH}_{2} \mathrm{Cl}_{2} 100 \%\right)$ to give $7 \mathbf{n}$ as a yellow solid (77\% yield). ${ }^{1} \mathrm{H} \mathrm{NMR}\left(\mathrm{CDCl}_{3}, 300 \mathrm{MHz}\right) \delta 8.70(\mathrm{~d}, J=1.8 \mathrm{~Hz}, 1 \mathrm{H}), 8.28(\mathrm{~d}, J=7.2 \mathrm{~Hz}, 2 \mathrm{H}), 8.24(\mathrm{~d}, J=$ $2.1 \mathrm{~Hz}, 1 \mathrm{H}), 7.93(\mathrm{~s}, 1 \mathrm{H}), 7.62-7.50(\mathrm{~m}, 3 \mathrm{H}), 7.42(\mathrm{~d}, J=7.8 \mathrm{~Hz}, 1 \mathrm{H}), 7.37(\mathrm{~d}, J=7.8 \mathrm{~Hz}, 1 \mathrm{H})$, $7.22(\mathrm{~d}, J=7.8 \mathrm{~Hz}, 1 \mathrm{H}), 7.14-7.13(\mathrm{~m}, 2 \mathrm{H}), 7.10-7.08(\mathrm{~m}, 1 \mathrm{H}), 6.94($ br d, $J=8.4 \mathrm{~Hz}, 2 \mathrm{H}), 3.89$ (s, 3H), $3.87(\mathrm{~s}, 3 \mathrm{H}) ;{ }^{13} \mathrm{C} \mathrm{NMR}\left(\mathrm{CDCl}_{3}, 75 \mathrm{MHz}\right) \delta 160.2(\mathrm{Cq}), 160.1(\mathrm{Cq}), 146.9(\mathrm{Cq}), 144.4$ $(\mathrm{CH}), 139.8(\mathrm{Cq}), 138.3(\mathrm{Cq}), 134.1(\mathrm{CH}), 133.8(\mathrm{Cq}), 132.9(\mathrm{Cq}), 130.2(\mathrm{CH}), 130.1(\mathrm{CH})$, $129.1(2 \mathrm{CH}), 128.1(2 \mathrm{CH}), 127.4(\mathrm{CH}), 123.4(\mathrm{CH}), 121.6(\mathrm{Cq}), 120.6(\mathrm{Cq}), 119.9(2 \mathrm{CH})$, $113.4(\mathrm{CH}), 113.3(\mathrm{CH}), 113.1(\mathrm{CH}), 112.9(\mathrm{CH}), 55.4\left(\mathrm{CH}_{3}\right), 55.3\left(\mathrm{CH}_{3}\right)$. HRMS (ESI+) calcd for $\mathrm{C}_{27} \mathrm{H}_{23} \mathrm{~N}_{2} \mathrm{O}_{4} \mathrm{~S}[\mathrm{M}+\mathrm{H}]^{+}$471.1379, found 471.1361. IR (neat, $\mathrm{cm}^{-1}$ ): $v 2830,1599,1380$.

Representative Procedure for $N$-Benzenesulfonyl Removal (RP3):

3-Phenyl-5-phenyl-1H-pyrrolo[2,3-b]pyridine (1e). To a solution of 7e (125 mg, $0.31 \mathrm{mmol})$ in $\mathrm{MeOH}(700 \mu \mathrm{L})$ was added $\mathrm{NaOH}(90 \mu \mathrm{L}$ of a $2 \mathrm{~N}$ solution in water, $0.18 \mathrm{mmol})$. The reaction mixture was heated at $80^{\circ} \mathrm{C}$ during $1 \mathrm{~h}$, cooled to room temperature and concentrated in vacuo. It was then partitioned between water and $\mathrm{CH}_{2} \mathrm{Cl}_{2}$. The aqueous layer was extracted with $\mathrm{CH}_{2} \mathrm{Cl}_{2}$ and the combined organic layers were dried $\left(\mathrm{MgSO}_{4}\right)$ and concentrated in vacuo. The residue was purified by flash chromatography on silica gel $\left(\mathrm{CH}_{2} \mathrm{Cl}_{2} / \mathrm{MeOH}, 9: 1\right)$ to give $1 \mathrm{e}$ as 
a pale yellow solid (67\% yield). ${ }^{1} \mathrm{H}$ NMR $\left(\mathrm{CDCl}_{3}, 300 \mathrm{MHz}\right) \delta 10.93(\mathrm{~s}, 1 \mathrm{H}), 8.65(\mathrm{~d}, J=1.8$ $\mathrm{Hz}, 1 \mathrm{H}), 8.45(\mathrm{~d}, J=1.8 \mathrm{~Hz}, 1 \mathrm{H}), 7.73-7.6(\mathrm{~m}, 4 \mathrm{H}), 7.54(\mathrm{~s}, 1 \mathrm{H}), 7.52-7.46(\mathrm{~m}, 4 \mathrm{H}), 7.43-7.31$ $(\mathrm{m}, 2 \mathrm{H}) ;{ }^{13} \mathrm{C} \mathrm{NMR}\left(\mathrm{CDCl}_{3}, 75 \mathrm{MHz}\right) \delta 148.7(\mathrm{Cq}), 142.4(\mathrm{CH}), 139.5(\mathrm{Cq}), 134.9(\mathrm{Cq}), 130.3$ (Cq), $129.0(2 \mathrm{CH}), 128.9(2 \mathrm{CH}), 127.5(2 \mathrm{CH}), 127.2(2 \mathrm{CH}), 127.1(\mathrm{CH}), 126.9(\mathrm{CH}), 126.3$ $(\mathrm{CH}), 122.9(\mathrm{CH}), 118.6(\mathrm{Cq}), 116.8(\mathrm{Cq})$. HRMS (ESI+) calcd for $\mathrm{C}_{19} \mathrm{H}_{15} \mathrm{~N}_{2}[\mathrm{M}+\mathrm{H}]^{+}$ 271.1235, found 271.1226. IR (neat, $\mathrm{cm}^{-1}$ ): v. 3136, 2884, 1602. UPLC $R_{\mathrm{t}}=4.51 \mathrm{~min}$; area $100 \%$.

3-Phenyl-5-(4-methoxyphenyl)-1H-pyrrolo[2,3-b]pyridine (1b). This compound was prepared according to RP3 using $7 \mathbf{b}(100 \mathrm{mg}, 0.23 \mathrm{mmol})$ in $\mathrm{MeOH}(520 \mu \mathrm{L})$ and $\mathrm{NaOH}(70$ $\mu \mathrm{L}$ of a $2 \mathrm{~N}$ solution in water, $0.14 \mathrm{mmol}$ ). The residue was purified by flash chromatography on silica gel $\left(\mathrm{CH}_{2} \mathrm{Cl}_{2} / \mathrm{MeOH}, 99: 1\right)$ to give $\mathbf{1 b}$ as a white solid (72\% yield). ${ }^{1} \mathrm{H} \mathrm{NMR}\left(\mathrm{CDCl}_{3}\right.$, $300 \mathrm{MHz}) \delta 10.24(\mathrm{~s}, 1 \mathrm{H}), 8.57(\mathrm{~d}, J=2.1 \mathrm{~Hz}, 1 \mathrm{H}), 8.40(\mathrm{~d}, J=2.1 \mathrm{~Hz}, 1 \mathrm{H}), 7.68(\mathrm{~d}, J=7.2$ $\mathrm{Hz}, 2 \mathrm{H}), 7.60-7.56(\mathrm{~m}, 3 \mathrm{H}), 7.52-7.46(\mathrm{~m}, 2 \mathrm{H}), 7.37-7.34(\mathrm{~m}, 1 \mathrm{H}), 7.03(\mathrm{br} \mathrm{d}, J=8.7 \mathrm{~Hz}, 2 \mathrm{H})$, $3.89(\mathrm{~s}, 3 \mathrm{H}) ;{ }^{13} \mathrm{C} \mathrm{NMR}\left(\mathrm{CDCl}_{3}, 75 \mathrm{MHz}\right) \delta 159.2(\mathrm{Cq}), 147.6(\mathrm{Cq}), 141.5(\mathrm{CH}), 134.6(\mathrm{Cq})$, $131.7(\mathrm{Cq}), 130.1(\mathrm{Cq}), 129.0(2 \mathrm{CH}), 128.5(2 \mathrm{CH}), 127.2(2 \mathrm{CH}), 127.0(\mathrm{CH}), 126.5(\mathrm{CH})$, $123.3(\mathrm{CH}), 118.9(\mathrm{Cq}), 116.9(\mathrm{Cq}), 114.5(2 \mathrm{CH}), 55.4\left(\mathrm{CH}_{3}\right)$. HRMS (ESI+) calcd for $\mathrm{C}_{20} \mathrm{H}_{17} \mathrm{~N}_{2} \mathrm{O}[\mathrm{M}+\mathrm{H}]^{+}$301.1341, found 301.1337. IR (neat, $\mathrm{cm}^{-1}$ ): $v$ 3097, 2830, 1604. UPLC $R_{\mathrm{t}}$ $=4.36 \mathrm{~min}$; area $100 \%$.

3,5-Di-(4-methoxyphenyl)-1H-pyrrolo[2,3-b]pyridine (1c). This compound was prepared according to RP3 using $7 \mathbf{c}(90 \mathrm{mg}, 0.19 \mathrm{mmol})$ in $\mathrm{MeOH}(0.5 \mathrm{~mL})$ and $\mathrm{NaOH}(60 \mu \mathrm{L}$ of a $2 \mathrm{~N}$ solution in water, $0.12 \mathrm{mmol})$. The residue was purified by flash chromatography on silica gel $\left(\mathrm{CH}_{2} \mathrm{Cl}_{2} / \mathrm{MeOH}\right.$, gradient 100:0 to $\left.93: 7\right)$ to give $1 \mathrm{c}$ as a white solid (98\% yield). $\mathrm{Mp} 190^{\circ} \mathrm{C}$. ${ }^{1} \mathrm{H} \mathrm{NMR}\left(\mathrm{CDCl}_{3}, 300 \mathrm{MHz}\right) \delta 10.60($ br s, $1 \mathrm{H}), 8.58(\mathrm{~d}, J=2.1 \mathrm{~Hz}, 1 \mathrm{H}), 8.33(\mathrm{~d}, J=2.1 \mathrm{~Hz}$, 
1H), 7.63-7.57 (m, 4H), $7.51(\mathrm{~s}, 1 \mathrm{H}), 7.03(\mathrm{~d}, J=8.4 \mathrm{~Hz}, 4 \mathrm{H}) 3.89(\mathrm{~s}, 3 \mathrm{H}), 3.88(\mathrm{~s}, 3 \mathrm{H}) ;{ }^{13} \mathrm{C}$ NMR $\left(\mathrm{CDCl}_{3}, 75 \mathrm{MHz}\right) \delta 159.1(\mathrm{Cq}), 158.3(\mathrm{Cq}), 148.3(\mathrm{Cq}), 142.1(\mathrm{CH}), 132.1(\mathrm{Cq}), 129.8$ (Cq), $128.5(2 \mathrm{CH}), 128.3(2 \mathrm{CH}), 127.5(\mathrm{Cq}), 126.4(\mathrm{CH}), 122.1(\mathrm{CH}), 118.7(\mathrm{Cq}), 116.4(\mathrm{Cq})$, $114.5(2 \mathrm{CH}), 114.4(2 \mathrm{CH}), 55.4\left(\mathrm{CH}_{3}\right), 55.3\left(\mathrm{CH}_{3}\right)$. HRMS (ESI-) calcd for $\mathrm{C}_{21} \mathrm{H}_{17} \mathrm{~N}_{2} \mathrm{O}_{2}$ [M$\mathrm{H}]^{-}$329.1290, found 329.1282. IR (neat, $\mathrm{cm}^{-1}$ ): $v 3143,2853,1606$. UPLC $R_{\mathrm{t}}=4.20$ min; area $100 \%$.

3,5-Di-(3,4-dimethoxyphenyl)-1H-pyrrolo[2,3-b]pyridine (1d). This compound was prepared according to RP3 using 7d (475 mg, $0.90 \mathrm{mmol})$ in $\mathrm{MeOH}(2.1 \mathrm{~mL})$ and $\mathrm{NaOH}(270$ $\mu \mathrm{L}$ of a $2 \mathrm{~N}$ solution in water, $0.54 \mathrm{mmol})$. The residue was purified by flash chromatography on silica gel $\left(\mathrm{CH}_{2} \mathrm{Cl}_{2} / \mathrm{MeOH}\right.$, gradient 100:0 to 98:2) to give 1d as a pale yellow solid (77\% yield). ${ }^{1} \mathrm{H} \mathrm{NMR}\left(\mathrm{CDCl}_{3}, 300 \mathrm{MHz}\right) \delta 10.10($ br s, $1 \mathrm{H}), 8.54(\mathrm{~s}, 1 \mathrm{H}), 8.42(\mathrm{~s}, 1 \mathrm{H}), 7.54(\mathrm{~s}, 1 \mathrm{H})$, 7.24-7.11 (m, 4H), $7.01(\mathrm{~d}, J=8.1 \mathrm{~Hz}, 2 \mathrm{H}), 3.98(\mathrm{~s}, 3 \mathrm{H}), 3.97(\mathrm{~s}, 3 \mathrm{H}), 3.96(\mathrm{~s}, 6 \mathrm{H}) ;{ }^{13} \mathrm{C} \mathrm{NMR}$ $\left(\mathrm{CDCl}_{3}, 75 \mathrm{MHz}\right) \delta 149.4(2 \mathrm{Cq}), 148.8(\mathrm{Cq}), 148.2(\mathrm{Cq}), 146.9(\mathrm{Cq}), 140.9(\mathrm{CH}), 132.0(\mathrm{Cq})$ $130.3(\mathrm{Cq}), 127.4(\mathrm{CH}), 127.3(\mathrm{Cq}), 122.7(\mathrm{CH}), 119.8(\mathrm{CH}), 119.7(\mathrm{CH}), 119.4(\mathrm{Cq}), 117.1$ $(\mathrm{Cq}), 111.9(\mathrm{CH}), 111.8(\mathrm{CH}), 110.9(\mathrm{CH}), 110.8(\mathrm{CH}), 56.1\left(4 \mathrm{CH}_{3}\right)$. HRMS (ESI+) calcd for $\mathrm{C}_{23} \mathrm{H}_{23} \mathrm{~N}_{2} \mathrm{O}_{4}[\mathrm{M}+\mathrm{H}]^{+}$391.1658, found 391.1663. IR (neat, $\mathrm{cm}^{-1}$ ): $v$ 3124, 2833, 1604, 1247. UPLC $R_{\mathrm{t}}=3.52 \mathrm{~min}$; area $100 \%$.

3-Phenyl-5-(3-methoxyphenyl)-1H-pyrrolo[2,3-b]pyridine (1f). This compound was prepared according to RP3 using $7 \mathbf{f}(184 \mathrm{mg}, 0.42 \mathrm{mmol})$ in $\mathrm{MeOH}(1.0 \mathrm{~mL})$ and $\mathrm{NaOH}(125$ $\mu \mathrm{L}$ of a $2 \mathrm{~N}$ solution in water, $0.25 \mathrm{mmol}$ ). The residue was purified by flash chromatography on silica gel $\left(\mathrm{CH}_{2} \mathrm{Cl}_{2} / \mathrm{MeOH}\right.$, gradient 100:0 to $\left.97: 3\right)$ to give $\mathbf{1 f}$ as a pale yellow solid (52\% yield). ${ }^{1} \mathrm{H} \mathrm{NMR}\left(\mathrm{CDCl}_{3}, 300 \mathrm{MHz}\right) \delta 9.77$ (br s, $\left.1 \mathrm{H}\right), 8.62$ (s, $\left.1 \mathrm{H}\right), 8.43$ (s, 1H), 7.70 (d, $J=7.8$ $\mathrm{Hz}, 2 \mathrm{H}), 7.58(\mathrm{~s}, 1 \mathrm{H}), 7.52-7.34(\mathrm{~m}, 4 \mathrm{H}), 7.25-7.27(\mathrm{~m}, 1 \mathrm{H})$, 7.24-7.18 (m, 1H), 6.97-6.92 (m, 
1H), $3.91(\mathrm{~s}, 3 \mathrm{H}) ;{ }^{13} \mathrm{C} \mathrm{NMR}\left(\mathrm{CDCl}_{3}, 75 \mathrm{MHz}\right) \delta 160.1(\mathrm{Cq}), 146.9(\mathrm{Cq}), 140.7(\mathrm{Cq}), 140.3(\mathrm{Cq})$, $134.2(\mathrm{Cq}), 130.5(\mathrm{Cq}), 130.1(\mathrm{CH}), 129.1(2 \mathrm{CH}), 128.2(\mathrm{CH}), 127.3(2 \mathrm{CH}), 126.7(\mathrm{CH}), 123.3$ $(\mathrm{CH}), 119.9(\mathrm{CH}), 119.5(\mathrm{Cq}), 117.4(\mathrm{Cq}), 113.4(\mathrm{CH}), 112.7(\mathrm{CH}), 55.4\left(\mathrm{CH}_{3}\right) . \mathrm{HRMS}(\mathrm{ESI}+)$ calcd for $\mathrm{C}_{20} \mathrm{H}_{17} \mathrm{~N}_{2} \mathrm{O}[\mathrm{M}+\mathrm{H}]^{+}$301.1341, found 301.1346. IR (neat, $\mathrm{cm}^{-1}$ ): $v$ 3115, 2854, 1604 . UPLC $R_{\mathrm{t}}=4.45 \mathrm{~min}$; area $100 \%$.

3-Phenyl-5-(2-methoxyphenyl)-1H-pyrrolo[2,3-b]pyridine (1g). This compound was prepared according to RP3 using $7 \mathbf{g}(374 \mathrm{mg}, 0.85 \mathrm{mmol})$ in $\mathrm{MeOH}(2.3 \mathrm{~mL})$ and $\mathrm{NaOH}(260$ $\mu \mathrm{L}$ of a $2 \mathrm{~N}$ solution in water, $0.51 \mathrm{mmol})$. The residue was purified by flash chromatography on silica gel $\left(\mathrm{CH}_{2} \mathrm{Cl}_{2} / \mathrm{MeOH}\right.$, gradient 100:0 to $\left.98: 2\right)$ to give $1 \mathrm{~g}$ as a yellow solid (42\% yield). ${ }^{1} \mathrm{H} \mathrm{NMR}\left(\mathrm{CDCl}_{3}, 500 \mathrm{MHz}\right) \delta 11.50$ (br s, $\left.1 \mathrm{H}\right), 8.61$ (s, $\left.1 \mathrm{H}\right), 8.43$ (s, 1H), 7.70 (d, J=8.0 Hz, 2H), $7.62(\mathrm{~s}, 1 \mathrm{H}), 7.49-7.38(\mathrm{~m}, 4 \mathrm{H}), 7.33-7.30(\mathrm{~m}, 1 \mathrm{H}), 7.13-7.10(\mathrm{~m}, 1 \mathrm{H}), 7.06(\mathrm{br} \mathrm{d}, J=8.0$ $\mathrm{Hz}, 1 \mathrm{H}), 3.87(\mathrm{~s}, 3 \mathrm{H}) ;{ }^{13} \mathrm{C} \mathrm{NMR}\left(\mathrm{CDCl}_{3}, 75 \mathrm{MHz}\right) \delta 156.7(\mathrm{Cq}), 148.3(\mathrm{Cq}), 143.9(\mathrm{CH}), 135.1$ $(\mathrm{Cq}), 131.3(\mathrm{CH}), 129.4(\mathrm{CH}), 128.9(2 \mathrm{CH}), 128.8(\mathrm{CH}), 128.7(\mathrm{Cq}), 127.1(2 \mathrm{CH}+\mathrm{Cq}), 126.1$ $(\mathrm{CH}), 122.7(\mathrm{CH}), 121.0(\mathrm{CH}), 118.3(\mathrm{Cq}), 116.5(\mathrm{Cq}), 111.3(\mathrm{CH}), 55.6\left(\mathrm{CH}_{3}\right)$. HRMS (ESI+) calcd for $\mathrm{C}_{20} \mathrm{H}_{17} \mathrm{~N}_{2} \mathrm{O}[\mathrm{M}+\mathrm{H}]^{+}$301.1341, found 301.1337. IR (neat, $\mathrm{cm}^{-1}$ ): $v$ 3124, 2833, 1599 . $\operatorname{UPLC~} R_{\mathrm{t}}=4.35 \mathrm{~min}$; area $100 \%$.

3-Phenyl-5-(2,4-dimethoxyphenyl)-1H-pyrrolo[2,3-b]pyridine (1h). This compound was prepared according to RP3 using $7 \mathbf{h}(245 \mathrm{mg}, 0.52 \mathrm{mmol})$ in $\mathrm{MeOH}(1.4 \mathrm{~mL})$ and $\mathrm{NaOH}(160$ $\mu \mathrm{L}$ of a $2 \mathrm{~N}$ solution in water, $0.31 \mathrm{mmol}$ ). The residue was purified by flash chromatography on silica gel $\left(\mathrm{CH}_{2} \mathrm{Cl}_{2} / \mathrm{MeOH}\right.$, gradient 100:0 to 98:2) to give $\mathbf{1 h}$ as a pale yellow solid (70\% yield). ${ }^{1} \mathrm{H} \mathrm{NMR}\left(\mathrm{CDCl}_{3}, 300 \mathrm{MHz}\right) \delta 10.17$ (br s, $\left.1 \mathrm{H}\right), 8.51(\mathrm{~s}, 1 \mathrm{H}), 8.34(\mathrm{~s}, 1 \mathrm{H}), 7.68(\mathrm{~d}, J=$ 7.2 Hz, 2H), 7.56 (s, 1H), 7.49-7.43 (m, 2H), 7.34-7.28 (m, 2H), 6.64-6.61 (m, 2H), 3.89 (s, 3H), $3.83(\mathrm{~s}, 3 \mathrm{H}) ;{ }^{13} \mathrm{C} \mathrm{NMR}\left(\mathrm{CDCl}_{3}, 75 \mathrm{MHz}\right) \delta 160.5(\mathrm{Cq}), 157.6(\mathrm{Cq}), 148.0(\mathrm{Cq}), 143.9$ 
$(\mathrm{CH}), 135.1(\mathrm{Cq}), 131.6(\mathrm{CH}), 129.2(\mathrm{CH}), 128.8(2 \mathrm{CH}), 127.0(2 \mathrm{CH}), 126.9(\mathrm{Cq}), 126.1(\mathrm{CH})$, 122.6 (CH), $121.4(\mathrm{Cq}), 118.3(\mathrm{Cq}), 116.4(\mathrm{Cq}), 104.7(\mathrm{CH}), 99.1(\mathrm{CH}), 55.6\left(\mathrm{CH}_{3}\right), 55.5\left(\mathrm{CH}_{3}\right)$. HRMS (ESI + ) calcd for $\mathrm{C}_{21} \mathrm{H}_{19} \mathrm{~N}_{2} \mathrm{O}_{2}[\mathrm{M}+\mathrm{H}]^{+}$331.1447, found 331.1438. IR (neat, $\mathrm{cm}^{-1}$ ): $v$ $3121,2869,1601$. UPLC $R_{\mathrm{t}}=4.25 \mathrm{~min}$; area $85 \%$.

3-Phenyl-5-(3,4-dimethoxyphenyl)-1H-pyrrolo[2,3-b]pyridine (1i). This compound was prepared according to RP3 using $7 \mathbf{i}(190 \mathrm{mg}, 0.40 \mathrm{mmol})$ in $\mathrm{MeOH}(1.1 \mathrm{~mL})$ and $\mathrm{NaOH}(125$ $\mu \mathrm{L}$ of a $2 \mathrm{~N}$ solution in water, $0.24 \mathrm{mmol}$ ). The residue was purified by flash chromatography on silica gel $\left(\mathrm{CH}_{2} \mathrm{Cl}_{2} / \mathrm{MeOH}\right.$, gradient 100:0 to $\left.98: 2\right)$ to give $\mathbf{1} \mathbf{i}$ as a pale yellow solid (57\% yield). ${ }^{1} \mathrm{H}$ NMR $\left(\mathrm{CDCl}_{3}, 300 \mathrm{MHz}\right) \delta 11.36(\mathrm{br} \mathrm{s}, 1 \mathrm{H}), 8.60(\mathrm{~d}, J=2.1 \mathrm{~Hz}, 1 \mathrm{H}), 8.39(\mathrm{~d}, J=2.1$ $\mathrm{Hz}, 1 \mathrm{H}), 7.70(\mathrm{~d}, J=6.9 \mathrm{~Hz}, 2 \mathrm{H}), 7.69(\mathrm{~s}, 1 \mathrm{H}), 7.63-7.46(\mathrm{~m}, 2 \mathrm{H}), 7.37-7.31(\mathrm{~m}, 1 \mathrm{H}), 7.22-$ $7.15(\mathrm{~m}, 2 \mathrm{H}), 7.01(\mathrm{~d}, J=8.1 \mathrm{~Hz}, 1 \mathrm{H}), 3.99(\mathrm{~s}, 3 \mathrm{H}), 3.97$ (s, 3H); ${ }^{13} \mathrm{C} \mathrm{NMR}\left(\mathrm{CDCl}_{3}, 75 \mathrm{MHz}\right)$ $\delta 149.4(\mathrm{Cq}), 148.6(\mathrm{Cq}), 148.4(\mathrm{Cq}), 141.9(\mathrm{CH}), 134.9(\mathrm{Cq}), 132.5(\mathrm{Cq}), 130.2(\mathrm{Cq}), 129.0$ (2CH), $127.2(2 \mathrm{CH}), 126.7(\mathrm{CH}), 126.3(\mathrm{CH}), 123.2(\mathrm{CH}), 119.8(\mathrm{CH}), 118.7(\mathrm{Cq}), 116.6(\mathrm{Cq})$, $111.7(\mathrm{CH}), 110.9(\mathrm{CH}), 56.1\left(\mathrm{CH}_{3}\right), 56.0\left(\mathrm{CH}_{3}\right)$. HRMS (ESI+) calcd for $\mathrm{C}_{21} \mathrm{H}_{19} \mathrm{~N}_{2} \mathrm{O}_{2}[\mathrm{M}+\mathrm{H}]^{+}$ 331.1447, found 331.1448. IR (neat, $\mathrm{cm}^{-1}$ ): $v$ 3109, 2824, 1590. UPLC $R_{\mathrm{t}}=3.98$ min; area $100 \%$.

3-(4-Methoxyphenyl)-5-(2,4-dimethoxyphenyl)-1H-pyrrolo[2,3-b]pyridine $\quad(1 \mathrm{j}) . \quad$ This compound was prepared according to RP3 using $7 \mathbf{j}$ (406 mg, $0.81 \mathrm{mmol}$ ) in $\mathrm{MeOH}(2.2 \mathrm{~mL}$ ) and $\mathrm{NaOH}(245 \mu \mathrm{L}$ of a $2 \mathrm{~N}$ solution in water, $0.49 \mathrm{mmol})$. The residue was purified by flash chromatography on silica gel $\left(\mathrm{CH}_{2} \mathrm{Cl}_{2} / \mathrm{MeOH}\right.$, gradient 100:0 to 95:5) to give $\mathbf{1} \mathbf{j}$ as a white solid (60\% yield). Mp $90{ }^{\circ} \mathrm{C} .{ }^{1} \mathrm{H}$ NMR $\left(\mathrm{CDCl}_{3}, 300 \mathrm{MHz}\right) \delta 10.21(\mathrm{br} \mathrm{s}, 1 \mathrm{H}), 8.50(\mathrm{~s}, 1 \mathrm{H}), 8.31$ $(\mathrm{d}, J=2.1 \mathrm{~Hz}, 1 \mathrm{H}), 7.61-7.58(\mathrm{~m}, 2 \mathrm{H}), 7.48(\mathrm{~s}, 1 \mathrm{H}), 7.32-7.29(\mathrm{~m}, 1 \mathrm{H}), 7.03-7.00(\mathrm{~m}, 2 \mathrm{H})$, 6.65-6.61 (m, 2H), $3.89(\mathrm{~s}, 3 \mathrm{H}), 3.87(\mathrm{~s}, 3 \mathrm{H}), 3.83(\mathrm{~s}, 3 \mathrm{H}) ;{ }^{13} \mathrm{C} \mathrm{NMR}\left(\mathrm{CDCl}_{3}, 75 \mathrm{MHz}\right) \delta 160.5$ 
$(\mathrm{CH}), 158.3(\mathrm{Cq}), 157.6(\mathrm{Cq}), 147.5(\mathrm{Cq}), 143.9(\mathrm{CH}), 131.6(\mathrm{CH}), 129.3(\mathrm{CH}), 128.3(2 \mathrm{CH})$, $127.5(\mathrm{Cq}), 126.9(\mathrm{Cq}), 121.7(\mathrm{CH}), 121.4(\mathrm{Cq}), 118.4(\mathrm{Cq}), 116.5(\mathrm{Cq}), 114.4(2 \mathrm{CH}), 104.8$ $(\mathrm{CH}), 99.1(\mathrm{CH}), 55.6\left(\mathrm{CH}_{3}\right), 55.5\left(\mathrm{CH}_{3}\right), 55.3\left(\mathrm{CH}_{3}\right)$. HRMS (ESI+) calcd for $\mathrm{C}_{22} \mathrm{H}_{21} \mathrm{~N}_{2} \mathrm{O}_{3}$ $[\mathrm{M}+\mathrm{H}]^{+}$361.1552, found 361.1557. IR (neat, $\mathrm{cm}^{-1}$ ): $v 3312,1998,1616$. UPLC $R_{\mathrm{t}}=4.08 \mathrm{~min}$; area $100 \%$.

3-(4-Methoxyphenyl)-5-(3,4-dimethoxyphenyl)-1H-pyrrolo[2,3-b]pyridine $\quad(1 \mathrm{k}) . \quad$ This compound was prepared according to RP3 using 7k $(280 \mathrm{mg}, 0.56 \mathrm{mmol})$ in $\mathrm{MeOH}(1.3 \mathrm{~mL})$ and $\mathrm{NaOH}(170 \mu \mathrm{L}$ of a $2 \mathrm{~N}$ solution in water, $0.34 \mathrm{mmol})$. The residue was purified by flash chromatography on silica gel $\left(\mathrm{CH}_{2} \mathrm{Cl}_{2} / \mathrm{MeOH}\right.$, gradient 100:0 to $\left.97: 3\right)$ to give $\mathbf{1 k}$ as a pale yellow solid (82\% yield). ${ }^{1} \mathrm{H}$ NMR $\left(\mathrm{CDCl}_{3}, 300 \mathrm{MHz}\right) \delta 10.11$ (br s, $\left.1 \mathrm{H}\right), 8.56(\mathrm{~d}, J=2.1 \mathrm{~Hz}$, $1 \mathrm{H}), 8.35(\mathrm{~d}, J=2.1 \mathrm{~Hz}, 1 \mathrm{H}), 7.60(\mathrm{~d}, J=8.7 \mathrm{~Hz}, 2 \mathrm{H}), 7.52(\mathrm{~s}, 1 \mathrm{H}), 7.20-7.14(\mathrm{~m}, 2 \mathrm{H}), 7.06-$ $6.99(\mathrm{~m}, 3 \mathrm{H}), 3.99(\mathrm{~s}, 3 \mathrm{H}), 3.96(\mathrm{~s}, 3 \mathrm{H}), 3.89(\mathrm{~s}, 3 \mathrm{H}) ;{ }^{13} \mathrm{C} \mathrm{NMR}\left(\mathrm{CDCl}_{3}, 75 \mathrm{MHz}\right) \delta 158.5(\mathrm{Cq})$, $149.4(\mathrm{Cq}), 148.7(\mathrm{Cq}), 147.5(\mathrm{Cq}), 141.5(\mathrm{CH}), 132.3(\mathrm{Cq}), 130.2(\mathrm{Cq}), 128.4(2 \mathrm{CH}), 127.1$ $(\mathrm{Cq}), 127.0(\mathrm{CH}), 122.3(\mathrm{CH}), 119.8(\mathrm{CH}), 119.0(\mathrm{Cq}), 116.7(\mathrm{Cq}), 114.5(2 \mathrm{CH}), 111.7(\mathrm{CH})$, $110.9(\mathrm{CH}), 56.1\left(\mathrm{CH}_{3}\right), 56.0\left(\mathrm{CH}_{3}\right), 55.4\left(\mathrm{CH}_{3}\right)$. HRMS (ESI-) calcd for $\mathrm{C}_{22} \mathrm{H}_{19} \mathrm{~N}_{2} \mathrm{O}_{3}[\mathrm{M}-\mathrm{H}]^{-}$ 359.1396, found 359.1389. IR (neat, $\mathrm{cm}^{-1}$ ): $v 3112,2833,1571,1241$. UPLC $R_{\mathrm{t}}=3.85$ min; area $100 \%$.

3-(3,4-Dimethoxyphenyl)-5-(2,4-dimethoxyphenyl)-1H-pyrrolo[2,3-b]pyridine (11). This compound was prepared according to RP3 using 71 (213 mg, $0.40 \mathrm{mmol})$ in $\mathrm{MeOH}(1.0 \mathrm{~mL})$ and $\mathrm{NaOH}(120 \mu \mathrm{L}$ of a $2 \mathrm{~N}$ solution in water, $0.24 \mathrm{mmol})$. The residue was purified by flash chromatography on silica gel $\left(\mathrm{CH}_{2} \mathrm{Cl}_{2} / \mathrm{MeOH}\right.$, gradient 100:0 to 98:2) to give $\mathbf{1 l}$ as a yellow solid (78\% yield). ${ }^{1} \mathrm{H}$ NMR $\left(\mathrm{CDCl}_{3}, 300 \mathrm{MHz}\right) \delta 10.70($ br s, $1 \mathrm{H}), 8.51(\mathrm{~s}, 1 \mathrm{H}), 8.33(\mathrm{~d}, J=2.1$ $\mathrm{Hz}, 1 \mathrm{H}), 7.51(\mathrm{~s}, 1 \mathrm{H}), 7.33-7.29(\mathrm{~m}, 1 \mathrm{H}), 7.24-7.18(\mathrm{~m}, 2 \mathrm{H}), 6.98(\mathrm{~d}, J=8.4 \mathrm{~Hz}, 1 \mathrm{H}), 6.65-$ 
$6.60(\mathrm{~m}, 2 \mathrm{H}), 3.97(\mathrm{~s}, 3 \mathrm{H}), 3.94(\mathrm{~s}, 3 \mathrm{H}), 3.88(\mathrm{~s}, 3 \mathrm{H}), 3.83(\mathrm{~s}, 3 \mathrm{H}) ;{ }^{13} \mathrm{C} \mathrm{NMR}\left(\mathrm{CDCl}_{3}, 75 \mathrm{MHz}\right)$ $\delta 160.5(\mathrm{Cq}), 157.6(\mathrm{Cq}), 149.3(\mathrm{Cq}), 147.8(\mathrm{Cq}), 147.6(\mathrm{Cq}), 143.9(\mathrm{CH}), 131.5(\mathrm{CH}), 129.2$ $(\mathrm{CH}), 128.0(\mathrm{Cq}), 126.9(\mathrm{Cq}), 122.0(\mathrm{CH}), 121.3(\mathrm{Cq}), 119.5(\mathrm{CH}), 118.4(\mathrm{Cq}), 116.5(\mathrm{Cq})$, $111.8(\mathrm{CH}), 110.8(\mathrm{CH}), 104.8(\mathrm{CH}), 99.1(\mathrm{CH}), 56.0\left(\mathrm{CH}_{3}\right), 55.9\left(\mathrm{CH}_{3}\right), 55.6\left(\mathrm{CH}_{3}\right), 55.5$ $\left(\mathrm{CH}_{3}\right)$. HRMS (ESI+) calcd for $\mathrm{C}_{23} \mathrm{H}_{23} \mathrm{~N}_{2} \mathrm{O}_{4}[\mathrm{M}+\mathrm{H}]^{+}$391.1658, found 391.1657. IR (neat, $\mathrm{cm}^{-}$ $\left.{ }^{1}\right): v 3124,2934,1611,1248$. UPLC $R_{\mathrm{t}}=3.74 \mathrm{~min}$; area $100 \%$.

3-(3,4-Dimethoxyphenyl)-5-(2,5-dimethoxyphenyl)- $1 \mathrm{H}$-pyrrolo[2,3-b]pyridine (1m). This compound was prepared according to RP3 using 7m (503 mg, $0.95 \mathrm{mmol})$ in $\mathrm{MeOH}(2.4 \mathrm{~mL})$ and $\mathrm{NaOH}(280 \mu \mathrm{L}$ of a $2 \mathrm{~N}$ solution in water, $0.57 \mathrm{mmol})$. The residue was purified by flash chromatography on silica gel $\left(\mathrm{CH}_{2} \mathrm{Cl}_{2} / \mathrm{MeOH}\right.$, gradient 100:0 to 98:2) to give $\mathbf{1 m}$ as a yellow solid (29\% yield over two steps). ${ }^{1} \mathrm{H}$ NMR $\left(\mathrm{CDCl}_{3}, 300 \mathrm{MHz}\right) \delta 10.89$ (br s, $\left.1 \mathrm{H}\right), 8.56$ (d, $J=$ $1.5 \mathrm{~Hz}, 1 \mathrm{H}), 8.39$ (d, $J=1.8 \mathrm{~Hz}, 1 \mathrm{H}), 7.54(\mathrm{~s}, 1 \mathrm{H}), 7.25-7.18(\mathrm{~m}, 2 \mathrm{H}), 7.00-6.97(\mathrm{~m}, 3 \mathrm{H}), 6.93-$ $6.88(\mathrm{~m}, 1 \mathrm{H}), 3.97(\mathrm{~s}, 3 \mathrm{H}), 3.94(\mathrm{~s}, 3 \mathrm{H}), 3.84(\mathrm{~s}, 3 \mathrm{H}), 3.79(\mathrm{~s}, 3 \mathrm{H}) ;{ }^{13} \mathrm{C} \mathrm{NMR}\left(\mathrm{CDCl}_{3}, 75 \mathrm{MHz}\right)$ $\delta 153.9(\mathrm{Cq}), 150.9(\mathrm{Cq}), 149.3(\mathrm{Cq}), 147.9(\mathrm{Cq}), 147.8(\mathrm{Cq}), 143.8(\mathrm{CH}), 129.5(\mathrm{Cq}), 129.3$ $(\mathrm{CH}), 127.8(\mathrm{Cq}), 126.8(\mathrm{Cq}), 122.1(\mathrm{CH}), 119.5(\mathrm{CH}), 118.4(\mathrm{Cq}), 117.1(\mathrm{CH}), 116.6(\mathrm{Cq})$, $113.1(\mathrm{CH}), 112.6(\mathrm{CH}), 111.8(\mathrm{CH}), 110.7(\mathrm{CH}), 56.3\left(\mathrm{CH}_{3}\right), 56.0\left(\mathrm{CH}_{3}\right), 55.9\left(\mathrm{CH}_{3}\right), 55.8$ $\left(\mathrm{CH}_{3}\right)$. HRMS (ESI+) calcd for $\mathrm{C}_{23} \mathrm{H}_{23} \mathrm{~N}_{2} \mathrm{O}_{4}[\mathrm{M}+\mathrm{H}]^{+}$391.1658, found 391.1648. IR (neat, $\mathrm{cm}^{-}$ $\left.{ }^{1}\right): v 3130,2830,1582,1245$. UPLC $R_{\mathrm{t}}=3.80$ min; area $100 \%$.

3,5-Di-(3-methoxyphenyl)-1H-pyrrolo[2,3-b]pyridine (1n). This compound was prepared according to RP3 using $7 \mathbf{n}(472 \mathrm{mg}, 1.00 \mathrm{mmol})$ in $\mathrm{MeOH}(2.7 \mathrm{~mL})$ and $\mathrm{NaOH}(305 \mu \mathrm{L}$ of a $2 \mathrm{~N}$ solution in water, $0.60 \mathrm{mmol})$. The residue was purified by flash chromatography on silica gel $\left(\mathrm{CH}_{2} \mathrm{Cl}_{2} / \mathrm{MeOH}\right.$, gradient 100:0 to 99:1) to give $\mathbf{1 n}$ as a pale yellow solid (59\% yield). ${ }^{1} \mathrm{H}$ NMR $\left(\mathrm{CDCl}_{3}, 300 \mathrm{MHz}\right) \delta 10.64(\mathrm{br} \mathrm{s}, 1 \mathrm{H}), 8.63(\mathrm{~d}, J=2.1 \mathrm{~Hz}, 1 \mathrm{H}), 8.44(\mathrm{~d}, J=2.1 \mathrm{~Hz}, 1 \mathrm{H})$, 
$7.62(\mathrm{~s}, 1 \mathrm{H}), 7.45-7.38(\mathrm{~m}, 2 \mathrm{H}), 7.31-7.18(\mathrm{~m}, 5 \mathrm{H}), 6.97-6.87(\mathrm{~m}, 2 \mathrm{H}), 3.91(\mathrm{~s}, 3 \mathrm{H}), 3.90(\mathrm{~s}$, $3 \mathrm{H}) ;{ }^{13} \mathrm{C} \mathrm{NMR}\left(\mathrm{CDCl}_{3}, 75 \mathrm{MHz}\right) \delta 160.1(\mathrm{Cq}), 160.0(\mathrm{Cq}), 148.4(\mathrm{Cq}), 142.1(\mathrm{CH}), 140.9(\mathrm{Cq})$, $136.1(\mathrm{Cq}), 130.2(\mathrm{Cq}), 130.0(2 \mathrm{CH}), 127.2(\mathrm{CH}), 123.2(\mathrm{CH}), 120.0(\mathrm{CH}), 119.7(\mathrm{CH}), 118.7$ $(\mathrm{Cq}), 116.8(\mathrm{Cq}), 113.4(\mathrm{CH}), 113.1(\mathrm{CH}), 112.5(\mathrm{CH}), 111.7(\mathrm{CH}), 55.4\left(\mathrm{CH}_{3}\right), 55.3\left(\mathrm{CH}_{3}\right)$. HRMS (ESI+) calcd for $\mathrm{C}_{21} \mathrm{H}_{19} \mathrm{~N}_{2} \mathrm{O}_{2}[\mathrm{M}+\mathrm{H}]^{+} 331.1447$, found 331.1443. IR (neat, $\mathrm{cm}^{-1}$ ): $v$ 3109, 2830, 1607, 1207. UPLC $R_{\mathrm{t}}=4.39 \mathrm{~min}$; area $100 \%$.

Representative Procedure for De-O-methylation (RP4):

3-Phenyl-5-(4-hydroxyphenyl)-1H-pyrrolo[2,3-b]pyridine (2b). To a solution of $\mathbf{1 b}$ (48 mg, $0.16 \mathrm{mmol})$ in $\mathrm{CH}_{2} \mathrm{Cl}_{2}(130 \mu \mathrm{L})$ was added $\mathrm{BBr}_{3}\left(480 \mu \mathrm{L}\right.$ of a $1 \mathrm{~N}$ solution in $\mathrm{CH}_{2} \mathrm{Cl}_{2}, 0.48$ mmol). The reaction mixture was stirred at room temperature during $15 \mathrm{~h}$, then quenched at $0^{\circ} \mathrm{C}$ with $\mathrm{MeOH}$ and concentrated in vacuo. The residue was purified by preparative TLC $\left(\mathrm{CH}_{2} \mathrm{Cl}_{2} / \mathrm{MeOH} 90: 10\right)$ to give compound $\mathbf{2 b}$ as a pale yellow solid (46\% yield). ${ }^{1} \mathrm{H}$ NMR $\left(\mathrm{CD}_{3} \mathrm{OD}, 300 \mathrm{MHz}\right) \delta 8.40(\mathrm{~d}, J=2.1 \mathrm{~Hz}, 1 \mathrm{H}), 8.32(\mathrm{~d}, J=2.1 \mathrm{~Hz}, 1 \mathrm{H}), 7.64(\mathrm{br} \mathrm{d}, J=6.9 \mathrm{~Hz}$, 2H), $7.61(\mathrm{~s}, 1 \mathrm{H}) 7.48-7.39(\mathrm{~m}, 4 \mathrm{H}), 7.28-7.25(\mathrm{~m}, 1 \mathrm{H}), 6.89(\mathrm{br} \mathrm{d}, J=8.7 \mathrm{~Hz}, 2 \mathrm{H}) ;{ }^{13} \mathrm{C} \mathrm{NMR}$ $\left(\mathrm{CD}_{3} \mathrm{OD}, 75 \mathrm{MHz}\right) \delta 158.2(\mathrm{Cq}), 148.9(\mathrm{Cq}), 142.4(\mathrm{CH}), 136.3(\mathrm{Cq}), 131.8(\mathrm{Cq}), 131.3(\mathrm{Cq})$ $129.9(2 \mathrm{CH}), 129.4(2 \mathrm{CH}), 127.9(2 \mathrm{CH}), 127.1(\mathrm{CH}), 127.0(\mathrm{CH}), 124.7(\mathrm{CH}), 120.0(\mathrm{Cq})$, $117.3(\mathrm{Cq}), 116.8(2 \mathrm{CH})$. HRMS (ESI+) calcd for $\mathrm{C}_{19} \mathrm{H}_{15} \mathrm{~N}_{2} \mathrm{O}[\mathrm{M}+\mathrm{H}]^{+}$287.1184, found 287.1188. IR (neat, $\mathrm{cm}^{-1}$ ): $v 3142,2890,1602,1259$. UPLC $R_{\mathrm{t}}=3.44 \mathrm{~min}$; area $100 \%$.

3,5-Di-(4-hydroxyphenyl)-1H-pyrrolo[2,3-b]pyridine (2c). This compound was prepared according to RP4 using $1 \mathrm{c}(63 \mathrm{mg}, 0.19 \mathrm{mmol})$ in $\mathrm{CH}_{2} \mathrm{Cl}_{2}(175 \mu \mathrm{L})$ with $\mathrm{BBr}_{3}(1.2 \mathrm{~mL}$ of a $1 \mathrm{~N}$ solution in $\left.\mathrm{CH}_{2} \mathrm{Cl}_{2}, 1.14 \mathrm{mmol}\right)$. The residue was purified by preparative TLC $\left(\mathrm{CH}_{2} \mathrm{Cl}_{2} / \mathrm{MeOH}\right.$ $85: 15)$ to give $2 \mathrm{c}$ as a pale yellow solid (70\% yield). Mp $150-160{ }^{\circ} \mathrm{C} .{ }^{1} \mathrm{H}$ NMR $\left(\mathrm{CD}_{3} \mathrm{OD}, 300\right.$ MHz) $\delta 8.38(\mathrm{~d}, J=1.5 \mathrm{~Hz}, 1 \mathrm{H}), 8.29(\mathrm{~d}, J=2.1 \mathrm{~Hz}, 1 \mathrm{H}), 7.52-7.46(\mathrm{~m}, 5 \mathrm{H}), 6.92-6.88(\mathrm{~m}$, 
$4 \mathrm{H}) ;{ }^{13} \mathrm{C}$ NMR $\left(\mathrm{CD}_{3} \mathrm{OD}, 75 \mathrm{MHz}\right) \delta 158.1(\mathrm{Cq}), 157.1(\mathrm{Cq}), 148.8(\mathrm{Cq}), 142.2(\mathrm{CH}), 132.0$ (Cq), $131.1(\mathrm{Cq}), 129.4(2 \mathrm{CH}), 129.3(2 \mathrm{CH}), 127.7(\mathrm{Cq}), 127.2(\mathrm{CH}), 123.9(\mathrm{CH}), 120.2(\mathrm{Cq})$, $117.5(\mathrm{Cq}), 116.9(2 \mathrm{CH}), 116.8(2 \mathrm{CH})$. HRMS (ESI+) calcd for $\mathrm{C}_{19} \mathrm{H}_{15} \mathrm{~N}_{2} \mathrm{O}_{2}[\mathrm{M}+\mathrm{H}]^{+} 303.1134$, found 303.1127. IR (neat, $\mathrm{cm}^{-1}$ ): $v 3136,2937,1601,1257$. UPLC $R_{\mathrm{t}}=2.47 \mathrm{~min}$; area 100\%.

3,5-Di-(3,4-dihydroxyphenyl)-1H-pyrrolo[2,3-b]pyridine (2d). This compound was prepared according to RP4 using $\mathbf{1 d}(225 \mathrm{mg}, 0.59 \mathrm{mmol})$ in $\mathrm{CH}_{2} \mathrm{Cl}_{2}(480 \mu \mathrm{L})$ with $\mathrm{BBr}_{3}(7.0$ $\mathrm{mL}$ of a $1 \mathrm{~N}$ solution in $\mathrm{CH}_{2} \mathrm{Cl}_{2}, 7.04 \mathrm{mmol}$ ). The residue was purified by flash chromatography on silica gel $\left(\mathrm{CH}_{2} \mathrm{Cl}_{2} / \mathrm{MeOH}\right.$, gradient $95: 5$ to $\left.85: 15\right)$ and then by preparative TLC $\left(\mathrm{CH}_{2} \mathrm{Cl}_{2} / \mathrm{MeOH} 80: 20\right)$ to give $\mathbf{2 d}$ as a grey solid (61\% yield). Mp $190^{\circ} .{ }^{1} \mathrm{H} \mathrm{NMR}\left(\mathrm{CD}_{3} \mathrm{OD}, 300\right.$ MHz) $\delta 8.37(\mathrm{~d}, J=2.1 \mathrm{~Hz}, 1 \mathrm{H}), 8.31(\mathrm{~d}, J=2.1 \mathrm{~Hz}, 1 \mathrm{H}), 7.49(\mathrm{~s}, 1 \mathrm{H}), 7.14(\mathrm{~d}, J=2.1 \mathrm{~Hz}$, 1H), $7.09(\mathrm{~d}, J=2.1 \mathrm{~Hz}, 1 \mathrm{H}), 7.03-6.97(\mathrm{~m}, 2 \mathrm{H}), 6.89(\mathrm{~d}, J=3.9 \mathrm{~Hz}, 1 \mathrm{H}), 6.86(\mathrm{~d}, J=3.9 \mathrm{~Hz}$, $1 \mathrm{H}) ;{ }^{13} \mathrm{C} \mathrm{NMR}\left(\mathrm{CD}_{3} \mathrm{OD}, 75 \mathrm{MHz}\right) \delta 148.8(\mathrm{Cq}), 146.8(\mathrm{Cq}), 146.6(\mathrm{Cq}), 146.0(\mathrm{Cq}), 145.1$ $(\mathrm{Cq}), 142.2(\mathrm{CH}), 132.6(\mathrm{Cq}), 131.2(\mathrm{Cq}), 128.3(\mathrm{Cq}), 127.2(\mathrm{CH}), 123.8(\mathrm{CH}), 120.1(\mathrm{Cq})$, $119.8(\mathrm{CH}), 119.6(\mathrm{CH}), 117.6(\mathrm{Cq}), 117.0(2 \mathrm{CH}), 115.3(2 \mathrm{CH})$. HRMS (ESI+) calcd for $\mathrm{C}_{19} \mathrm{H}_{15} \mathrm{~N}_{2} \mathrm{O}_{4}[\mathrm{M}+\mathrm{H}]^{+}$335.1032, found 335.1038. IR (neat, $\mathrm{cm}^{-1}$ ): $v$ 3172, 3047, 1596, 1270. UPLC $R_{\mathrm{t}}=1.99$ min; area $100 \%$.

3-Phenyl-5-(3-hydroxyphenyl)-1H-pyrrolo[2,3-b]pyridine (2f). This compound was prepared according to RP4 using $1 \mathbf{f}(51 \mathrm{mg}, 0.17 \mathrm{mmol})$ in $\mathrm{CH}_{2} \mathrm{Cl}_{2}(140 \mu \mathrm{L})$ with $\mathrm{BBr}_{3}(0.5 \mathrm{~mL}$ of a $1 \mathrm{~N}$ solution in $\mathrm{CH}_{2} \mathrm{Cl}_{2}, 0.51 \mathrm{mmol}$ ). The residue was purified by preparative TLC $\left(\mathrm{CH}_{2} \mathrm{Cl}_{2} / \mathrm{MeOH} 90: 10\right)$ to give $\mathbf{2 f}$ as a white solid (43\% yield). ${ }^{1} \mathrm{H}$ NMR $\left(\mathrm{CD}_{3} \mathrm{OD}, 300 \mathrm{MHz}\right) \delta$ $8.45(\mathrm{~d}, J=2.1 \mathrm{~Hz}, 1 \mathrm{H}), 8.38(\mathrm{~d}, J=2.1 \mathrm{~Hz}, 1 \mathrm{H}), 7.69-7.65(\mathrm{~m}, 3 \mathrm{H}), 7.46-7.41(\mathrm{~m}, 2 \mathrm{H}), 7.31-$ $7.24(\mathrm{~m}, 2 \mathrm{H}), 7.13-7.08(\mathrm{~m}, 2 \mathrm{H}), 6.80(\mathrm{dd}, J=8.1 \mathrm{~Hz}, 1.5 \mathrm{~Hz}, 1 \mathrm{H}) ;{ }^{13} \mathrm{C} \mathrm{NMR}\left(\mathrm{CD}_{3} \mathrm{OD}, 75\right.$ MHz) $159.1(\mathrm{Cq}), 149.4(\mathrm{Cq}), 142.7(\mathrm{CH}), 142.0(\mathrm{Cq}), 136.3(\mathrm{Cq}), 131.3(\mathrm{Cq}), 131.1(\mathrm{CH})$, 
$129.9(2 \mathrm{CH}), 128.0(2 \mathrm{CH}), 127.6(\mathrm{CH}), 127.2(\mathrm{CH}), 125.0(\mathrm{CH}), 120.0(\mathrm{Cq}), 119.6(\mathrm{CH}), 117.5$ $(\mathrm{Cq}), 115.2(\mathrm{CH}), 115.0(\mathrm{CH})$. HRMS $(\mathrm{ESI}+)$ calcd for $\mathrm{C}_{19} \mathrm{H}_{15} \mathrm{~N}_{2} \mathrm{O}[\mathrm{M}+\mathrm{H}]^{+} 287.1184$, found 287.1182. IR (neat, $\mathrm{cm}^{-1}$ ): $v 3124,2919,1596$. UPLC $R_{\mathrm{t}}=3.64 \mathrm{~min}$; area $100 \%$.

3-Phenyl-5-(2-hydroxyphenyl)-1H-pyrrolo[2,3-b]pyridine (2g). This compound was prepared according to RP4 using $1 \mathrm{~g}(113 \mathrm{mg}, 0.38 \mathrm{mmol})$ in $\mathrm{CH}_{2} \mathrm{Cl}_{2}(325 \mu \mathrm{L})$ with $\mathrm{BBr}_{3}(1.1$ $\mathrm{mL}$ of a $1 \mathrm{~N}$ solution in $\mathrm{CH}_{2} \mathrm{Cl}_{2}, 1.13 \mathrm{mmol}$ ). The residue was purified by preparative TLC $\left(\mathrm{CH}_{2} \mathrm{Cl}_{2} / \mathrm{MeOH} 94: 6\right)$ to give $2 \mathrm{~g}$ as a white solid (34\% yield). ${ }^{1} \mathrm{H}$ NMR $\left(\mathrm{CD}_{3} \mathrm{OD}, 300 \mathrm{MHz}\right) \delta$ $8.42(\mathrm{~s}, 1 \mathrm{H}), 8.32(\mathrm{~d}, J=2.1 \mathrm{~Hz}, 1 \mathrm{H}), 7.63(\mathrm{br} \mathrm{d}, J=6.9 \mathrm{~Hz}, 2 \mathrm{H}), 7.58(\mathrm{~s}, 1 \mathrm{H}) 7.40-7.35(\mathrm{~m}$, 2H), 7.31-7.28 (m, 1H), 7.24-7.14 (m, 2H), 6.95-6.89 (m, 2H); ${ }^{13} \mathrm{C}$ NMR $\left(\mathrm{CD}_{3} \mathrm{OD}, 75 \mathrm{MHz}\right) \delta$ $155.6(\mathrm{Cq}), 148.5(\mathrm{Cq}), 144.5(\mathrm{CH}), 136.3(\mathrm{Cq}), 131.9(\mathrm{Cq}), 130.3(\mathrm{CH}), 129.8(2 \mathrm{CH}), 129.7$ $(\mathrm{CH}), 128.6(\mathrm{Cq}), 127.9(2 \mathrm{CH}), 127.6(\mathrm{CH}), 127.0(\mathrm{CH}), 124.4(\mathrm{CH}), 121.2(\mathrm{CH}), 119.6(\mathrm{Cq})$, $117.4(\mathrm{Cq}), 117.0(\mathrm{CH})$. HRMS (ESI+) calcd for $\mathrm{C}_{19} \mathrm{H}_{15} \mathrm{~N}_{2} \mathrm{O}[\mathrm{M}+\mathrm{H}]^{+}$287.1184, found 287.1188. IR (neat, $\mathrm{cm}^{-1}$ ): $v 3267,2869,1602,1262$. UPLC $R_{\mathrm{t}}=3.67 \mathrm{~min}$; area $100 \%$.

3-Phenyl-5-(2,4-dihydroxyphenyl)-1H-pyrrolo[2,3-b]pyridine (2h). This compound was prepared according to RP4 using $\mathbf{1 h}(100 \mathrm{mg}, 0.30 \mathrm{mmol})$ in $\mathrm{CH}_{2} \mathrm{Cl}_{2}(260 \mu \mathrm{L})$ with $\mathrm{BBr}_{3}(1.8$ $\mathrm{mL}$ of a $1 \mathrm{~N}$ solution in $\mathrm{CH}_{2} \mathrm{Cl}_{2}, 1.82 \mathrm{mmol}$ ). The residue was purified by preparative TLC $\left(\mathrm{CH}_{2} \mathrm{Cl}_{2} / \mathrm{MeOH} 94: 6\right)$ to give $\mathbf{2 h}$ as a white solid (53\% yield). ${ }^{1} \mathrm{H}$ NMR $\left(\mathrm{CD}_{3} \mathrm{OD}, 300 \mathrm{MHz}\right) \delta$ $8.39(\mathrm{~s}, 2 \mathrm{H}), 7.69$ (br d, $J=9.3 \mathrm{~Hz}, 2 \mathrm{H}), 7.62(\mathrm{~s}, 1 \mathrm{H}), 7.45-7.39(\mathrm{~m}, 2 \mathrm{H}), 7.28-7.22(\mathrm{~m}, 1 \mathrm{H})$, $7.15(\mathrm{~d}, J=8.1 \mathrm{~Hz}, 1 \mathrm{H}), 6.45-6.41(\mathrm{~m}, 2 \mathrm{H}) ;{ }^{13} \mathrm{C} \mathrm{NMR}\left(\mathrm{CD}_{3} \mathrm{OD}, 75 \mathrm{MHz}\right) \delta 159.2(\mathrm{Cq}), 156.5$ $(\mathrm{Cq}), 148.3(\mathrm{Cq}), 144.5(\mathrm{CH}), 136.5(\mathrm{Cq}), 132.4(\mathrm{CH}), 130.1(\mathrm{CH}), 129.9(2 \mathrm{CH}), 128.9(\mathrm{Cq})$, $127.9(2 \mathrm{CH}), 127.0(\mathrm{CH}), 124.3(\mathrm{CH}), 119.7(\mathrm{Cq}), 119.3(\mathrm{Cq}), 117.3(\mathrm{Cq}), 108.4(\mathrm{CH}), 104.1$ (CH). HRMS (ESI+) calcd for $\mathrm{C}_{19} \mathrm{H}_{15} \mathrm{~N}_{2} \mathrm{O}_{2}[\mathrm{M}+\mathrm{H}]^{+}$303.1134, found 303.1124. IR (neat, $\mathrm{cm}^{-}$ 1): $v 3252,2833,1605,1259$. UPLC $R_{\mathrm{t}}=2.94 \mathrm{~min}$; area $100 \%$. 
3-Phenyl-5-(3,4-dihydroxyphenyl)-1H-pyrrolo[2,3-b]pyridine (2i). This compound was prepared according to RP4 using $1 \mathbf{i}(70 \mathrm{mg}, 0.21 \mathrm{mmol})$ in $\mathrm{CH}_{2} \mathrm{Cl}_{2}(185 \mu \mathrm{L})$ with $\mathrm{BBr}_{3}(1.3 \mathrm{~mL}$ of a $1 \mathrm{~N}$ solution in $\mathrm{CH}_{2} \mathrm{Cl}_{2}, 1.27 \mathrm{mmol}$ ). The residue was purified by preparative TLC $\left(\mathrm{CH}_{2} \mathrm{Cl}_{2} / \mathrm{MeOH} 95: 5\right)$ to give $2 \mathbf{i}$ as a white solid (52\% yield). ${ }^{1} \mathrm{H}$ NMR (DMSO- $d_{6}, 300 \mathrm{MHz}$ ) $\delta 11.90($ br s, 1H), $9.01(\mathrm{~s}, 1 \mathrm{H}), 9.00(\mathrm{~s}, 1 \mathrm{H}), 8.44(\mathrm{~d}, J=1.8 \mathrm{~Hz}, 1 \mathrm{H}), 8.27(\mathrm{~d}, J=2.1 \mathrm{~Hz}, 1 \mathrm{H})$ $7.87(\mathrm{~s}, 1 \mathrm{H}), 7.76(\mathrm{~d}, J=7.5 \mathrm{~Hz}, 2 \mathrm{H}), 7.48-7.43(\mathrm{~m}, 2 \mathrm{H}), 7.28-7.23(\mathrm{~m}, 1 \mathrm{H}), 7.09(\mathrm{~s}, 1 \mathrm{H}), 7.01$ $(\mathrm{d}, J=8.1 \mathrm{~Hz}, 1 \mathrm{H}), 6.84(\mathrm{~d}, J=8.1 \mathrm{~Hz}, 1 \mathrm{H}) ;{ }^{13} \mathrm{C}$ NMR (DMSO- $\left.d_{6}, 75 \mathrm{MHz}\right) \delta 148.2(\mathrm{Cq})$ $145.6(\mathrm{Cq}), 144.8(\mathrm{Cq}), 141.6(\mathrm{CH}), 135.1(\mathrm{Cq}), 131.3(\mathrm{Cq}), 130.3(\mathrm{Cq}), 129.2(\mathrm{CH}), 128.9$ $(2 \mathrm{CH}), 126.3(2 \mathrm{CH}), 125.6(\mathrm{CH}), 124.4(\mathrm{CH}), 124.3(\mathrm{Cq}), 118.0(\mathrm{CH}), 117.2(\mathrm{Cq}), 116,2(\mathrm{CH})$, 114.4 (CH). HRMS (ESI+) calcd for $\mathrm{C}_{19} \mathrm{H}_{15} \mathrm{~N}_{2} \mathrm{O}_{2}[\mathrm{M}+\mathrm{H}]^{+}$303.1134, found 303.1143. IR (neat, $\left.\mathrm{cm}^{-1}\right): v 3112,2830,1601,1254$. UPLC $R_{\mathrm{t}}=3.74 \mathrm{~min}$; area $100 \%$.

3-(4-Hydroxyphenyl)-5-(2,4-dihydroxyphenyl)- $1 H$-pyrrolo[2,3-b]pyridine $\quad(2 \mathrm{j}) . \quad$ This compound was prepared according to RP4 using $\mathbf{1 j}(170 \mathrm{mg}, 0.47 \mathrm{mmol})$ in $\mathrm{CH}_{2} \mathrm{Cl}_{2}(395 \mu \mathrm{L})$ with $\mathrm{BBr}_{3}\left(4.1 \mathrm{~mL}\right.$ of a $1 \mathrm{~N}$ solution in $\left.\mathrm{CH}_{2} \mathrm{Cl}_{2}, 4.25 \mathrm{mmol}\right)$. The residue was purified by flash chromatography on silica gel $\left(\mathrm{CH}_{2} \mathrm{Cl}_{2} / \mathrm{MeOH}\right.$, gradient 100:0 to 95:5) and then by preparative TLC $\left(\mathrm{CH}_{2} \mathrm{Cl}_{2} / \mathrm{MeOH} 90: 10\right)$ to give $2 \mathbf{j}$ as a pale brown solid $\left(75 \%\right.$ yield). Mp $201-210^{\circ} \mathrm{C} .{ }^{1} \mathrm{H}$ NMR $\left(\mathrm{CD}_{3} \mathrm{OD}, 300 \mathrm{MHz}\right) \delta 8.34(\mathrm{~d}, J=2.1 \mathrm{~Hz}, 1 \mathrm{H}), 8.31(\mathrm{~d}, J=2.1 \mathrm{~Hz}, 1 \mathrm{H}), 7.48-7.51(\mathrm{~m}$, 2H), $7.47(\mathrm{~s}, 1 \mathrm{H}), 7.14(\mathrm{~d}, J=8.1 \mathrm{~Hz}, 1 \mathrm{H}), 6.88(\mathrm{dd}, J=8.4 \mathrm{~Hz}, 2.1 \mathrm{~Hz}, 2 \mathrm{H}), 6.44(\mathrm{~s}, 1 \mathrm{H})$, 6.41-6.45 (m, 1H); ${ }^{13} \mathrm{C}$ NMR $\left(\mathrm{CD}_{3} \mathrm{OD}, 75 \mathrm{MHz}\right) \delta 159.1(\mathrm{Cq}), 157.0(\mathrm{Cq}), 156.5(\mathrm{Cq}), 148.3$ (Cq), $144.4(\mathrm{CH}), 132.5(\mathrm{CH}), 130.0(\mathrm{CH}), 129.2(2 \mathrm{CH}), 128.6(\mathrm{Cq}), 127.9(\mathrm{Cq}), 123.2(\mathrm{CH})$, $119.8(\mathrm{Cq}), 119.4(\mathrm{Cq}), 117.4(\mathrm{Cq}), 116.7(2 \mathrm{CH}), 108.4(\mathrm{CH}), 104.1(\mathrm{CH})$. HRMS (ESI+) calcd for $\mathrm{C}_{19} \mathrm{H}_{15} \mathrm{~N}_{2} \mathrm{O}_{3}[\mathrm{M}+\mathrm{H}]^{+}$319.1083, found 319.1087. IR (neat, $\mathrm{cm}^{-1}$ ): $v 3189,3008,1605,1260$. $\operatorname{UPLC~} R_{\mathrm{t}}=2.10 \mathrm{~min}$; area $100 \%$. 
3-(4-Hydroxyphenyl)-5-(3,4-dihydroxyphenyl)-1H-pyrrolo[2,3-b]pyridine $\quad$ (2k). This compound was prepared according to RP4 using $1 \mathbf{k}(125 \mathrm{mg}, 0.35 \mathrm{mmol})$ in $\mathrm{CH}_{2} \mathrm{Cl}_{2}(300 \mu \mathrm{L})$ with $\mathrm{BBr}_{3}\left(3.1 \mathrm{~mL}\right.$ of a $1 \mathrm{~N}$ solution in $\left.\mathrm{CH}_{2} \mathrm{Cl}_{2}, 3.12 \mathrm{mmol}\right)$. The residue was purified by preparative TLC $\left(\mathrm{CH}_{2} \mathrm{Cl}_{2} / \mathrm{MeOH} 90: 10\right)$ to give $\mathbf{2 k}$ as a pale grey solid (53\% yield). $\mathrm{Mp} 275^{\circ} \mathrm{C}$ (degradation). ${ }^{1} \mathrm{H}$ NMR $\left(\mathrm{CD}_{3} \mathrm{OD}, 300 \mathrm{MHz}\right) \delta 8.37(\mathrm{~d}, J=2.1 \mathrm{~Hz}, 1 \mathrm{H}), 8.27(\mathrm{~d}, J=2.1 \mathrm{~Hz}$, 1H), 7.52-7.49 (m, 3H), $7.08(\mathrm{~d}, J=2.1 \mathrm{~Hz}, 1 \mathrm{H}), 7.00-6.97(\mathrm{~m}, 1 \mathrm{H}), 6.91-6.86(\mathrm{~m}, 3 \mathrm{H}) ;{ }^{13} \mathrm{C}$ NMR (CD $\left.{ }_{3} \mathrm{OD}, 75 \mathrm{MHz}\right) \delta 157.1(\mathrm{Cq}), 148.9(\mathrm{Cq}), 146.8(\mathrm{Cq}), 146.1(\mathrm{Cq}), 142.2(\mathrm{CH}), 132.6$ $(\mathrm{Cq}), 131.2(\mathrm{Cq}), 129.3(2 \mathrm{CH}), 127.7(\mathrm{Cq}), 127.1(\mathrm{CH}), 123.8(\mathrm{CH}), 120.2(\mathrm{Cq}), 119.8(\mathrm{CH})$, $117.5(\mathrm{Cq}), 117.0(\mathrm{CH}), 116.8(2 \mathrm{CH}), 115.3(\mathrm{CH})$. HRMS (ESI-) calcd for $\mathrm{C}_{19} \mathrm{H}_{13} \mathrm{~N}_{2} \mathrm{O}_{3}[\mathrm{M}-\mathrm{H}]^{-}$ 317.0926, found 317.0936. IR (neat, $\mathrm{cm}^{-1}$ ): $v$ 3264, 3017, 1601, 1257. UPLC $R_{\mathrm{t}}=2.22 \mathrm{~min}$; area $100 \%$.

3-(3,4-Dihydroxyphenyl)-5-(2,4-dihydroxyphenyl)-1 $H$-pyrrolo[2,3-b]pyridine (2I). This compound was prepared according to RP4 using 11 (110 mg, $0.28 \mathrm{mmol})$ in $\mathrm{CH}_{2} \mathrm{Cl}_{2}(235 \mu \mathrm{L})$ with $\mathrm{BBr}_{3}\left(3.4 \mathrm{~mL}\right.$ of a $1 \mathrm{~N}$ solution in $\left.\mathrm{CH}_{2} \mathrm{Cl}_{2}, 3.38 \mathrm{mmol}\right)$. The residue was purified by preparative TLC $\left(\mathrm{CH}_{2} \mathrm{Cl}_{2} / \mathrm{MeOH} 80: 20\right)$ to give $\mathbf{2 l}$ as a black solid (53\% yield). Mp $197^{\circ} \mathrm{C} .{ }^{1} \mathrm{H}$ NMR (CD 3 OD, $300 \mathrm{MHz}) \delta 8.36-8.33(\mathrm{~m}, 2 \mathrm{H}), 7.54(\mathrm{~s}, 1 \mathrm{H}), 7.16-7.13(\mathrm{~m}, 2 \mathrm{H}), 7.02-6.98(\mathrm{~m}$, $1 \mathrm{H}), 6.85(\mathrm{br} \mathrm{d}, J=8.1 \mathrm{~Hz}, 1 \mathrm{H}), 6.45-6.40(\mathrm{~m}, 2 \mathrm{H}) ;{ }^{13} \mathrm{C} \mathrm{NMR}\left(\mathrm{CD}_{3} \mathrm{OD}, 75 \mathrm{MHz}\right) \delta 159.1(\mathrm{Cq})$, $156.5(\mathrm{Cq}), 148.3(\mathrm{Cq}), 146.6(\mathrm{Cq}), 145.0(\mathrm{Cq}), 144.4(\mathrm{CH}), 132.5(\mathrm{CH}), 130.0(\mathrm{CH}), 128.6$ $(\mathrm{Cq}), 128.5(\mathrm{Cq}), 123.2(\mathrm{CH}), 119.8(\mathrm{Cq}), 119.7(\mathrm{CH}), 119.5(\mathrm{Cq}), 117.5(\mathrm{Cq}), 116.9(\mathrm{CH})$, $115.3(\mathrm{CH}), 108.4(\mathrm{CH}), 104.1(\mathrm{CH})$. HRMS (ESI+) calcd for $\mathrm{C}_{19} \mathrm{H}_{15} \mathrm{~N}_{2} \mathrm{O}_{4}[\mathrm{M}+\mathrm{H}]^{+}$335.1032, found 335.1025. IR (neat, $\mathrm{cm}^{-1}$ ): $v 3136,2842,1604,1259$. UPLC $R_{\mathrm{t}}=1.89 \mathrm{~min}$; area 100\%. 
3-(3,4-Dihydroxyphenyl)-5-(2,5-dihydroxyphenyl)-1 $H$-pyrrolo[2,3-b]pyridine (2m). This compound was prepared according to RP4 using $1 \mathbf{m}(150 \mathrm{mg}, 0.38 \mathrm{mmol})$ in $\mathrm{CH}_{2} \mathrm{Cl}_{2}(320 \mu \mathrm{L})$ with $\mathrm{BBr}_{3}$ (4.6 mL of a $1 \mathrm{~N}$ solution in $\left.\mathrm{CH}_{2} \mathrm{Cl}_{2}, 4.61 \mathrm{mmol}\right)$. The residue was purified by preparative TLC $\left(\mathrm{CH}_{2} \mathrm{Cl}_{2} / \mathrm{MeOH} 80: 20\right)$ to give $\mathbf{2 m}$ as a brown solid (41\% yield). $\mathrm{Mp} 180^{\circ} \mathrm{C}$. ${ }^{1} \mathrm{H}$ NMR $\left(\mathrm{CD}_{3} \mathrm{OD}, 300 \mathrm{MHz}\right) \delta 8.40(\mathrm{~m}, 2 \mathrm{H}), 7.48(\mathrm{~s}, 1 \mathrm{H}), 7.13(\mathrm{~d}, J=2.1 \mathrm{~Hz}, 1 \mathrm{H}), 7.01(\mathrm{dd}$, $J=8.1 \mathrm{~Hz}, 2.1 \mathrm{~Hz}, 1 \mathrm{H}), 6.87-6.77(\mathrm{~m}, 3 \mathrm{H}), 6.68-6.64(\mathrm{~m}, 1 \mathrm{H}) ;{ }^{13} \mathrm{C} \mathrm{NMR}\left(\mathrm{CD}_{3} \mathrm{OD}, 75 \mathrm{MHz}\right) \delta$ $151.7(\mathrm{Cq}), 148.6(\mathrm{Cq}), 148.4(\mathrm{Cq}), 146.6(\mathrm{Cq}), 145.0(\mathrm{Cq}), 144.3(\mathrm{CH}), 130.2(\mathrm{CH}), 128.4$ (3Cq), $123.4(\mathrm{CH}), 119.7(\mathrm{Cq}), 119.6(\mathrm{CH}), 118.1(\mathrm{CH}), 118.0(\mathrm{CH}), 117.7(\mathrm{Cq}), 116.9(\mathrm{CH})$, $116.1(\mathrm{CH}), 115.3(\mathrm{CH})$. HRMS (ESI+) calcd for $\mathrm{C}_{19} \mathrm{H}_{15} \mathrm{~N}_{2} \mathrm{O}_{4}[\mathrm{M}+\mathrm{H}]^{+}$335.1032, found 335.1023. IR (neat, $\mathrm{cm}^{-1}$ ): $v 3216,2916,1605,1276$. UPLC $R_{\mathrm{t}}=1.75 \mathrm{~min}$; area $100 \%$.

3,5-Di-(3-hydroxyphenyl)-1H-pyrrolo[2,3-b]pyridine (2n). This compound was prepared according to RP4 using 1 n $(158 \mathrm{mg}, 0.48 \mathrm{mmol})$ in $\mathrm{CH}_{2} \mathrm{Cl}_{2}(400 \mu \mathrm{L})$ with $\mathrm{BBr}_{3}(2.8 \mathrm{~mL}$ of a $1 \mathrm{~N}$ solution in $\mathrm{CH}_{2} \mathrm{Cl}_{2}, 2.87 \mathrm{mmol}$ ). The residue was purified by preparative TLC $\left(\mathrm{CH}_{2} \mathrm{Cl}_{2} / \mathrm{MeOH} 90: 10\right)$ to give $2 \mathrm{n}$ as a white solid (47\% yield). ${ }^{1} \mathrm{H}$ NMR $\left(\mathrm{CD}_{3} \mathrm{OD}, 300 \mathrm{MHz}\right)$ $\delta 8.45(\mathrm{~s}, 1 \mathrm{H}), 8.42(\mathrm{~d}, J=2.1 \mathrm{~Hz}, 1 \mathrm{H}), 7.64(\mathrm{~s}, 1 \mathrm{H}), 7.32-7.24(\mathrm{~m}, 2 \mathrm{H}), 7.19-7.08(\mathrm{~m}, 4 \mathrm{H})$, 6.82-6.70 (m, 2H); ${ }^{13} \mathrm{C}$ NMR $\left(\mathrm{CD}_{3} \mathrm{OD}, 75 \mathrm{MHz}\right) \delta 159.1(\mathrm{Cq}), 158.9(\mathrm{Cq}), 149.3(\mathrm{Cq}), 142.6$ $(\mathrm{CH}), 142.0(\mathrm{Cq}), 137.6(\mathrm{Cq}), 131.2(\mathrm{Cq}), 131.1(\mathrm{CH}), 131.0(\mathrm{CH}), 127.7(\mathrm{CH}), 124.9(\mathrm{CH})$, $119.9(\mathrm{CH}), 119.6(\mathrm{CH}), 119.3(\mathrm{CH}), 117.5(\mathrm{CH}), 115.2(\mathrm{CH}), 115.0(\mathrm{CH}), 114.7(\mathrm{CH}), 114.2$ (CH). HRMS (ESI+) calcd for $\mathrm{C}_{19} \mathrm{H}_{15} \mathrm{~N}_{2} \mathrm{O}_{2}[\mathrm{M}+\mathrm{H}]^{+}$303.1134, found 303.1127. IR (neat, cm $\left.{ }^{1}\right): v 3314,3014,1599,1275$. UPLC $R_{\mathrm{t}}=2.91 \mathrm{~min}$; area $100 \%$.

\section{Molecular Modeling Study}

The putative binding mode between the ATP binding site of DYRK1A and the most active compounds of the series $\mathbf{2 c}, \mathbf{2} \mathbf{d}, \mathbf{2 k}$ and $\mathbf{2} \mathbf{j}$ was examined by molecular modeling experiments 
using Schrodinger Suite ${ }^{\mathrm{TM}} 2012$ Update $1 .{ }^{27}$ The model used was based on the structure of DYRK1A 2WO6.pdb available in the Protein Data Bank (PDB). The structure was treated using Protein Preparation Wizard module, hydrogen atoms were added and refined using PROPKA algorithm at $\mathrm{pH}$ 7.0, restrained minimization was conducted with OPLS2005 forcefield with a convergence criterion for heavy atoms of $0.30 \AA$. All ligands were constructed and minimized using OPLS2005 force field. Structures were prepared for docking experiments with the LigPrep module with generation of all possible states using Epik algorithm (target $\mathrm{pH}$ of $7.0 \pm$ 2.0). The grid was generated using Glide Receptor Grid Generation module from the prepared protein structure (volume of $20 \AA^{3}$ centered on the native ligand K00611A of 2 WO6.pdb). The docking experiments were conducted with the Glide module of Schrodinger Suite ${ }^{\mathrm{TM}}$ with extra precision algorithm (XP Glide), flexible ligand sampling and adding Epik state penalties to docking score.

\section{Expression and Purification of the Recombinant DYRK1A Catalytic Domain (DYRK1A-} $\Delta \mathbf{C})$

The cDNA coding for the catalytic domain (residues 1-502) of rat DYRK1A (99.6\% amino acid identity with human DYRK1A) was a kind gift of Prof. W. Becker (Aachen University, Germany). This cDNA was subcloned into pET28 plasmid and used to produce recombinant 6xHis-tagged DYRK1A catalytic domain (DYRK1A- $\Delta$ C). The pET28-DYRK1A- $\Delta$ C plasmid was transformed into E. coli BL21(DE3) cells for production and purification of the protein. Briefly, transformed bacterial cells were grown at $37^{\circ} \mathrm{C}$ for $4 \mathrm{~h}$ in the presence of $0.5 \mathrm{mM}$ isopropyl $\beta$-D-1-thiogalactopyranoside and further grown at $4{ }^{\circ} \mathrm{C}$ overnight. Cells were harvested by centrifugation and resuspended in phosphate buffered saline buffer (PBS) supplemented with protease inhibitors, $1 \mathrm{mg} / \mathrm{ml}$ lysozyme and $0.1 \%$ Triton X-100. After 30 min incubation at $4{ }^{\circ} \mathrm{C}$, the lysate was subjected to sonication on ice and pelleted $(12,000 \mathrm{xg}, 30$ 
min). The supernatant was incubated with His-select Nickel resin (Sigma) for $2 \mathrm{~h}$ at $4{ }^{\circ} \mathrm{C}$. Resin was poured into a column and washed with Tris- $\mathrm{HCl} 20 \mathrm{mM}, \mathrm{pH}$ 7.5, $10 \mathrm{mM}$ imidazole. Proteins were eluted in Tris-HCl 20 mM, pH 7.5, $300 \mathrm{mM}$ imidazole. Proteins were reduced with $10 \mathrm{mM}$ dithiothreitol (DTT) and dialyzed overnight against Tris-HCl $20 \mathrm{mM}, \mathrm{pH} 7.5$. Proteins were quantified with Bradford's reagent (Bio-rad). Purity was assessed by SDSPAGE. Proteins were kept at $-80^{\circ} \mathrm{C}$.

\section{DYRK1A Inhibition Assay}

Measurement of DYRK1A kinase activity was carried out using a high pressure liquid chromatography (HPLC)-based approach using a fluorescent peptide substrate of DYRK1A. The fluorescent peptide substrate was derived from the sequence of the human transcription factor FKHR which is known to be a physiological substrate of DYRK1A. ${ }^{28}$ The peptide substrate is coupled to fluorescein by its $\mathrm{N}$-terminal amino acid and has the following sequence: KISGRLSPIMTEQ (the serine residue that is phosphorylated by DYRK1A is underlined). DYRK1A- $\Delta$ C activity assays were performed in 96-well plates, in a total volume of $50 \mu 1$ consisting of kinase buffer (Tris-HCl $50 \mathrm{mM}, \mathrm{pH} 7.5,10 \mathrm{mM}$ DTT, $5 \mathrm{mM} \mathrm{MgCl}$ ), peptide substrates (ranging from 5-60 $\mu \mathrm{M}$ ) and $20 \mathrm{ng}$ of purified DYRK1A- $\Delta \mathrm{C}$. The reaction was initiated by addition of ATP (ranging from 50 to $800 \mu \mathrm{M}$ ) and the mixture was incubated for $30 \mathrm{~min}$ at $37^{\circ} \mathrm{C}$. Reactions were stopped by addition of $50 \mu \mathrm{l}$ of $15 \% \mathrm{HClO}_{4}(\mathrm{v} / \mathrm{v})$ and $20 \mu \mathrm{l}$ of the mixture was analyzed by HPLC (Shimadzu) on a C8 reverse-phase column (Ascentis). Mobile phases used consisted of $0.12 \%$ trifluoroacetic acid (TFA) (solvent A) and acetonitrile in $0.12 \%$ TFA. Phosphorylated and unphosphorylated peptides were separated by isocratic flow ( $85 \%$ solvent $\mathrm{A} / 15 \%$ solvent $\mathrm{B}$ ) at a flow rate of $1.5 \mathrm{ml} / \mathrm{min}$. The peptides were monitored by fluorimetry (excitation at $485 \mathrm{~nm}$, emission at $530 \mathrm{~nm}$ ) and quantified by integration of the peak absorbance area. A calibration curve established with different known concentrations of 
peptides was used for quantification. Initial velocities and kinetic parameters were determined by fitting the data iteratively to the following equation : $\mathrm{V}_{\mathrm{i}}=\mathrm{V}_{\max }\left[\mathrm{S}_{\mathrm{A}}\right]\left[\mathrm{S}_{\mathrm{B}}\right] /\left(K_{\mathrm{AB}}+K_{\mathrm{mB}}\left[\mathrm{S}_{\mathrm{A}}\right]+\right.$ $\left.K_{\mathrm{mA}}\left[\mathrm{S}_{\mathrm{B}}\right]+\left[\mathrm{S}_{\mathrm{A}}\right]\left[\mathrm{S}_{\mathrm{B}}\right]\right)$ using the Prism $5(\mathrm{GraphPad})$ program, where $\mathrm{V}_{\mathrm{i}}$ is the initial velocity, $\mathrm{V}_{\mathrm{m}}$ is the maximal velocity, $\mathrm{K}_{\mathrm{AB}}$ is the dissociation constant and $K_{\mathrm{mA}} K_{\mathrm{mB}}$ are the Michaelis-Menten constants. $^{29}$

For inhibition studies, the compounds were added at different concentrations to the well prior to addition of ATP. Determination of the mode of inhibition (competitive/non competitive) of the compounds and inhibition constant $\left(\mathrm{K}_{\mathrm{i}}\right)$ values were obtained by carrying out assays with different concentrations of inhibitors and fitting the data to the following equations: $V_{i}=V_{\max }$ $[\mathrm{S}] /\left(K_{\mathrm{m}}\left(1+[\mathrm{I}] / K_{\mathrm{I}}\right)+[\mathrm{S}]\right)$ and $\mathrm{V}_{\mathrm{i}}=\left(\mathrm{V}_{\max } /\left(1+[\mathrm{I}] / K_{\mathrm{I}}\right)[\mathrm{S}]\right) /\left(K_{\mathrm{m}}+[\mathrm{S}]\right)$ for competitive and non competitive inhibition, respectively. ${ }^{29}$ All experiments were done in triplicate, mean values are reported.

\section{Cell Culture and Proliferation Assay}

Cancer cell lines were obtained from the American Type Culture Collection (Rockville, MD, USA) and were cultured according to the supplier's instructions. Briefly, human KB epidermal carcinoma cells were grown in Dulbecco minimal essential medium (DMEM) containing $4.5 \mathrm{~g} / \mathrm{L}$ glucose supplemented with $10 \%$ fetal calf serum (FCS) and $1 \%$ glutamine, $100 \mathrm{UI}$ penicillin, $100 \mu \mathrm{g} / \mathrm{ml}$ streptomycin and $1.5 \mu \mathrm{g} / \mathrm{ml}$ fungizone and maintained at $37{ }^{\circ} \mathrm{C}$ in a humidified atmosphere containing 5\% $\mathrm{CO}_{2}$. Cell viability was assessed using Promega CellTiter-Blue TM reagent according to the manufacturer's instructions. Briefly, cells were seeded in 96-well plates $\left(5 \times 10^{3}\right.$ cells/well) containing $50 \mathrm{ml}$ growth medium. After $24 \mathrm{~h}$ of culture, the cells were supplemented with $50 \mathrm{ml}$ of the studied compound dissolved in DMSO (less than $0.1 \%$ in each preparation). After $72 \mathrm{~h}$ of incubation, $20 \mathrm{ml}$ of resazurin was added for 
$2 \mathrm{~h}$ before recording fluorescence $\left(\lambda_{\mathrm{ex}}=560 \mathrm{~nm}, \lambda_{\mathrm{em}}=590 \mathrm{~nm}\right)$ using a Victor microtiter plate fluorimeter (Perkin-Elmer, USA).

\section{Acknowledgements}

The authors thank the Romeo Cluster (https://romeo.univ-reims.fr/) for calculation facilities, Schrodinger Products licensing, the technical platform "BioProfiler-UFLC" for provision of HPLC facilities and Ms. Geneviève Aubert and Dr. Thierry Cresteil of the ICSN for the cancer cell growth inhibition assays. This work was supported by grants from Université Paris Diderot, CNRS, Agence Nationale de la Recherche (project n ANR-09-MNPS-008 "DSther"), the Laboratory of Excellence "LERMIT", "la Caisse d'Assurance Maladie des Professions Liberales de Province" and "La Fondation Jérôme Lejeune".

\section{Associated Content}

Supporting Information

RP-HPLC traces showing the purity of the compounds tested. Copies of 1H NMR This material is available free of charge via the Internet at http://pubs.acs.org.

\section{Author Information}

Corresponding author

Tel.: 33-1-69824594; Fax: 33-1-69077247;

E-mail: robert.dodd@cnrs.fr

\section{Abbreviations used}


AKT, Protein Kinase B; Alk, alkyl; CK1 $\alpha$, casein kinase $1 \alpha$; CLKs, cdc2-like kinases; DANDYs, Diaryl-Azaindole iNhibitors of DYRK1A; DMEM, Dulbecco minimal essential medium; DYRKs, dual specificity, tyrosine phosphorylation regulated kinases; DS, Down Syndrome; EGCG, Epigallocatechin gallate; FCS, fetal calf serum; FKHR, Forkhead box protein O1; GSK, glycogen synthase kinase; INDY, (1Z)-1-(3-ethyl-5-hydroxy-1,3benzothiazol-2-ylidene)propan-2-one; JAK, Janus Kinase; ND, Not Determined; NFTs, Neurofibrillary Tangles; NIS, $N$-Iodosuccinimide; Pim1, proto-oncogene serine/threonineprotein kinase; Rt, Retention time, TRK, tropomyosin-receptor kinase A.

\section{References}

1. (a) Becker, W.; Joost, H. G. Structural and Functional Characteristics of Dyrk, a Novel Subfamily of Protein Kinases with Dual Specificity. Prog. Nucleic. Acid Res. Mol. Biol. 1999, 62, 1-17; (b) Hanks, S. K.; and Quinn, A. M. Protein kinase Catalytic Domain Sequence Database: Identification of Conserved Features of Primary Structure and Classification of Family Members. Methods Enzymol. 1991, 200, 38-62; (c) Becker, W.; Sippl, W. Activation Regulation, and Inhibition of DYRK1A. FEBS J. 2011, 278, 246-256.

2. (a) Guimerá, J.; Casas, C.; Pucharcos, C.; Solans, A.; Domenech, A.; Planas, A. M.; Ashley, J.; Lovett, M.; Estivill, X.; Pritchard, M. A. A Human Homologue of Drosophila Minibrain (MNB) is Expressed in the Neuronal Regions Affected in Down Syndrome and Maps to the Critical Region. Hum. Mol. Genet.1996, 5, 1305-1310; (b) Smith, D. J.; Stevens, M. E.; Sudanagunta, S. P.; Bronson, R. T.; Makhinson, M.; Watabe, A. M.; O'Dell, T. J.; Fung, J.; Weier, H.-U. G.; Cheng, J.-F. and Rubin, E. M. Functional Screening of $2 \mathrm{Mb}$ of Human Chromosome 21q22.2 in Transgenic Mice Implicates Minibrain in Learning Defects Associated with Down Syndrome. Nat. Genet. 1997, 16, 28-36; (c) Tejedor, F.; Zhu, X. R.; Kaltenbach, E.; Ackermann, A.; Baumann, A.; Canal, I.; Heisenberg, M.; Fischbach, K. F. and 
Pongs, O. Minibrain: a New Protein Kinase Family Involved in Postembryonic Neurogenesis in Drosophila. Neuron 1995, 14, 287-301; (d) Aranda, S.; Laguna, A. ; de la Luna, S. DYRK Family of Protein Kinases: Evolutionnary Relationships, Biochemical Properties, and Functionnal Roles. FASEB J. 2011, 25, 449-462.

3. (a) Sitz, J. H.; Baumgärtel, K.; Hämmerle, B.; Papadopoulos, C.; Hekerman, P.; Tejedor, F. J.; Becker, W.; Lutz, B. The Down Syndrome Candidate Dual-Specificity Tyrosine Phosphorylation-Regulated Kinase 1A Phosphorylates the Neurodegeneration-Related Septin4. Neurscience 2008, 157, 596-605; (b) Ruparelia, A.; Pearn, M. L.; Mobley, W. C. Cognitive and Pharmacological Insights from the Ts65Dn Mouse Model of Down Syndrome. Curr. Opin. Neurobiol. 2012, 22, 1-7.

4. Dowjat, W. K.; Adayev, T.; Kuchna, I.; Nowicki, K.; Palminiello, S.; Hwang, Y. W.; Wegiel, J. Trisomy-Driven Overexpression of DYRK1A Kinase in the Brain of Subjects with Down Syndrome. Neurosci. Lett. 2007, 413, 77-81.

5. Bittles, A. H.; Bower, C.; Hussain, R.; Glasson E. J. The Four Ages of Down Syndrome. Eur J Public Health 2007, 17, 221-225.

6. (a) Sheppard, O.; Plattner, F.; Rubin, A.; Slender, A.; Linehan, J. M.; Brandner, S.; Tybulewicz, V. L. J.; Fisher, E. M. C.; Wiseman, F. K. Altered Regulation of Tau Phosphorylation in a Mouse Model of Down Syndrome Aging. Neurobiol. Aging 2012, 33, 828.e31-828.e44; (b) Park, J.; Oh, Y.; Chung, K. C. Two Key Genes Closely Implicated with the Neuropathological Characteristics in Down Syndrome: DYRK1A and RCAN1. BMB Rep. 2008, 42, 6-15 (c) Wegiel, J.; Gong, C.-X.; Hwang, Y.-W. The Role of DYRK1A in Neurodegenerative Diseases. FEBS J. 2011, 278, 236-245; (d) Ryoo, S.-R.; Jeong, H. K.; Radnaabazar, C.; Yoo, J.-J.; Cho, H.-J.; Lee, H. W.; Kim, I.-S.; Cheon, Y.-H.; Ahn, Y. S.; Chung, S.-H.; Song, W.-J. DYRK1A-Mediated Hyperphosphorylation of Tau: A Functional 
Link Between Down Syndrome and Alzheimer Disease. J. Biol. Chem. 2007, 282, 3485034857.

7. (a) Savage, M. J.; Gingrich, D. E. Advances in the Development of Kinase Inhibitor Therapuetics for Alzheimer's Disease. Drug Dev. Res. 2009, 70, 125-144; (b) Liu, F.; Liang, Z.; Wegiel, J.; Hwang, Y.-W.; Iqbal, K.; Grundke-Iqbal, I.; Ramakrishna, N.; Gong, C.-X. Overexpression of DYRK1A Contributes to Neurofibrillary Degeneration in Down Syndrome. FASEB J. 2008, 22, 3224-3233; (c) Götz, J.; Gladbach, A.; Pennanenb, L.; van Eersel, J.; Schild, A.; David, D.; Ittner, L. M. Animal Models Reveal Role for Tau Phosphorylation in Human Disease. Biochim. Biophys. Acta 2010, 1802, 860-871.

8. Ryoo, S.-R.; Cho, H.-J.; Lee, H.-W.; Jeong, H. K.; Radnaabazar, C.; Kim, Y.-S.; Kim, M.J.; Son, M.-Y.; Seo, H.; Chung, S.-H.; Song, W.-J. Dual-Specificity Tyrosine(Y)Phosphorylation Regulated Kinase 1A-Mediated Phosphorylation of Amyloid Precursor Protein: Evidence for a Functional Link Between Down Syndrome and Alzheimer's Disease. $J$. Neurochem. 2008, 104, 1333-1344.

9. Smith, B.; Medda, F.; Gokhale, V.; Dunckley, T.; Hulme, C. Recent Advances in the Design, Synthesis, and Biological Evaluation of Selective DYRK1A Inhibitors: A New Avenue for a Disease Modifying Treatment of Alzheimer's ? ACS Chem. Neurosci. 2012, 3, $857-872$.

10. (a) Bain, J.; McLauchlan, H.; Elliot, M.; Cohen, P. The Specificities of Protein Kinase Inhibitors: an Update. Biochem. J. 2003, 371, 199-204; (b) Egger, G.; Liang, G.; Aparicio, A.; Jones, P. A. Epigenetics in Human Disease and Prospects for Epigenetic Therapy. Nature 2004, 429, 457-463; (c) Xie, W.; Ramakrishna, N.; Wieraszko, A.; Hwang, Y.-W. Promotion of Neuronal Plasticity by (-)-Epigallocatechin-3-Gallate. Neurochem Res. 2008, 33, 776-783.

11. (a) Bain, J.; Plater, L.; Elliot, M.; Shpiro, N.; Hastie, C. J.; McLauchlan, H.; Klevernic, I.; Arthur, J. S. C.; Alessi, D. R.; Cohen, P. The Selectivity of Protein Kinase Inhibitors: a Further 
Update. Biochem. J. 2007, 408, 297-315; (b) Göckler, N.; Jofre, G.; Papadopoulos, C.; Soppa, U.; Tejedor, F. J.; Becker, W. Harmine Specifically Inhibits Protein Kinase DYRK1A and Interferes with Neurite Formation. FEBS J. 2009, 276, 6324-6337; (c) Adayev, T.; Wegiel, J.; Hwang, Y. W. Harmine is an ATP-Competitive Inhibitor for Dual-Specificity Tyrosine Phosphorylation-Regulated Kinase 1A (Dyrk1A). Arch. Biochem. Biophys. 2011, 2, 212-218. 12. Rosenthal, A. S.; Tanega, C.; Shen, M.; Mott, B. T.; Bougie, J. M.; Nguyen, D.-T.; Misteli, T.; Auld, D. S.; Maloney, D. J.; Thomas, C. J. Potent and Selective Small Molecule Inhibitors of Specific Isoforms of Cdc2-Like Kinases (Clk) and Dual Specificity TyrosinePhosphorylation-Regulated Kinases (Dyrk). Bioorg. Med. Chem. Lett. 2011, 21, 3152-3158.

13. (a) Mott, B. T.; Tanega, C.; Shen, M.; Maloney, D. J.; Shinn, P.; Leister, W.; Marugan, J. J.; Inglese J.; Austina, C. P.; Misteli, T.; Auld, D. S.; Thomas, C. J. Evaluation of Substituted 6-Arylquinazolin-4-Amines as Potent and Selective Inhibitors of Cdc2-like Kinases (Clk). Bioorg. Med. Chem. Lett. 2009, 19, 6700-6705; (b) Muraki, M.; Ohkawara, B.; Hosoya, T.; Onogi, H.; Koizumi, J.; Koizumi, T.; Sumi, K.; Yomoda, J.; Murray, M. V.; Kimura, H.; Furuichi, K.; Shibuya, H.; Krainer, A. R.; Suzuki, M.; Hagiwara, M. Manipulation of Alternative Splicing by a Newly Developed Inhibitor of Clks. J. Biol. Chem. 2004, 279, 2424624254.

14. Ogawa, Y.; Nonaka, Y.; Goto, T.; Ohnishi, E.; Hiramatsu, T.; Kii, I.; Yoshida, M.; Ikura, T.; Onogi, H.; Shibuya, H.; Hosoya, T.; Ito, N.; Hagiwara, M. Development of a novel selective inhibitor of the Down syndrome-related kinase Dyrk1A. Nat. Commun. 2010, 1, 1-9.

15. Akue-Gedua, R.; Debitonc, E.; Ferandin, Y.; Meijer, L.; Prudhomme, M.; Anizon, F.; Moreau, P. Synthesis and Biological Activities of Aminopyrimidyl-Indoles Structurally Related to Meridianins. Bioorg. Med. Chem. 2009, 17, 4420-4424.

16. (a) Debdab, M.; Carreaux, F.; Renault, S.; Soundararajan, M.; Fedorov, O.; Filippakopoulos, P.; Lozach, O.; Babault, L.; Tahtouh, T.; Baratte, B.; Ogawa, Y.; Hagiwara, 
M.; Eisenreich, A.; Rauch, U.; Knapp, S.; Meijer, L.; Bazureau, J.-P. Leucettines, a Class of Potent Inhibitors of Cdc2-Like Kinases and Dual Specificity, Tyrosine Phosphorylation Regulated Kinases Derived from the Marine Sponge Leucettamine B: Modulation of Alternative Pre-RNA Splicing. J. Med. Chem. 2011, 54, 4172-4186; (b) Tahtouh, T.; Elkins, J. M.; Filippakopoulos, P.; Soundararajan, M.; Burgy, G.; Durieu, E.; Cochet, C.; Schmid, R. S.; Lo, D. C.; Delhommel, F.; Oberholzer, A. E.; Pearl, L. H.; Carreaux, F.; Bazureau, J.-P. Knapp, S.; Meijer, L.; Selectivity, Cocrystal Structures, and Neuroprotective Properties of Leucettines, a Family of Protein Kinase Inhibitors Derived from the Marine Sponge Alkaloid Leucettamine B J. Med. Chem. 2012, 55, 9312-9330.

17. Giraud, F.; Alves, G.; Debiton, E.; Nauton, L.; Théry, V.; Durieu, E.; Ferandin, Y.; Lozach, O.; Meijer, L.; Anizon, F.; Pereira, E.; Moreau, P. Synthesis, Protein Kinase Inhibitory Potencies, and in Vitro Antiproliferative Activities of Meridianin Derivatives. J. Med. Chem. 2011, 54, 4474-4489.

18. (a) Echalier, A.; Bettayeb, K.; Ferandin, Y.; Lozach, O.; Clément, M.; Valette, A.; Liger, F.; Marquet, B.; Morris, J. C.; Endicott, J. A.; Joseph, B.; Meijer, L. Meriolins (3-(Pyrimidin4-yl)-7-azaindoles): Synthesis, Kinase Inhibitory Activity, Cellular Effects, and Structure of a CDK2/Cyclin A/Meriolin Complex. J. Med. Chem. 2008, 51, 737-751; (b) Bettayeb, K.; Tirado, O. M.; Marionneau-Lambot, S.; Ferandin, Y.; Lozach, O.; Morris, J. C.; Mateo-Lozano, S.; Drueckes, P.; Schächtele, C.; Kubbutat, M. H. G.; Liger, F.; Marquet, B.; Joseph, B.; Echalier, A.; Endicott, J. A.; Notario, V.; Meijer L. Meriolins, a New Class of Cell DeathInducing Kinase Inhibitors with Enhanced Selectivity for Cyclin-Dependent Kinases. Cancer Res. 2012, 67, 8325-8334.

19. Neagoie, C.; Vedrenne, E.; Buron, F.; Mérour, J.-Y.; Rosca, S.; Bourg, S.; Lozach, O.; Meijer, L; Baldeyrou, B.; Lansiaux, A.; Routier, S. Synthesis of Chromeno[3,4-b]indoles as 
Lamellarin D Analogues : A Novel DYRK1A Inhibitor Class. Eur. J. Med. Chem. 2012, 49, $379-396$.

20. Kassis , P.; Brzeszcz, J.; Bénéteau, V.; Lozachc, O.; Meijer, L.; Le Guével, R.; Guillouzo,

C.; Lewinski, K.; Bourg, S.; Colliandre, L.; Routier, S.; Mérour, J.-Y. Synthesis and Biological Evaluation of New 3-(6-Hydroxyindol-2-yl)-5-(Phenyl) Pyridine or Pyrazine V-Shaped Molecules as Kinase Inhibitors and Cytotoxic Agents. Eur. J. Med. Chem. 2011, 46, 54165434.

21. For a recent in silico study of other DYRK1A inhibitors, see: Pan, Y.; Wang, Y.; Bryant, S.

H. Pharmacophore and 3D-QSAR Characterization of 6-Arylquinazolin-4-amines as Cdc2-like Kinase 4 (Clk4) and Dual Specificity Tyrosine-phosphorylation-regulated Kinase 1A (Dyrk1A) Inhibitors. J. Chem. Inf. Model. 2013, 53, 938-947.

22. (a) Doisy, X.; Dekhane, M.; Le Hyaric, M.; Rousseau, J.-F.; Singh, S. K.; Tan, S.; Guilleminot, V.; Schoemaker, H.; Sevrin, M.; George, P.; Potier, P.; Dodd, R. H. Synthesis and Benzodiazepine Receptor ( $\omega$ Receptor) Affinities of 3-Substituted Derivatives of Pyrrolo[2,3c]pyridine-5-carboxylate, a Novel Class of $\omega_{1}$ Selective Ligands. Bioorg. Med. Chem. 1999, 7, 921-932; (b) Rousseau, J.-F.; Dodd, R. H. Synthesis of 3-Deaza- $\beta$-hydroxyhistidine Derivatives and Their Use for the Preparation of Substituted Pyrrolo[2,3-c]pyridine-5carboxylates via the Pictet-Spengler Reaction. J. Org. Chem. 1998, 63, 2731-2737; (c) Dekhane, M.; Potier, P.; Dodd, R. H. A Practical Synthesis of 1H-Pyrrolo[2,3c]pyridines-5Carboxylic Acid Derivatives from Pyrrole-2-Carboxaldehydes. Tetrahedron 1993, 49, 81398146.

23. Recently the 7-azaindole core has emerged as a privileged scaffold for kinase inhibitors, see: (a) Frazee, J .S; Hammond, M.; Kano, K.; Manns, S.; Nakamura, H.; Thompson, S. K. Washburn,D. G. 1H-Pyrrolo[2,3-B]pyridines WO2006/63167 A1; (b) Hammond, M.; Washburn,D. G.; Hoang, T. H.; Manns, S.; Frazee, J .S; Nakamura, H.; Patterson, J. R.; Trizna, 
W.; Wu, C.; Azzarano, L. M.; Nagilla, R.; Nord, M.; Trejo, R.; Head, M. S.; Zhao, B.; Smallwood, A. M.; Hightower, K.; Laping, N. J.; Schnackenberg, C. G.; Thompson, S. K. Design and Synthesis of Orally Bioavailable Serum and Glucocorticoid-Regulated Kinase 1 (SGK1) Inhibitors Bioorg. Med. Chem. Lett. 2009, 19, 4441-4445; (c) Ermoli, A. ; Bargiotti, A.; Brasca, M. G.; Ciavolella, A.; Colombo, N.; Fachin, G.; Isacchi, A.; Menichincheri, M.; Molinari, A.; Montagnoli, A.; Pillan, A.; Rainoldi, S.; Riccardi Sirtori, F.; Sola, F.; Thieffine, S.; Tibolla, M.; Valsasina, B.; Volpi, D.; Santocanale, C.; Vanotti , E. Cell Division Cycle 7 Kinase Inhibitors: 1H-Pyrrolo[2,3-b]pyridines, Synthesis and Structure-Activity Relationships. J. Med. Chem. 2009, 52, 4380-4390; (d) Wang, T.; Duffy, J. P.; Wang, J.; Halas, S.; Salituro, F. G.; Pierce, A. C.; Zuccola, H. J.; Black, J. R.; Hogan, J. K.; Jepson, S; Shlyakter, D.; Mahajan, S.; Gu, Y.; Hoock, T.; Wood, M.; Furey, B. F.; Frantz, J. D.; Dauffenbach, L. M.; Germann, U. A.; Fan, B.; Namchuk, M.; Bennani,Y. L.; Ledeboer M. W.; Janus Kinase 2 Inhibitors. Synthesis and Characterization of a Novel Polycyclic Azaindole J. Med. Chem. 2009, 52, 7938-7941; (e) Hong, S.; Kim, J.; Seo, J. H.; Jung, K. H.; Hong, S.-S.; Hong, S. Design, Synthesis, and Evaluation of 3,5-Disubstituted 7-Azaindoles as Trk Inhibitors with Anticancer and Antiangiogenic Activities. J. Med. Chem. 2012, 55, 5337-5349; (f) Hong, S.; Lee, S.; Kim, B.; Lee, H.; Hong, S.-S.; Hong, S. Discovery of New Azaindole-Based PI3Ka Inhibitors: Apoptotic and Antiangiogenic Effect on Cancer Cells. Bioorg. Med. Chem. Lett. 2010, 20, 7212-7215; (g) Selig, R.; Goettert, M.; Schattel, V.; Schollmeyer, D.; Albrecht, W.; Laufer, S. A Frozen Analogue Approach to Aminopyridinylimidazoles Leading to Novel and Promising p38 MAP Kinase Inhibitors. J. Med. Chem. 2012, 55, 8429-8439; (h) Heinrich, T.; Seenisamy, J.; Emmanuvel, L.; Kulkarni, S. S.; Bomke, J.; Rohdich, F.; Greiner, H.; Esdar, C.; Krier, M.; Grädler, U.; Musil, D. Fragment-Based Discovery of New Highly Substituted 1HPyrrolo[2,3-b]- and 3H-Imidazolo[4,5-b]-Pyridines as Focal Adhesion Kinase Inhibitors. $J$. 
Med. Chem. 2013, 56, 1160-1170; (i) Tong, Y.; Stewart, K. D.; Florjancic, A. S.; Harlan, J. E.; Merta, P. J.; Przytulinska, M.; Soni, N.; Swinger, K. K.; Zhu, H.; Johnson, E. F.; Shoemaker, A. R.; Penning, T. D. Azaindole-Based Inhibitors of Cdc7 Kinase: Impact of the Pre-DFG Residue, Val 195. ACS Med. Chem. Lett. 2013, 4, 211-215.

24. For related synthetic strategies, see ref 23 and Mérour, J.-Y. ; Routier, S. ; Suzenet, F. ; Joseph, B. Recent Advances in the Synthesis and Properties of 4-, 5-, 6- or 7-Azaindoles. Tetrahedron 2013, 69, 4767-4834.

24. Myrianthopoulos, V.; Kritsanida, M.; Gaboriaud-Kolar, N.; Magiatis, P.; Ferandin, Y.; Durieu, E.; Lozach, O.; Cappel, D.; Soundararajan, M.; Filippakopoulos, P.; Sherman, W.; Knapp, S.; Meijer, L.; Mikros, E.; Skaltsounis A.-L Novel Inverse Binding Mode of Indirubin Derivatives Yields Improved Selectivity for DYRK Kinases ACS Med. Chem. Lett. 2013, 4, $22-26$.

25. Kinase profiling was done by CEREP, Le Bois l'Evêque, Celle l'Evescault, France. All experiments were done in duplicate, the value reported is the mean value, staurosphorine was used as the reference compound for all kinase but CK1 $\alpha$ (hymenialdisin was used instead).

26. Exhonit SA has very recently patented comparatively potent thiazolo[5,4-f]quinazoline compounds, see: Leblond, B.; Casagrande, A.-S.; Désiré, L.; Foucourt A.; Besson, T. DYRK1 Inhibitors and Uses Tehreof. WO 2013/026806A1.

27. (a) Friesner, R. A.; Murphy, R. B.; Repasky, M. P.; Frye, L. L.; Greenwood, J. R.; Halgren,T. A.; Sanschagrin, P. C.; Mainz, D. T., Extra Precision Glide: Docking and Scoring Incorporating a Model of Hydrophobic Enclosure for Protein-Ligand Complexes, J. Med. Chem., 2006, 49, 6177-6196; (b) Halgren, T. A.; Murphy, R. B.; Friesner, R. A.; Beard, H. S.; Frye, L. L.; Pollard, W. T.; Banks, J. L., Glide: A New Approach for Rapid, Accurate Docking 
and Scoring. 2. Enrichment Factors in Database Screening, J. Med. Chem., 2004, 47, 17501759; (c) Friesner, R. A.; Banks, J. L.; Murphy, R. B.; Halgren, T. A.; Klicic, J. J.; Mainz, D. T.; Repasky, M. P.; Knoll, E. H.; Shaw, D. E.; Shelley, M.; Perry, J. K.; Francis, P.; Shenkin, P. S., Glide: A New Approach for Rapid, Accurate Docking and Scoring. 1. Method and Assessment of Docking Accuracy, J. Med. Chem., 2004, 47, 1739-1749.

28. Woods, Y.L.; Cohen, P.; Becker, W.; Jakes, R.; Goedert, M.; Wang, X.; Proud, C. G. The Kinase DYRK Phosphorylates Protein-Synthesis Initiation Factor EIF2Bepsilon at Ser539 and the Microtubule-Associated Protein Tau at Thr212: Potential Role for DYRK As a Glycogen Synthase Kinase 3-Priming Kinase. Biochem. J. 2001, 355, 609-615.

29. Cornish-Bowden, A. Fundamentals of Enzyme Kinetics, $4^{\text {th }}$ edition, Wiley-Blackwell, Weinheim, 2012. 
<smiles>COc1ccc2c(c1)[nH]c1c(C)nccc12</smiles>

harmine

$\mathrm{IC}_{50}: 30-80 \mathrm{nM}$

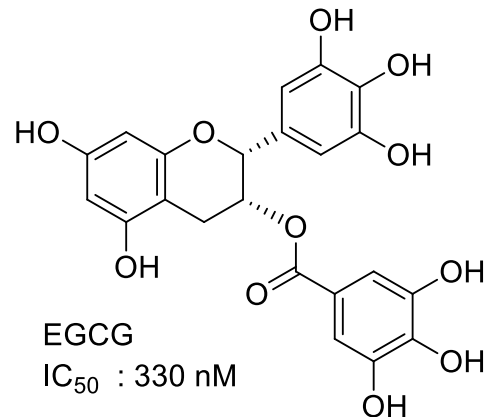<smiles>CC(C)(C)CNc1ncnc2ccc(-c3ccc4c(c3)OCO4)cc12</smiles>

NCGC 00010037 $\mathrm{IC}_{50}: 17 \mathrm{nM}$

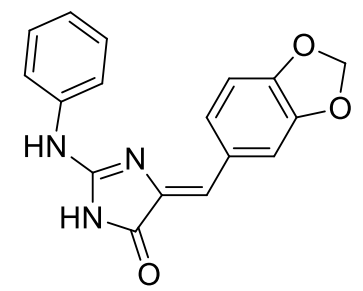

leucettine $\mathrm{IC}_{50}: 40 \mathrm{nM}$<smiles>[R]Oc1ccc2c(c1)N([Z7])/C(=C/C(C)=O)S2</smiles>

$\mathrm{R}=\mathrm{Me} \mathrm{TG003} I \mathrm{C}_{50}: 930 \mathrm{nM}$ $\mathrm{R}=\mathrm{H} \quad$ INDY $I C_{50}: 240 \mathrm{nM}$<smiles>CC[C@H](CO)Nc1nc(NCc2ccccc2)c2ncn(C(C)C)c2n1</smiles>

roscovitine $\mathrm{IC}_{50}: 3100 \mathrm{nM}$<smiles>Nc1ncc(I)c(-c2c[nH]c3cc(Br)ccc23)n1</smiles>

meridianin-like

$\mathrm{IC}_{50}: 34 \mathrm{nM}$

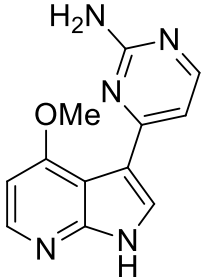

meriolin

$\mathrm{IC}_{50}: 29 \mathrm{nM}$<smiles>O=c1oc2ccc(O)cc2c2c1[nH]c1ccc(O)cc12</smiles>

lamellarin-like $\mathrm{IC}_{50}: 67 \mathrm{nM}$

Figure 1: Known DYRK1A Inhibitors. 


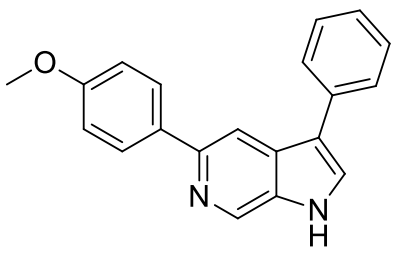

$1 a$

$\mathrm{IC}_{50}=17.0 \mu \mathrm{M}$

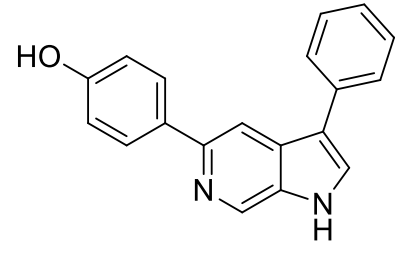

$2 a$

$\mathrm{IC}_{50}=27.4 \mu \mathrm{M}$

Figure 2. 3-Phenyl-5-aryl-6-azaindoles as Potential Hits 


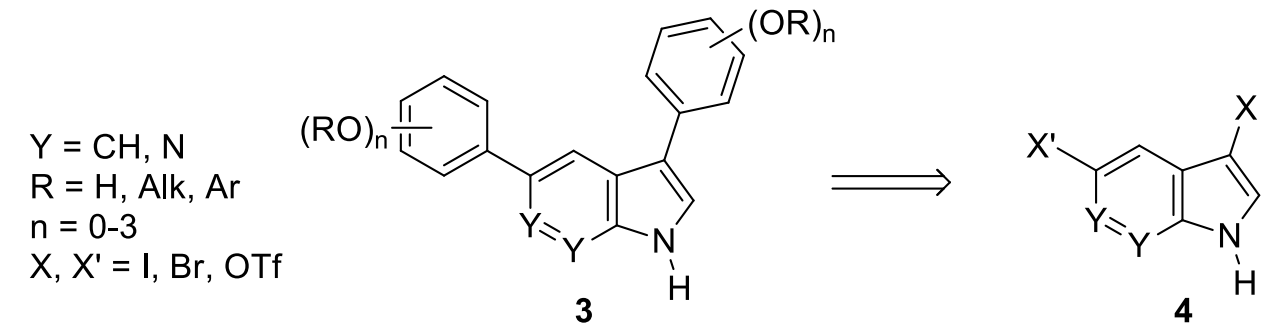

Figure 3: Initial Design. 

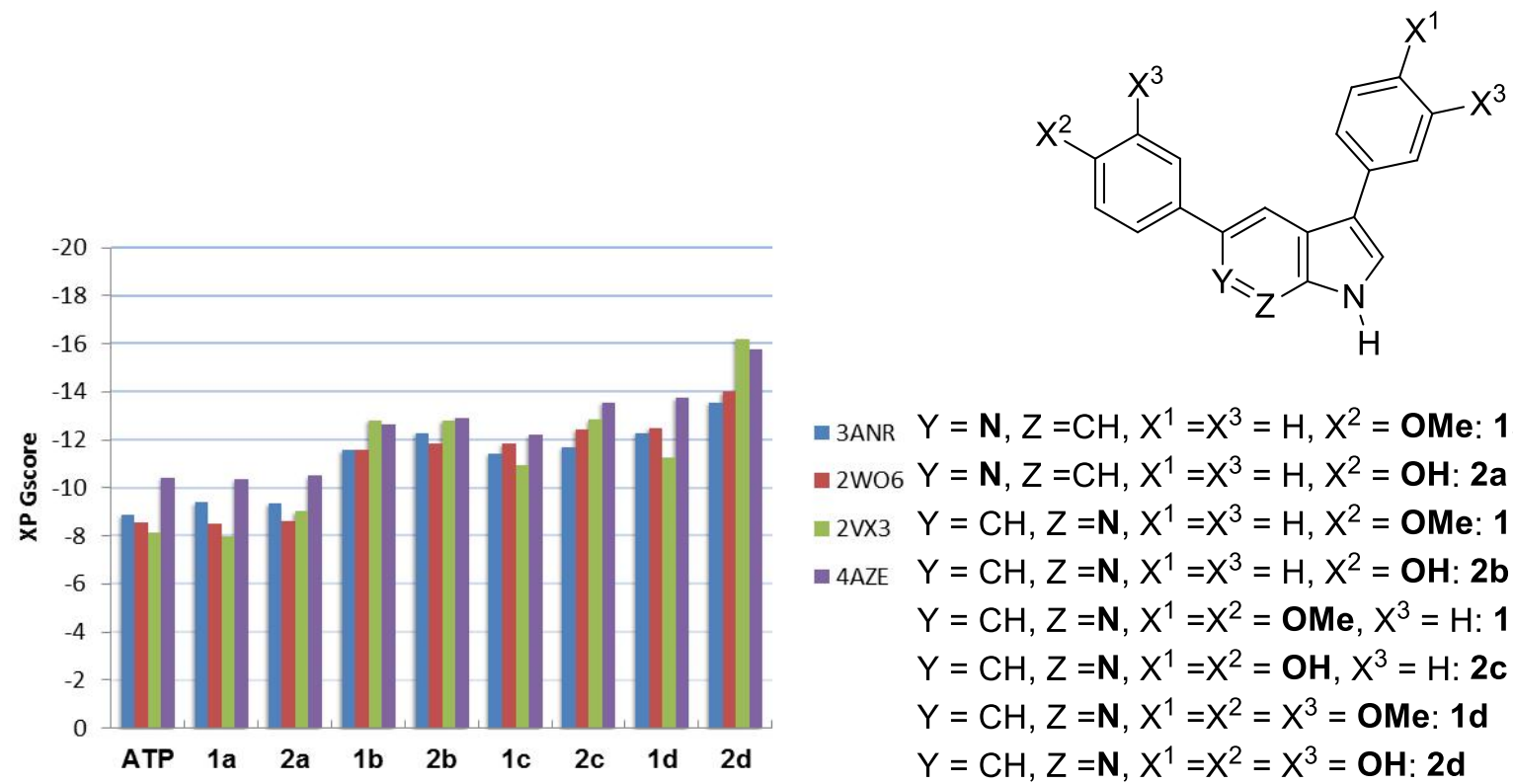

-3ANR $Y=\mathbf{N}, Z=C H, X^{1}=X^{3}=H, X^{2}=$ OMe: 1a -2w06 $Y=\mathbf{N}, Z=C H, X^{1}=X^{3}=H, X^{2}=\mathbf{O H}: 2 a$ $\because 2 \mathrm{VX} 3 \quad Y=\mathrm{CH}, \mathrm{Z}=\mathbf{N}, \mathrm{X}^{1}=\mathrm{X}^{3}=\mathrm{H}, \mathrm{X}^{2}=\mathbf{O M e}: \mathbf{1 b}$ - 4AZE $Y=C H, Z=N, X^{1}=X^{3}=H, X^{2}=O H: 2 b$ $Y=C H, Z=N, X^{1}=X^{2}=O M e, X^{3}=H: 1 c$ $Y=\mathrm{CH}, Z=\mathbf{N}, X^{1}=X^{2}=\mathrm{OH}, X^{3}=\mathrm{H}: \mathbf{2 c}$ $Y=C H, Z=N, X^{1}=X^{2}=X^{3}=O M e: 1 d$ $Y=C H, Z=N, X^{1}=X^{2}=X^{3}=O H: 2 d$

Figure 4: Comparison of Glide XP Docking Scores of Virtual Substrates. 


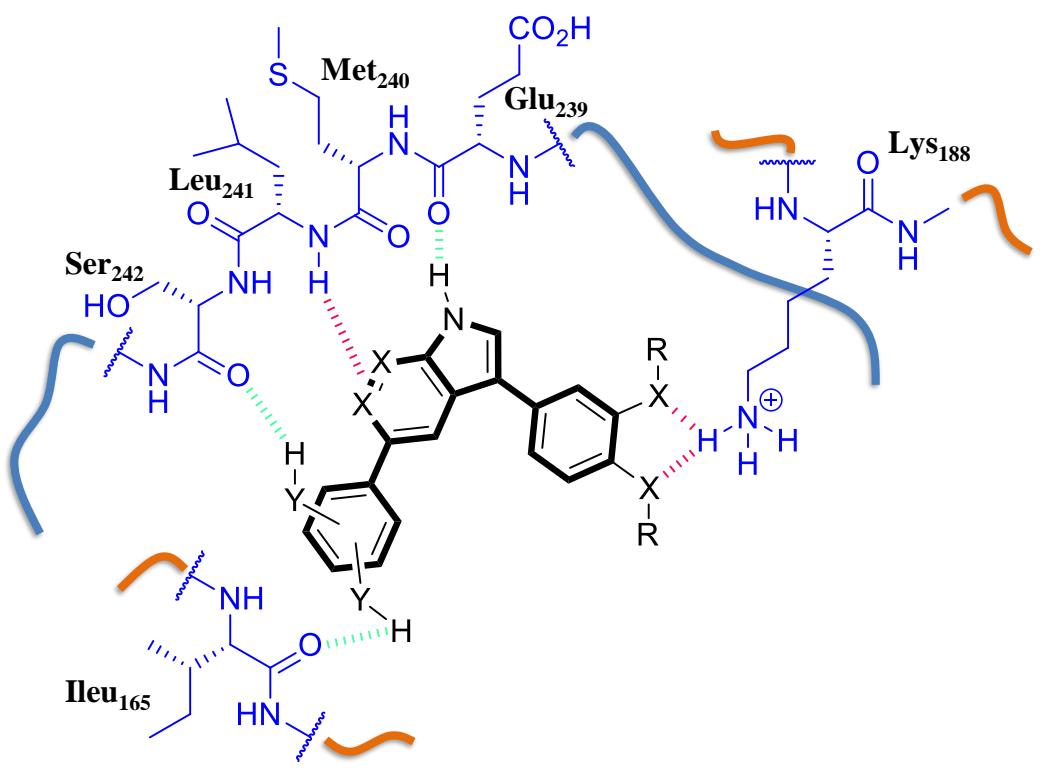

Figure 5: In Silico "Ideal Inhibitor" within the ATP-Binding Site . 
<smiles>COc1ccc(-c2cn(S(=O)(=O)Oc3ccccc3)c3ncc(-c4cccc(OC)c4)cc23)cc1</smiles>

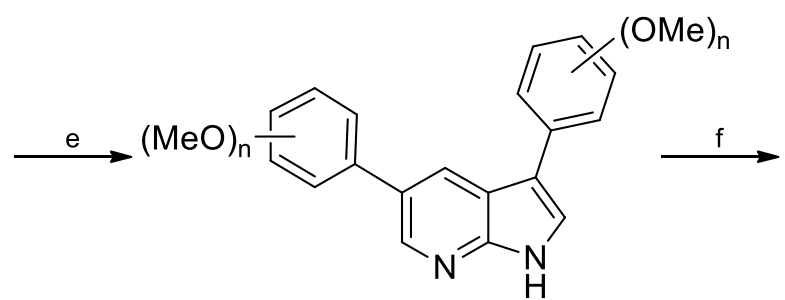

1<smiles>Oc1ccc(-c2cnc3[nH]cc(-c4ccc(O)cc4)c3c2)cc1</smiles>

${ }^{a}$ Reagents and conditions: (a) NIS (1.0 equiv.), KOH (0.5 equiv.), DCM, rt, 15 h; (b) $\mathrm{NaH}$ (60\% in mineral oil, 3equiv.), $\mathrm{PhSO}_{2} \mathrm{Cl}$ (1.2 equiv.), $\mathrm{BnEt} 3 \mathrm{NCl}$ (cat.), DCM, rt, 15 h; $97 \%$ over two steps (c) or (d) arylboronic acid, $\mathrm{Pd}\left(\mathrm{PPh}_{3}\right)_{4}$ (cat.), $\mathrm{K}_{2} \mathrm{CO}_{3} 2 \mathrm{M}$ (aqueous), toluene/EtOH 3:1, $110^{\circ} \mathrm{C}, 3.5 \mathrm{~h}$ (two successive steps with 1.0 equiv. of two different arylboronic acids or single step reaction with 2.0 equiv. of arylboronic acid, see materials and methods for details); 36$87 \%$ (e) $\mathrm{NaOH} 2 \mathrm{~N}$ (aqueous), $\mathrm{MeOH}, 80^{\circ} \mathrm{C}, 2 \mathrm{~h} ; 29-98 \%$ (f) $\mathrm{BBr}_{3}$ (3.0 equiv. per $\mathrm{Me}$ ), $\mathrm{DCM}$, $0^{\circ} \mathrm{C}$ to rt, $15 \mathrm{~h} ; 34-75 \%$. 
Table 1. In Vitro Activity of 3-Phenyl-5-Aryl-7-Azaindole Derivatives

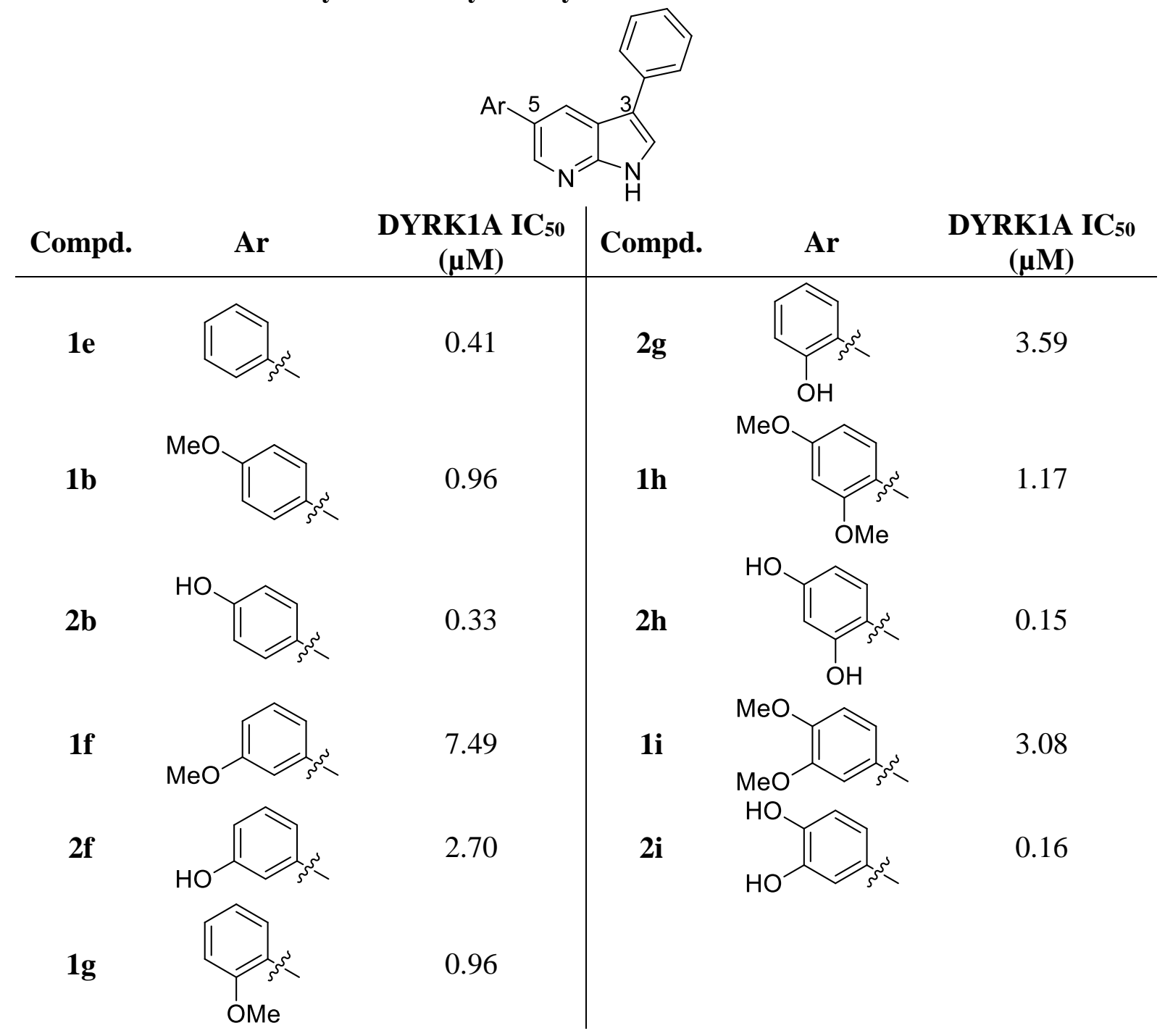




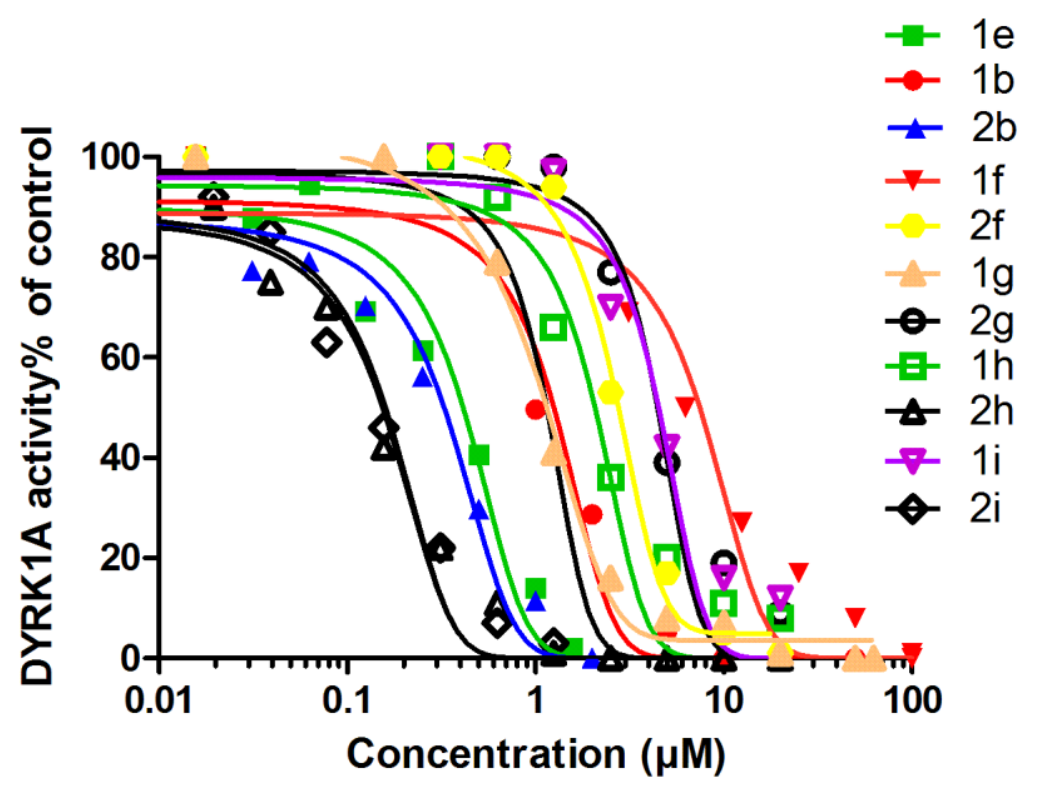

Figure 6: Dose-response of $\triangle \mathrm{DYRK} 1 \mathrm{~A}$ activity (normalized in the absence of inhibitor, expressed as percentage) obtained with varied concentration of 3-phenyl-7-azaindole derivatives $\mathbf{1 e , b , f - i}$ and $\mathbf{2 b , f - i}(0.02-100 \mu \mathrm{M})$ with $50 \mu \mathrm{M}$ of ATP. 
Table 2. In Vitro Activity of Polymethoxy 3,5-Diaryl-7-Azaindole Derivatives

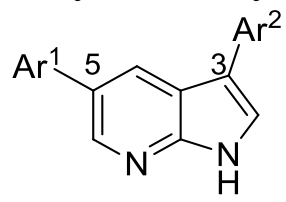

$\begin{array}{llll}\text { Compd } & A r^{1} & A r^{2} & \text { DYRK1A } \\ \text { IC }_{50}(\mu M)\end{array}$

1c

$\mathrm{MeO} O \mathrm{OMe}$

1.74

$\mathbf{1 j}$<smiles>COc1ccc(C)c(OC)c1</smiles><smiles>COc1ccc(I)cc1</smiles>

0.28

$1 k$<smiles>COc1ccc(I)cc1OC</smiles><smiles>COc1ccc(C)cc1</smiles>

0.46

11<smiles>COc1ccc(C)c(OC)c1</smiles><smiles>COc1ccc(I)cc1OC</smiles>

$1 m$<smiles>COc1ccc(OC)c(C)c1</smiles><smiles>COc1ccc(I)cc1OC</smiles>

1d<smiles>COc1ccc(I)cc1OC</smiles><smiles>COc1ccc(C)cc1OC</smiles>

57.78

1n<smiles>COc1cccc(CC(C)(C)C)c1</smiles>

14.63 


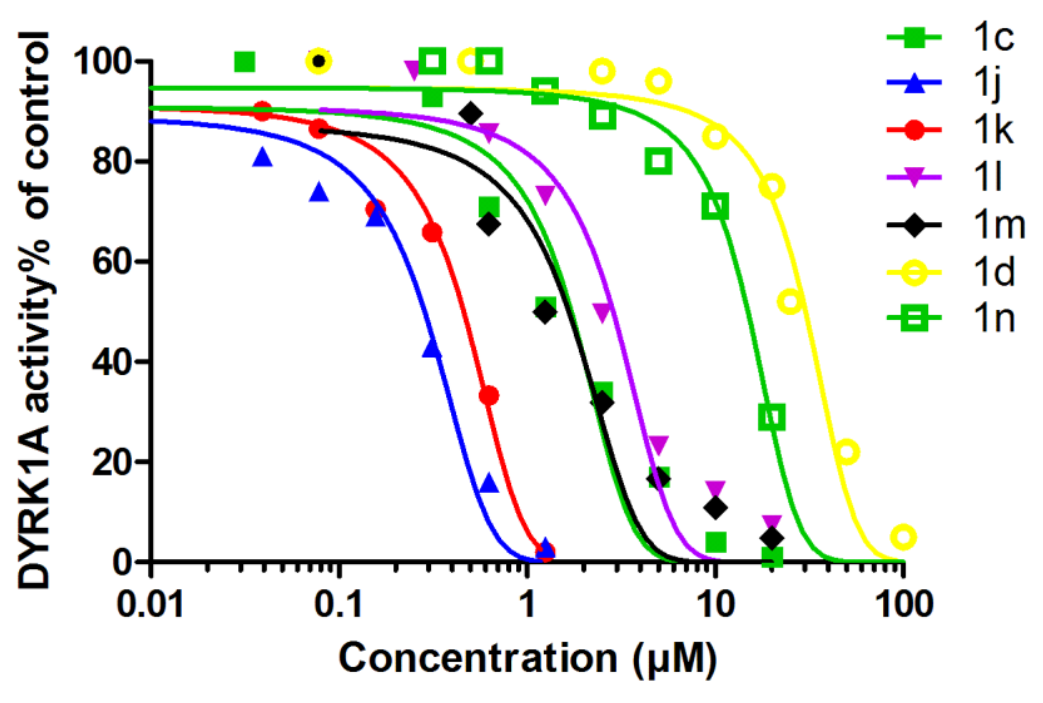

Figure 7: Dose-response of $\triangle \mathrm{DYRK} 1 \mathrm{~A}$ activity (normalized in the absence of inhibitor, expressed as percentage) obtained with varied concentration of polmethoxy 3,5-diaryl-7azaindole derivatives $\mathbf{1 c}, \mathbf{d}, \mathbf{j}-\mathbf{n}(0.02-100 \mu \mathrm{M})$ with $50 \mu \mathrm{M}$ of ATP. 
Table 3. In Vitro Activity of Polyhydroxy 3,5-Diaryl-7-Azaindole Derivatives

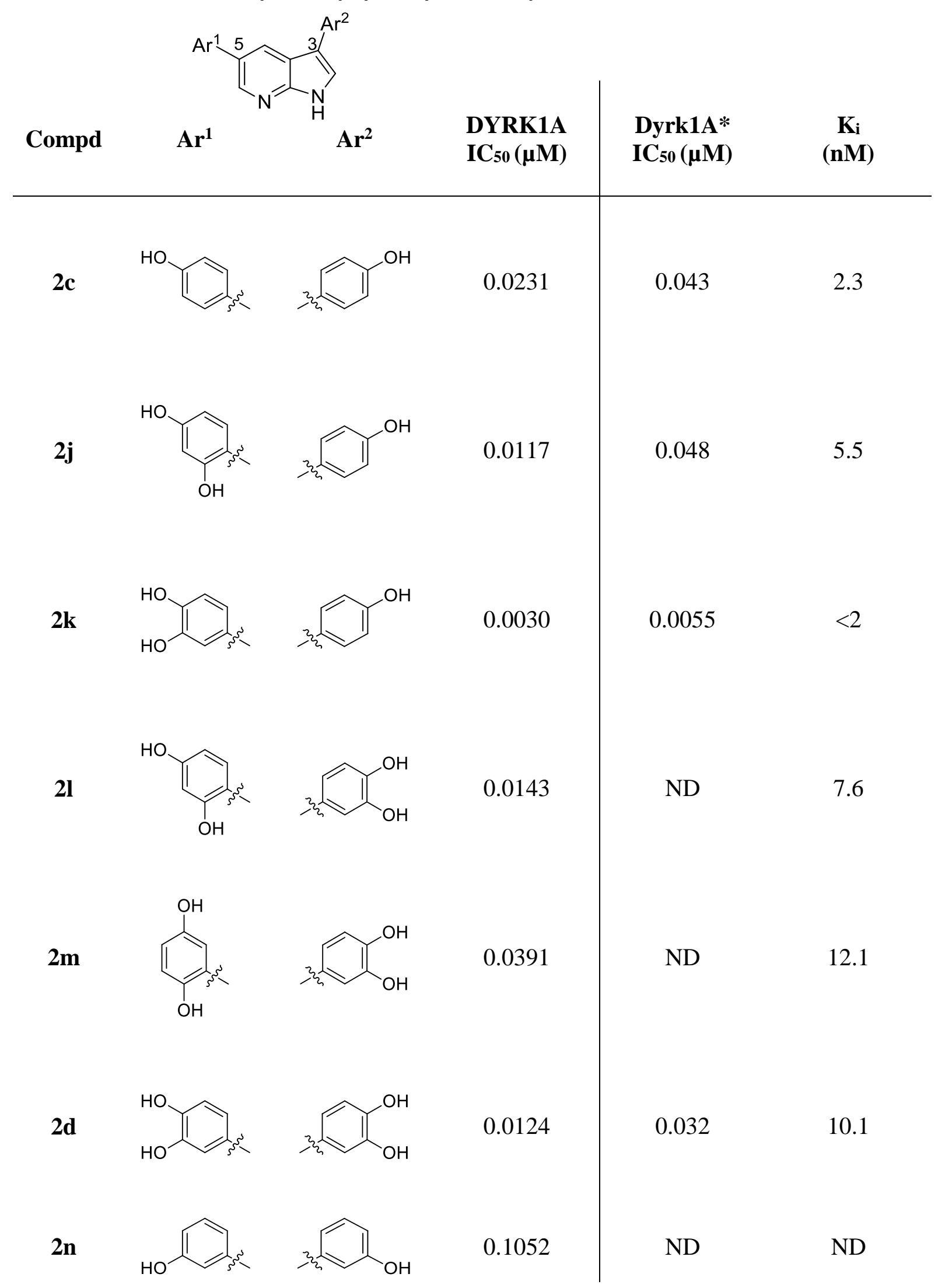

* $\mathrm{IC}_{50}$ were obtained with $1 \mathrm{mM}$ ATP instead of $50 \mu \mathrm{M}$, ND: not determined. 


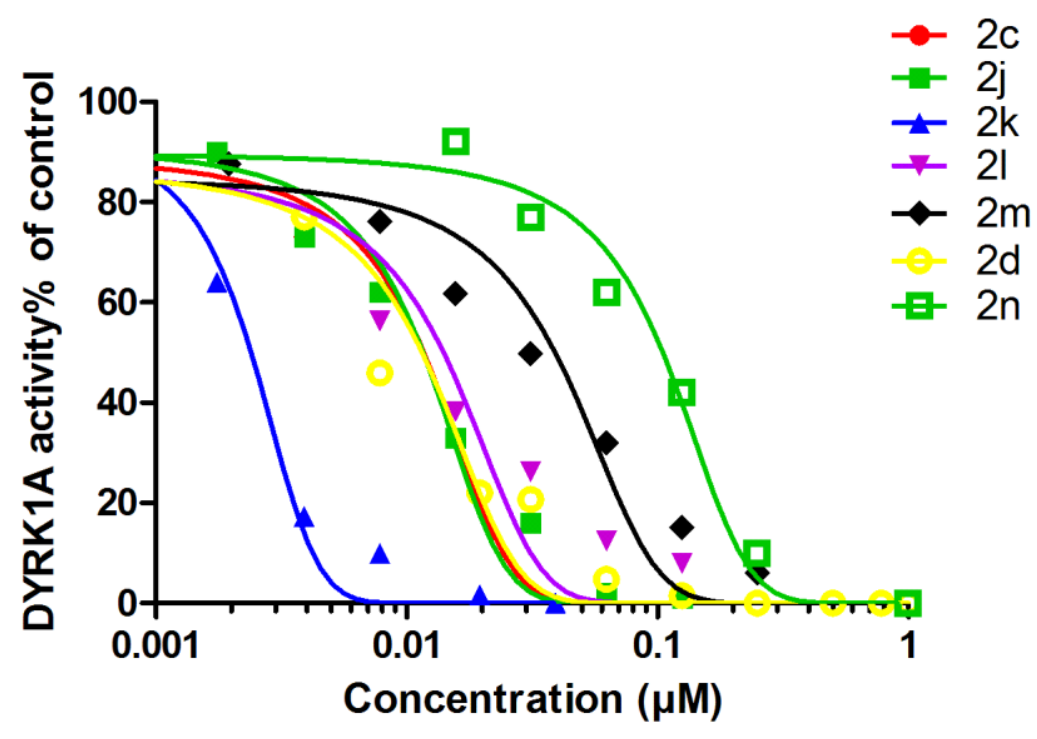

Figure 8: Dose-response of $\triangle \mathrm{DYRK} 1 \mathrm{~A}$ activity (normalized in the absence of inhibitor, expressed as percentage) obtained with varied concentration of polyhydroxy 3,5-diaryl-7azaindole derivatives $\mathbf{2 c , d , j} \mathbf{j}-\mathbf{n}(0.02-100 \mu \mathrm{M})$ with $50 \mu \mathrm{M}$ of ATP. 


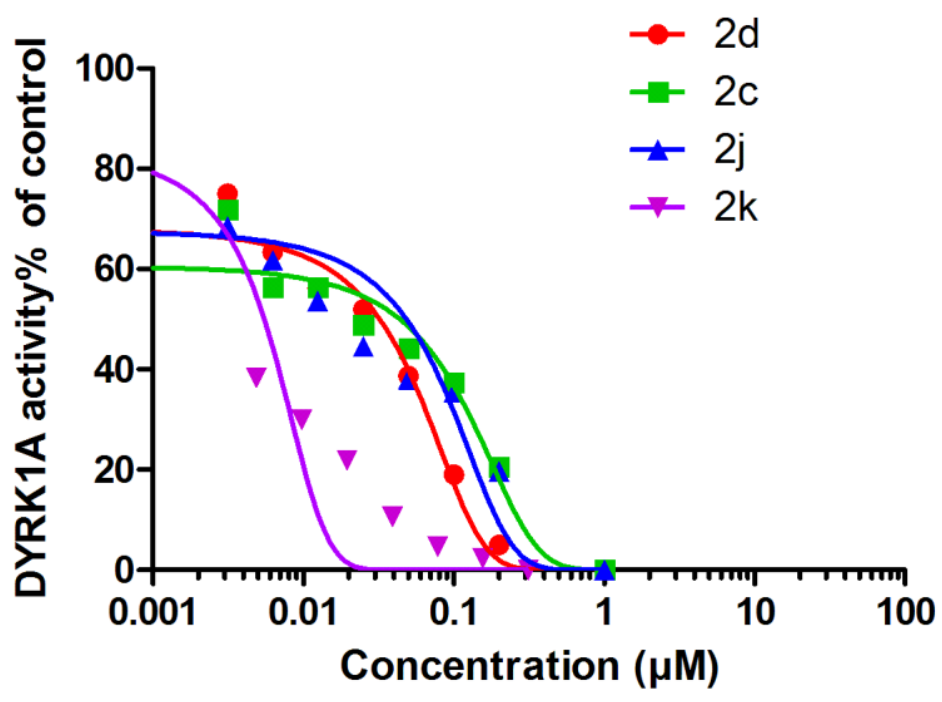

Figure 9: Dose-response of $\triangle \mathrm{DYRK} 1 \mathrm{~A}$ activity (normalized in the absence of inhibitor, expressed as percentage) obtained with varied concentration of polyhydroxy 3,5-diaryl-7azaindole derivatives $\mathbf{2} \mathbf{c}, \mathbf{d}, \mathbf{j}, \mathbf{k}(0.02-100 \mu \mathrm{M})$ with $1000 \mu \mathrm{M}$ of ATP. 


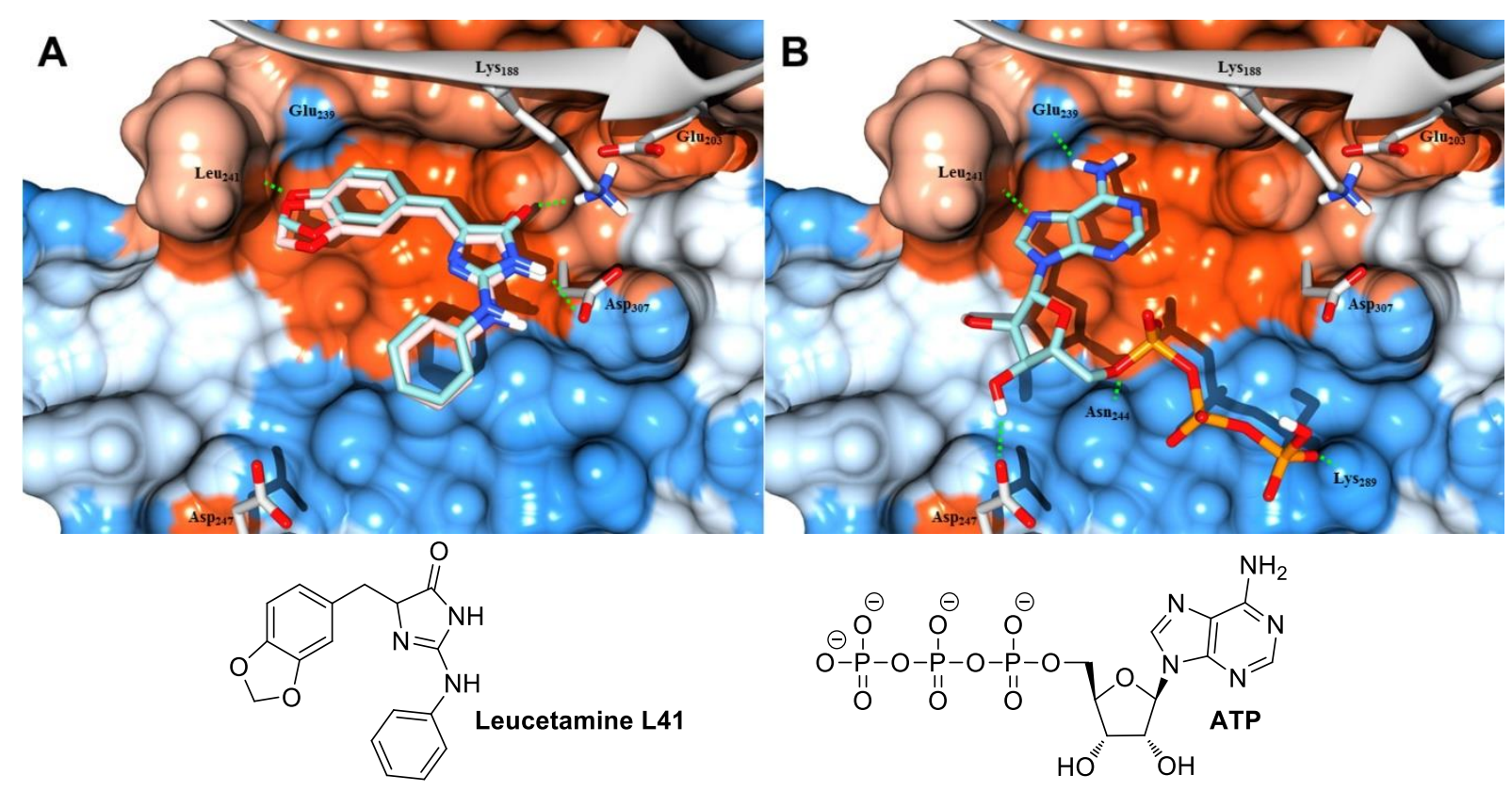

Figure 10. (A) Validation of the docking procedure via direct docking of L41 on 4AZE.pdb prepared structure (native ligand in purple (pink?) and top pose in green (blue?)). (B) Docking experiment using virtual ATP on the 4AZE.pdb prepared structure (Top residues 132 to 180 of the protein have been omitted for better clarity, pictures were made using Chimera and PovRay softwares). 


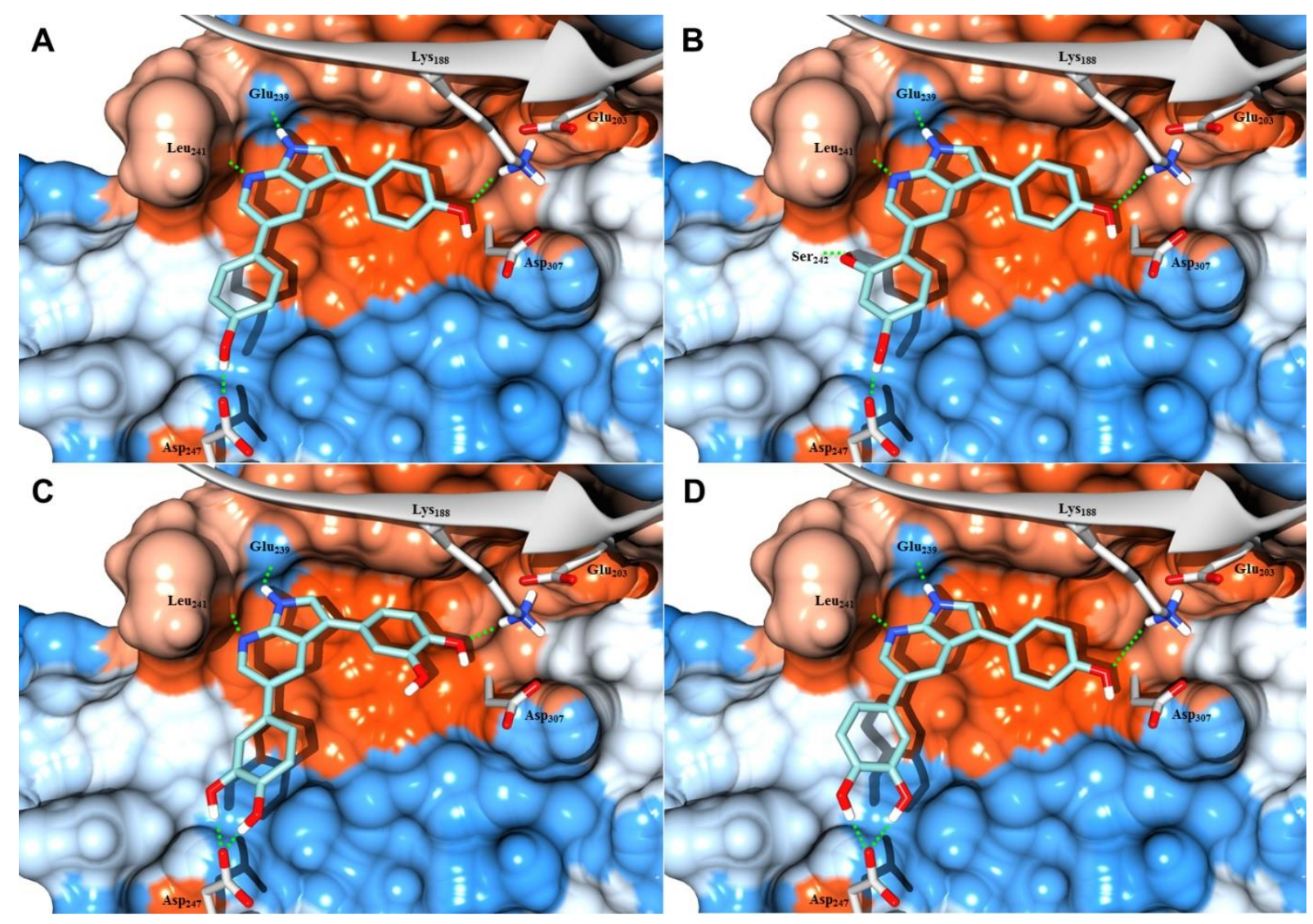<smiles>Oc1ccc(-c2cnc3[nH]cc(-c4ccc(O)cc4)c3c2)cc1</smiles>

2c

$\mathrm{IC}_{50}=23.1 \mathrm{nM}$<smiles>Oc1ccc(-c2c[nH]c3ncc(-c4ccc(O)cc4O)cc23)cc1</smiles>

2j

$\mathrm{C}_{50}=11.7 \mathrm{nM}$<smiles>Oc1ccc(-c2cnc3[nH]cc(-c4ccc(O)c(O)c4)c3c2)cc1O</smiles>

2d

$\mathrm{IC}_{50}=12.4 \mathrm{nM}$<smiles>Oc1ccc(-c2c[nH]c3ncc(-c4ccc(O)c(O)c4)cc23)cc1</smiles>

2k

$\mathrm{IC}_{50}=3.0 \mathrm{nM}$

Figure 11. Top poses of compounds $2 \mathbf{c}(\mathrm{A}), \mathbf{2} \mathbf{j}(\mathrm{B}), \mathbf{2 d}(\mathrm{C})$ and $\mathbf{2 k}$ (D). Generated with GlideXPTM algorithm on the 4AZE.pdb prepared structure (Top residues 132 to 180 of the protein have been omitted for better clarity, pictures were made using Chimera and PovRay softwares) 


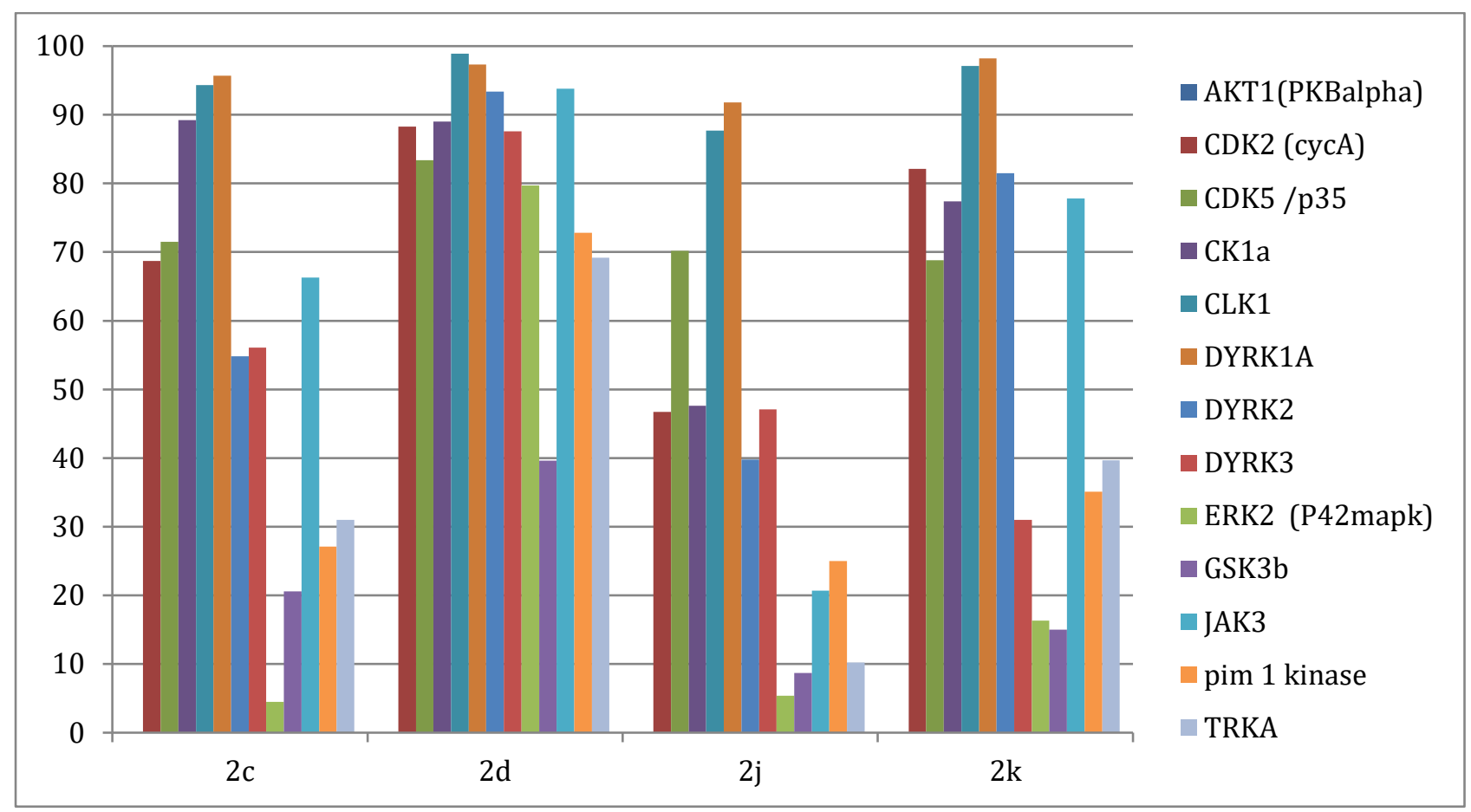

Figure 8. In vitro inhibition of a panel of kinases by compounds $\mathbf{2 c}, \mathbf{2 d}, \mathbf{2 \mathbf { j }}$ and $\mathbf{2 k}$, at $5 \cdot 10^{-8} \mathbf{M}$ concentration (100 represents full inhibition of the enzyme) 
Table 4: Growth Inhibition of KB cells for compounds 2c, 2j, 2l, 2k and 2d (percentage)

\begin{tabular}{|c|c|c|}
\hline compound & $\mathbf{A t ~ 1 0}^{-5} \mathbf{M}$ & At 10 $^{-\mathbf{6}} \mathbf{M}$ \\
\hline $\mathbf{2 c}$ & $95 \%$ & $51 \%$ \\
\hline $\mathbf{2 d}$ & $11 \%$ & $2 \%$ \\
\hline $\mathbf{2 j}$ & $83 \%$ & $21 \%$ \\
\hline $\mathbf{2 k}$ & $86 \%$ & $56 \%$ \\
\hline $\mathbf{2 l}$ & $9 \%$ & $0 \%$ \\
\hline
\end{tabular}


Table of Contents Graphic

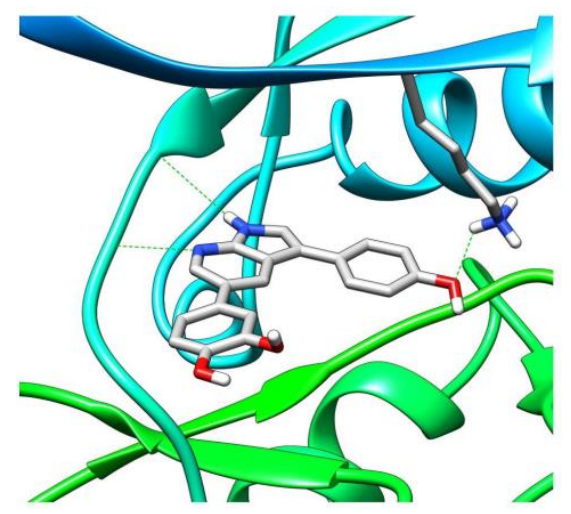<smiles>Oc1ccc(-c2c[nH]c3ncc(-c4ccc(O)c(O)c4)cc23)cc1</smiles>

$\mathrm{IC}_{50}=3 \mathrm{nM}$ Diaryl-Azaindole iNhibitors of DYRK1A (DANDY) 